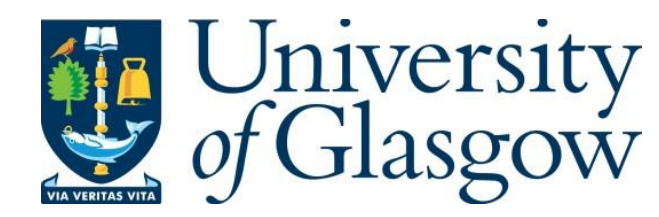

Westaway, R. (2018) Deep geothermal single well heat production: critical appraisal under UK conditions. Quarterly Journal of Engineering Geology and Hydrogeology, 51(4), pp. 424-449. (doi:10.1144/qjegh2017-029)

There may be differences between this version and the published version. You are advised to consult the publisher's version if you wish to cite from it.

http://eprints.gla.ac.uk/164303/

Deposited on: 21 June 2018

Enlighten - Research publications by members of the University of Glasgow http://eprints.gla.ac.uk 


\title{
Deep geothermal single well heat production: critical appraisal under UK conditions
}

\author{
Rob Westaway \\ School of Engineering, University of Glasgow, \\ James Watt (South) Building, Glasgow G12 8QQ, U.K. \\ e-mail: robert.westaway@glasgow.ac.uk
}

\section{Abstract}

The idea of Deep Geothermal Single Well (DGSW) heat production has existed for many years, but with no consensus regarding its potential applicability: proponents have made claims regarding thermal outputs that appear exaggerated, whereas detractors have stated that the concept can never be economic unless the capital cost of drilling has already been discounted. However, because this technology offers the potential of delivering geothermal heat projects 'off the shelf' with a minimum of site-dependent research, the possibility exists of achieving cost-effective solutions. The present study sets out to investigate this topic subject to environmental and subsidy regimes applicable in the UK; the results might also be useful for other jurisdictions. Under these conditions, the variant of the technology with greatest potential for cost effectiveness is the hcDGSW, or conductive DGSW with heat production via heat pump. Analytic modelling enables the physics of the heat-exchange processes within a hcDGSW to be approximated. It is thus established that this option can indeed be cost-effective under the current UK subsidy regime for deep geothermal heat, provided boreholes are deep enough and in localities where the geothermal gradient is high enough. The environmentally optimum operational mode (optimizing savings in $\mathrm{CO}_{2} \mathrm{e}$ emissions) involves heat production at a lower rate than the economically optimum mode (maximizing profit). If such projects are subsidized from public funds, then a particular operational mode might be specified, maybe as a compromise between these optima. After the 20 year duration of the subsidy, the technology might well no longer be economic, but the infrastructure might be easily repurposed for seasonal heat storage, thus offering the potential of making a significant long-term contribution to sustainable future heat supply. These preliminary results indicate that more detailed appraisal of this technology variant is warranted.

\section{Introduction}

Most deep geothermal heat production projects are based around the concept of well doublets, in which production of thermal water from one well is balanced by injection of the water (after heat is supplied from it to the heat load) in a second well. The injection of water serves two purposes: it avoids the drawdown in hydrostatic pressure that would result in the geothermal reservoir rocks if only a production well were in operation; it also avoids the need for treatment of the produced water before surface disposal, which in many circumstances would otherwise be necessary. Typically one or both of the injection and production wells are deviated so they reach the geothermal reservoir some distance (up to $2 \mathrm{~km}$; e.g., Smit, 2012) apart. Over time a project of this type gradually extracts heat from the reservoir rocks surrounding the production well; heat production usually takes place far faster than the associated 'thermal recharge' by upward heat flow from the Earth's interior. The cold thermal front emanating from the injection well will therefore eventually reach the production well, limiting the lifetime of the project (e.g., McDermott et al., 2006; van Wees et al., 2010; Satman, 2011; Smit, 2012). Used in this manner, this technology is thus not indefinitely 'sustainable' but is nonetheless regarded by most authorities as providing 'renewable' energy and therefore in principle eligible for subsidies (e.g., the UK government's Renewable Heat Incentive or RHI) designed to stimulate the development of 'low carbon' heat sources.

Such development requires the identification of reservoir rocks at appropriate temperatures and with suitable physical properties (porosity and permeability, or hydraulic conductivity, associated with fractures or pore spaces) to enable heat production at useful rates; it thus involves exploitation of complex systems that may well not be understood until the development is under way (e.g., Tenzer 
et al., 2010), and thus requires considerable technical skill. If suitable properties do not exist naturally they can in principle be created by techniques such as hydraulic fracturing, acid injection (to dissolve carbonate cement and increase pore space within rocks), or thermal fracturing (injection of cold water so thermal contraction causes fracturing of the rocks). However, hydraulic fracturing can cause induced seismicity and acid injection might cause environmental pollution; projects using these techniques might thus attract opposition. Commercial deep geothermal projects have nonetheless come on stream in western Europe. Examples include Soultz-sous-Forêts and Rittershoffen in eastern France (e.g., Vidal et al., 2016; Baujard et al., 2017), which have used the aforementioned well stimulation techniques, and many deep geothermal heat projects in the Netherlands (e.g., Bleiswijk; Ramaekers et al., 2006; Simmelink and Geel, 2008; Donselaar et al., 2015). However, each of these examples has depended on prior knowledge of rock properties from petroleum exploration. Since heat is inherently a less valuable commodity than oil or natural gas, it is more problematic whether a project of this type could be implemented on a commercial basis in a region that has not previously been documented in detail for this reason, such as most of the onshore UK, since the cost of the necessary site-dependent research might never be recoverable from the value of the heat that could be produced (cf. King et al., 2015). For both these reasons, the UK will benefit from any alternative approach to geothermal development that is uncontroversial and straightforward to implement 'off the shelf', without detailed site-dependent investigation.

The term Deep Geothermal Single Well (DGSW) denotes any geothermal project design that utilizes a single borehole (rather than a doublet), and which extends into the 'deep geothermal' regime, which under current UK regulations means depth $>500 \mathrm{~m}$ (e.g., AECOM, 2013); many possible variants exist, including both open- and closed-loop designs (Table 1; Figs. 1, 2, 3). Some of these variants extract heat by conduction from the rocks around any borehole (Fig. 3; see, also, below), making them potentially straightforward to implement (since they do not depend on knowledge of hydraulic transport properties); furthermore, no 'well stimulation', such as hydraulic fracturing, is necessary. This technology is thus potentially suitable for providing 'off the shelf' geothermal heat sources in the UK, provided it can achieve an economic return. In the UK, heat output from a DGSW is eligible, in

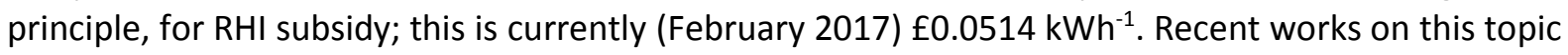
include those by Law (2014), Law et al. (2015), GEL et al. (2016), and Collins and Law (2017). As will become clear below, some aspects of these publications are open to question, including apparent overestimation of outputs of useable heat and underestimation of system operating costs and impacts of uncertainty in knowledge of rock properties at depth and regulatory issues. The present study seeks to focus discussion on the variant of this technology (the hcDGSW; Table 1 and Fig. 2(b)) that is shown to offer the greatest potential under present UK economic and regulatory conditions; the analysis might also be useful in other jurisdictions. This investigation concentrates on underlying principles; practical details, such as designs of components (e.g., pumps and heat exchangers) and wall thicknesses of pipework (to handle the imposed fluid pressures and maintain the necessary thermal insulation) are beyond the scope of the present study (see, e.g., Rafferty, 2001; Law et al., 2015; Alimonti et al., 2016).

Many workers have published analyses of deep DGSW case studies, for production of either geothermal electricity or geothermal heat (e.g., Nalla et al., 2004; Wang, 2009; Wang et al., 2010; Bu et al., 2012; Cheng et al., 2013; Law et al., 2015, 2016; Alimonti and Soldo, 2016; Alimonti et al., 2016; Cho et al., 2016; Noorollahi et al., 2016; Riahi et al., 2017). However, some of these analyses use numerical modelling techniques that are either not explained or not validated against analytic calculations, others incorporate non-physical assumptions such as constant-temperature boundary conditions at depth or the assumption that these systems can operate under steady state. Furthermore, some of these studies analyse the physics of heat exchange around and within boreholes 
without considering how this heat transfer interacts with any heat load. However, it is clear from the substantial literature on shallow borehole systems connected to heat pumps (e.g., Bloomquist, 1999; Rees et al., 2004; Orio et al., 2005; O'Neill et al., 2006; Kavanaugh et al., 2012; Liu et al., 2016) that borehole heat exchanger designs and heat loads should be matched, making it essential to consider both in combination, rather than either in isolation, to achieve optimal solutions; this is shown in the present study to also be so for deep borehole systems. In the absence of any established method, this study will present an analytic approach for modelling both subsurface installations and heat loads for deep DGSW installations, those aspects of the underlying physics that appear most important to the author being included. Such an analytic approach incorporates exact solutions for particular aspects of this coupled problem, which approximate the conditions that can be anticipated during the operation of real DGSW installations. This approach might be useful for validating future numerical solutions, but the immediate aim is to permit first-order assessments of recent DGSW investigations in the UK (e.g., Law et al., 2015, 2016; Collins and Law, 2017), for which high heat outputs have been reported. The existing literature on shallow systems (e.g., Rees et al., 2004; Banks, 2012) indicates that the useable heat output increases with borehole depth, so higher values are expected for increasing borehole depth, but the manner in which heat output scales with borehole depth has not hitherto been established. Law et al. $(2015,2016)$ and Collins and Law $(2017)$ have reported results of numerical analyses that quantify the rates of heat production that they consider feasible for particular borehole depths and bottom hole temperatures, but the software used has not been published, no validation against analytical calculations has been reported, nor any indication of how heat production depends on site conditions in general, or how much of the heat produced can provide output of useable heat, bearing in mind that most designs involve reinjection of water and the heat it contains.

The Southampton geothermal project in southern England, dating from the early 1980s, was the first to produce hot water from a deep borehole, discharging the cooled water into the environment, rather than reinjecting it (e.g., Barker, 1986). As many authors (e.g., Downing et al., 1984; Downing, 1986; Barker et al., 2010) have discussed, the Southampton-1 borehole reaches permeable Triassic sandstone at $76^{\circ} \mathrm{C}$ at $1827 \mathrm{~m}$ depth. Well-testing established that this aquifer would be unlikely to sustain the high flow rates originally envisaged, which would have provided several megawatts of heat output using a conventional well doublet. It was therefore decided to develop this single borehole as a heat source (wellhead temperature $74{ }^{\circ} \mathrm{C}$ ) for district heating, discharging the produced water into the sea. In its original form (here designated as wDGSW; Fig. 1(a)) this project had a useable heat output of $1.15 \mathrm{MW}$ (Barker et al., 2010). It was modified in 1991 with the addition of a heat pump (to the hwDGSW configuration in Fig. 1(b)); by reducing the temperature at which the produced water is rejected to the environment, this increased the output of useable heat to $2.2 \mathrm{MW}$ (Barker et al., 2010), the flow rate required for this being $\sim 7.5 \mathrm{I} \mathrm{s}^{-1}$.

Although the Southampton-1 produced water is not treated, in general in the UK treatment of produced water from deep geothermal projects will be necessary before discharge into the environment (e.g., Atkins, 2013). For example, the radionuclide ${ }^{226} \mathrm{Ra}$ is one of its more potentially hazardous constituents, since radium is chemically similar to calcium and so can participate in many chemical reactions in the environment. According to Edmunds (1986), the Southampton-1 well produces 39 picocuries of ${ }^{226} \mathrm{Ra}$ per $\mathrm{kg}$ of water, equivalent to $\sim 1.4 \mathrm{~Bq} \mathrm{~kg}^{-1}$ or $\sim 1.4 \mathrm{~Bq} \mathrm{l}^{-1}$. At $\sim 7.5 \mathrm{I} \mathrm{s}^{-1}$, this well thus discharges $\sim 340 \mathrm{MBq}$ of alpha radiation from ${ }^{226} \mathrm{Ra}$ per year. The relevant regulations (DEFRA, 2011, p. 81) permit discharges with ${ }^{226} \mathrm{Ra}$ activity of up to $100 \mathrm{~Bq} \mathrm{I}^{-1}$ for this purpose, although in water produced as a by-product of hydrocarbon production any concentration above $1 \mathrm{~Bq} \mathrm{I}^{-1}$ would require treatment. Edmunds (1986) also reported the concentration of iron in this water as $4.1 \mathrm{mg} \mathrm{l}^{-1}$. For each chemical contaminant, such as this, the regulatory requirement is for concentration in the water body receiving the discharge to not exceed a specified limit, which for iron is $1 \mathrm{mg} \mathrm{l}^{-1}$ (e.g., DEFRA, 2014). Since the Southampton discharge is into the sea, the dissolved iron is evidently diluted sufficiently for compliance. However, the present regulatory presumption is that no additional 
discharge should adversely affect any water body, which effectively means that concentrations in the discharge should not exceed the regulatory limit for the water body. Thus, as Atkins (2013) noted, 'discharge to surface without treatment is unlikely to be a viable option' for future DGSW systems in the UK. The UK has a widespread legacy of mining, which has caused many discharges of groundwater that do not comply with present environmental standards and so now require treatment (e.g., Younger et al., 2005). As Johnston et al. (2008) have explained, this situation arose as a consequence of an ambiguous legal framework concerning responsibility for historical discharges, which was rectified for future discharges by a change to the law in 1999. This situation thus provides no precedent for tolerating untreated discharges from future DGSW systems (see, also, Atkins, 2013, and Abesser et al., 2014); indeed, knowledge of mine water treatment costs can inform discussion of potential treatment costs for water discharged from these systems (see below).

Heat might also be extracted by conduction from the rocks surrounding a borehole heat exchanger, containing a closed loop of heat transfer fluid, a variant of the technology (depicted schematically in Fig. 2(a)) designated here as a conductive DGSW or CDGSW. As far as can be established, this idea was first proposed by Lockett (1986). This author reported that circulation of 'special fluids' within a borehole in rocks at a temperature of $150^{\circ} \mathrm{C}$ might produce sufficient heat for electricity generation at $2.5 \mathrm{MW}$, a claim that was unsupported by calculations and seems exaggerated (cf. Alimonti et al., 2016). A similar concept was independently studied by Rybach et al. (1992); these authors estimated the potential heat output as so low that this technology would in their view never be economic if drilling costs were included, but might be viable when applied to existing boreholes, for example 'dry' hydrocarbon wells or unsuccessful conventional geothermal boreholes. As Westaway (2016) noted, an attempt was made in 2011 to patent the cDGSW concept; it lapsed, presumably because the applicant became aware that the idea was not original. Law et al. (2015) noted that the cDGSW concept offers the potential for 'off the shelf' geothermal heat sources that require minimal sitespecific investigation, potentially speeding up the adoption of geothermal energy in the UK. Most recently, the Glasgow-based energy company Geothermal Power Ltd. (http://geothermalpowerltd.com/) has advocated cDSGW use for electricity generation and that they, too, are in the process of patenting the technology. In principle, a cDGSW installation might be combined with a heat pump, to increase the output of useable heat from the resulting hcDGSW (Fig. 2(b)) although (again, as far as can be established) there has been no published analysis of the potential output or economic viability of this DGSW variant.

A further recent development (e.g., Law et al., 2015; GEL et al., 2016) has been the variant (which might be termed the 'dual mode' DGSW, or dDGSW; Fig. 3(a)), with the borehole heat exchanger left open around its base so the heat production that is feasible from a cDGSW can be supplemented by 'bleed flow' of thermal ground water. GEL et al. (2016) have since proposed a further hdDGSW variant with a heat pump (Fig. 3(b)). They deduced that this might be economically viable with RHI subsidy payments, although their analysis omitted water treatment costs. However, the need for permeable bedrock for these variants to function, plus the site-specific nature of the options for treating the produced water, negate the original objective of providing 'off the shelf' geothermal heat. Collins and Law (2017) have discussed two such projects, for a hdDGSW installation in the Aberdeen Granite beneath the Aberdeen Exhibition and Conference Centre (AECC) in the Scottish city of Aberdeen, and for a scheme to heat part of an outdoor swimming pool in Penzance, Cornwall, involving drilling into the Land's End Granite, also mentioning a project in East Ayrshire, Scotland. Planning documentation (Cornwall, 2017; East Ayrshire, 2017; Geon, 2017) indicates that the Penzance scheme has a dDGSW design, whereas the latter project, now known as HALO and located in the town of Kilmarnock (where drilling into Palaeozoic sedimentary rocks is proposed), is intended to function as a hcDGSW (see below). 
This proliferation of alternatives (Figs. 1, 2, 3) has created a somewhat confused situation, especially as workers have not always been clear which variant is being described in a given document and some aspects, such as treatment of produced water, have not received sufficient attention. Furthermore, the contrasting claims regarding thermal output and economic viability or otherwise require resolution, especially as not all variants (including the hcDGSW) have been fully analysed. The present study sets out to address these issues. It will, first, present a quantitative evaluation, using analytical calculations, of the potential output of a hcDGSW (Fig. 2(b)) relative to a cDGSW (Fig. 2(a)). Second, two key issues affecting the viability of the alternative dDGSW variant, the low hydraulic conductivity of many lithologies and the potential cost of produced water treatment, will be discussed. Third, the analytical model for a hcDGSW, the technology variant shown to have the most potential, will be used to develop an economic model for assessing effectiveness in terms of both cost and greenhouse gas emissions. Finally, the cDGSW/hcDGSW conceptual model by Law et al. (2015) and some individual DGSW projects will be discussed in the light of the preceding analyses. Given the approximations made in the aforementioned analytical calculations, the potential merits of the hcDGSW variant, thus identified, require confirmation by more detailed numerical modelling, beyond the scope of the present study.

\section{cDGSW Theory}

A cDGSW can be envisaged as a closed loop formed by inserting a length of pipe into a cased borehole, as in Fig. 2(a). Water (or, possibly, an alternative heat transfer fluid; e.g., Alimonti and Soldo, 2016) is produced from the borehole at temperature $T_{0}$ and supplied to a surface heat exchanger that extracts heat to the heat load at its operational temperature $\mathrm{T}_{\mathrm{E}}$. The water (or other circulating heat-transfer fluid) is thus itself cooled to $T_{E}$ within the heat exchanger before reinjection at temperature $T_{D}$. As Law et al. (2015), Alimonti and Soldo (2016), and other workers have discussed, a suitable configuration has the upward flow in a central pipe within the well, with the downward flow in the surrounding annulus (Fig. 2(a)). During its downward flow the circulating fluid absorbs heat from the surrounding rocks; during its upward flow, which might be much faster if the pipe is much narrower than the annulus, it is assumed (for calculation purposes) that the fluid maintains temperature $T_{0}$. In principle, a cDGSW (and, indeed, any other variant of DGSW) might operate intermittently, possibly delivering heat on diurnal or seasonal cycles. However, since the thermal processes involved are governed by linear equations, after many such cycles the thermal state around a DGSW will be indistinguishable from that which would exist had it been operated to produce heat at a constant rate equal to the time-averaged rate for the actual pattern. The development of theory will therefore assume heat production at a constant rate.

Law et al. (2014) showed by field testing that in such a configuration the downward flow maintains roughly constant temperature $T_{D}$ until it reaches a depth $z_{L}$ where the initial temperature of the surrounding rock $T_{L}$ equals $T_{D}$. Thus, between the Earth's surface and depth $z_{L}$ the return flow heats this surrounding rock, and therefore only between $z_{L}$ and the well bottom at depth $z_{M}$ is heat extracted from the surrounding rock. This turns out to be a significant limitation of the cDGSW concept (see below). To facilitate the analysis, the ratio $\mathrm{z}_{\mathrm{L}} / \mathrm{z}_{\mathrm{M}}$ is designated as $\mathrm{f}$; the proportion of the borehole that acts as a heat source is thus 1-f.

The general equation governing heat flow in cylindrical polar co-ordinates is

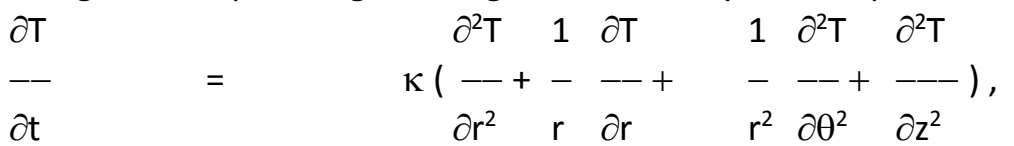

where $\mathrm{T}$ is temperature, $\mathrm{t}$ is time, $\mathrm{k}$ and $\mathrm{k}$ are the thermal diffusivity and conductivity of the rock around a borehole, and $\mathrm{r}, \theta$ and $\mathrm{z}$ are radial distance (from the axis of a borehole), azimuth, and depth. The solutions assume no azimuthal dependence, also that the abrupt radial temperature gradients 
$(\partial T / \partial r)$ that can be expected beyond the borehole radius a are much greater than the vertical geothermal gradient, so the latter is neglected. Equation (1) can thus be simplified to

$$
\begin{aligned}
& \partial \mathrm{T} \\
& \partial^{2} \mathrm{~T} \quad 1 \quad \partial \mathrm{T} \\
& --\quad=\quad \kappa(--+---) \\
& \partial \mathrm{t} \quad \partial \mathrm{r}^{2} r \partial \mathrm{r}
\end{aligned}
$$

Starting at time $t=0$, when radial temperature gradients first develop, heat is assumed to flow inward across the boundary at $r=a$ at a steady rate $\Lambda$, per unit surface area of the borehole, or at rate $\zeta$ per unit depth, where $\zeta=2 \pi$ a $\Lambda$ ( $2 \pi$ a being the circumference of the borehole). The resulting net heat production is the sum of all these contributions across the depth range from $z_{L}$ to $z_{M}$. Equation (2) has been solved subject to these boundary conditions by many workers (e.g., Carslaw and Jaeger, 1959, pp. 338-341). The solution can be expressed in terms of combinations of a decaying exponential function of time and Bessel functions of radial distance, and has no simple general form. However, Carslaw and Jaeger (1959) found power series approximations that are valid, separately, in the limits of $\mathrm{t}<<\mathrm{r}^{2} / \kappa$ and $\mathrm{t}>\mathrm{r}^{2} / \kappa$. The latter solution, valid at (relatively) long timescales after $\mathrm{t}=0$, can be written as

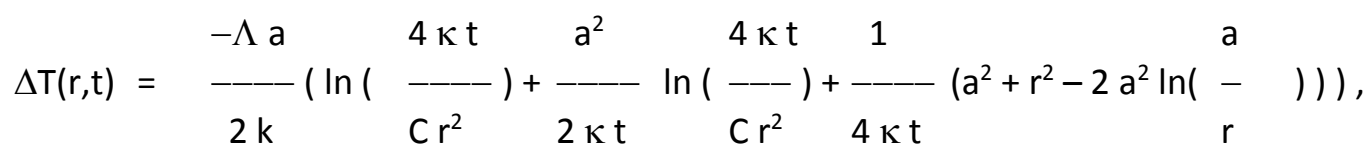

where $\Delta T$ is the temperature change from the initial conditions and $C \equiv \exp (\gamma), \gamma$ being Euler's constant $(\sim 0.57722 \ldots .$.$) . For t>>r^{2} / \kappa$, this solution can be approximated further and rewritten in terms of $\zeta$ as

$$
\Delta T=\frac{-\zeta}{4 \pi \mathrm{k}} \ln \left(\begin{array}{l}
4 \kappa \mathrm{t} \\
----
\end{array}\right) .
$$

Furthermore, if $\zeta$ is assumed to be zero at depth $z_{L}$ and to increase linearly to a maximum value $\zeta_{M}$ at depth $z_{M}$, then

$$
\zeta_{M}=\frac{2 Q}{z_{M}(1-f)} .
$$

$\Delta \mathrm{T}$ will thus be proportional to depth beneath $\mathrm{z}_{\mathrm{L}}$. The temperature of the water produced from the borehole, $T_{0}$, will therefore equal the initial temperature $T_{M}$ at depth $z_{M}$, minus $\Delta T$ calculated using equation (4) for $r=a$ and $z=z_{M}$ so $\zeta=\zeta_{M}$. It follows that the rock at $r=a$ at all depths $z_{L} \leq z \leq z_{M}$ will cool to the same limiting temperature in the limit of $t \rightarrow \infty$. This clearly approximates reality, as it implies a step change in T at depth $\mathrm{z}_{\mathrm{M}}$; the importance of this approximation is addressed below.

To summarize the underlying physics, the heat production from the borehole, at rate $Q$, occurs as a result of the warming of the circulating fluid as it flows downward, absorbing heat through the outer wall of the borehole heat exchanger. This fluid then flows upward along the inner pipe of the heat exchanger, maintaining the same flow rate $\mathrm{q}_{\mathrm{c}}$ as no 'bleed flow' into the borehole is assumed. For plausible operational modes of CDGSW or hcDGSW installations, the upward flow along this inner pipe (of internal diameter $D$ ) will be turbulent (see below), so will approximate a uniform velocity profile $\mathrm{V} ; \mathrm{q}_{\mathrm{c}}$ can thus be approximated as $\pi V D^{2} / 4$. If the circulating fluid is injected at temperature $T_{D}$ and produced at temperature $T_{0}$, the rate of heat production will balance the rate of heat gain by the circulating fluid; thus

$$
Q \quad=\quad \rho c\left(T_{O}-T_{D}\right) q_{C},
$$

where $\rho$ and $c$ are the density and specific heat capacity of this fluid. The value of $q_{c}$ that is required for a given cDGSW or hcDGSW installation to operate at a given rate of heat production $Q$ is calculated 
Since $T_{0}$ will decrease over time (as in Fig. 4), operational modes at constant $Q$ require progressive increases in $q_{C}$ over time, given that $\rho, c$ and $T_{D}$ are assumed to remain constant.

The workflow for present modelling approach involves specifying $z_{M}$, a, and $D$ for the borehole, $T_{S}, T_{M}$, $k$, and $\kappa$ for the surrounding rock volume, $\rho$ and $c$ for the circulating fluid, and $T_{D}$ from the characteristics of the surface heat exchanger installation. For each candidate rate of heat production $Q, T_{0}$ is calculated for a succession of times t using equations (4) and (5), with the corresponding value of $q_{c}$ determined using equation (7). This differs, for example, from the numerical modelling approach used by Alimonti and Soldo (2016), for which constant $q_{c}$ is specified and Q, at rates that decrease progressively over time, calculated from it. The present solution nonetheless incorporates the essential physics governing the energy balance for a cDGSW, whereby the heat produced in the flow through a borehole heat exchanger is equal to the heat lost by conduction from the surrounding rock volume.

Nonetheless, although this analytic solution maintains conservation of energy overall, it does not attempt to balance energy for any part of the model. For example, no attempt is made to explicitly model the progressive warming of the circulating fluid as it flows downward along the outer pipe (Fig. 2) or the cooling of the fluid flowing upward along the inner pipe as heat flows radially outward from it into its lower-temperature surroundings (cf. Alimonti et al., 2016). Furthermore, it is evident that (in addition to the pre-existing geothermal gradient) vertical temperature gradients will develop within the rock volume surrounding the borehole, meaning that the approximation used to justify equation (2) will not be valid. Each of these aspects will cause complexity that is not incorporated into the analytic model.

Differentiating equation (4) with respect to $r$ gives

$$
\begin{aligned}
& \partial \Delta \mathrm{T} \\
& -- \\
& \partial r
\end{aligned}=\frac{\zeta}{2 \pi \mathrm{kr}} \text {. }
$$

As time progresses, the volume of rock cooled thus gradually widens, but equation (8) means that the induced radial geothermal gradient increases inward, so the temperature gradient around the borehole will draw heat in from farther out (Fig. 5). Thus, although the borehole becomes surrounded by an ever-widening volume of cooled rock, this radial geothermal gradient will always direct heat inwards towards it. Nonetheless, the operational lifespan of a cDGSW, the time over which it can produce heat before the temperature at $r=a$ cools below any value that is useful, turns out to be very sensitive to choices of parameter values (see below). It is also noteworthy that although $Q$ is the rate of heat production from the borehole, it will only equal the rate of heat output to the load if $f=0$, i.e., if the reinjection temperature $T_{D}$ equals the ambient surface temperature $T_{S}$. Otherwise, only a proportion $f$, equal to $\left(T_{0}-T_{L}\right) /\left(T_{0}-T_{S}\right)$ of $Q$ will be output to the load and the remainder will be reinjected, contributing (as already noted) to heating the rock volume at $z<z_{L}$. Thus, as the rock volume at $z>z_{L}$ gradually cools, $T_{0}$ will eventually (at time $t_{L}$ ) decrease to $T_{L}$, at which point the DGSW will cease to deliver any useable heat output, effectively ending its useful life. At this point $\Delta T\left(z_{M}\right)=T_{L}-T_{M}$; substituting this condition into equation (4) and using equation (5), followed by other algebraic steps including recognizing that $T_{M-} T_{L}=(1-f)\left(T_{M}-T_{S}\right)$ and that $T_{M}-T_{S}=u z_{M}$, where $u$ is the geothermal gradient, gives

$$
\begin{aligned}
& \mathrm{Ca}^{2} \quad 2 \pi \mathrm{k}(1-\mathrm{f})^{2} \mathrm{z}_{\mathrm{M}}{ }^{2} \mathrm{u} \\
& \mathrm{t}_{\mathrm{L}}=\frac{\mathrm{C}}{4 \mathrm{~K}} \exp \left(\begin{array}{c}
2 \pi k\left(1-\mathrm{f}^{2} \mathrm{ZM}^{2} \mathrm{u}\right. \\
\mathrm{Q}
\end{array}\right.
\end{aligned}
$$


The exponential term in equation (9) means that $t_{L}$, thus calculated, is indeed very sensitive to choices of parameter values, as is illustrated in Fig. 6 .

The algebraic threshold of validity of the above 'long-timescale' solutions, at $t=r^{2} / \kappa$, corresponds to quite short timescales when $r$ is small; for example, at $r=a=0.1 \mathrm{~m}$ and with $\kappa=1 \mathrm{~mm}^{2} \mathrm{~s}^{-1}$ it is $10000 \mathrm{~s}$ or circa 2 hours 47 minutes. This solution is therefore applicable near the borehole on all timescales relevant to CDGSW operation. On the other hand, the use of equation (4) to determine the radius $r_{c}$ of this cooling effect, is more problematic. Equation (4) implies that $\Delta T=0$ when $r=r_{c}$, thus

$$
r_{c}=2 \sqrt{ }\left(\frac{\kappa \mathrm{t}}{\mathrm{C}}\right) \text {. }
$$

Plots of the function described by equation (4) indeed show that as $r$ approaches $r_{c}$ the value of $\partial \Delta T / \partial r$ is significant (Fig. 5), so $\partial \Delta \mathrm{T} / \partial \mathrm{r}$ has a discontinuity at $r=r_{c}$ which has no physical basis. The higher-order approximation in equation (3) also breaks down in the vicinity of $r=r_{c}$; this function indeed never actually satisfies $\Delta T=0$, it instead has a turning point beyond which $\Delta T$ starts to diverge away from zero. After several algebraic steps this can be shown to occur at $r=r_{C}$ where

$$
r_{c}^{2}=4 \kappa t+a^{2} \text {. }
$$

For operation of any significant duration, $r_{c}^{2}>>a^{2}$, thus

$$
r_{c} \approx 2 \sqrt{ }(\kappa t) \text {. }
$$

The estimate of $r_{c}$ from equation (12) is thus $\sqrt{ }$ times, or $~ 1.33$ times, that from equation (10).

It is also relevant that the solution for an infinitesimally thin 'line source', emitting or absorbing heat at a rate $\zeta$ per unit length, is

$$
\Delta \mathrm{T}=\frac{\zeta}{4 \pi \mathrm{k}} \mathrm{E}_{1}\left(\mathrm{r}^{2} /(4 \kappa \mathrm{t})\right)
$$

(e.g., Carslaw and Jaeger, 1959, p. 261), where $E_{1}(\chi)$ is the exponential integral function. As $r$ becomes larger this will be a close approximation to the solution for a heat source (or sink) of finite radius. However, since $E_{1}(0) \rightarrow \infty$ this equation is not physically meaningful at small values of $r$. Furthermore, although $E_{1}(\chi)$ decreases to very small values as $\chi$ increases, it never reaches precisely zero. $E_{1}(\chi)$ can be accurately approximated (for $\chi \geq 1$ ) as $\exp (-\chi) \times \ln (1+1 / \chi)$ (e.g., Abramowitz and Stegun, 1964, p. 229); for example, it is thus $\sim 0.25$ for $\chi=1, \sim 0.05$ for $\chi=2, \sim 0.01$ for $\chi=3$, and $\sim 0.004$ for $\chi=4$. Given that the term $\zeta /\left(4 \pi \mathrm{k}\right.$ ) is of the order of $1^{\circ} \mathrm{C}$ (see below) and a representative decrease in the temperature adjoining a DGSW can be a few tens of degrees Celsius (say, $\sim 50{ }^{\circ} \mathrm{C}$; see below), $\chi=1$ roughly corresponds to a temperature perturbation $\sim 0.5 \%$ as large as that adjoining the borehole and can thus provide an alternative estimate of the effective value of $r_{c}$. One thus obtains $r_{c}^{2} /(4 \kappa t) \approx 1$, indicating the same value for $r_{c}$ as is given by equation (12).

A further complicating factor is that in addition to the radial cooling at $z \leq z_{M}, c D G S W$ operation will cool the rock volume at depth $z>z_{M}$, which will add to the heat produced. An approximate correction will now be derived for this effect, in which it is assumed that this downward cooling effect extends over a depth range $r_{C}$ below the well bottom at depth $z_{M}$, with its radius $r_{E}$ and the associated temperature perturbation tapering linearly from $r_{C}$ and $\Delta T$ at depth $z_{M}$ to zero at depth $z_{M}+r_{c}$. Vertical position $w$ within this cooled zone is measured upwards from zero at $z=z_{M}+r_{c}$. The cooling at each value of $w$ can be approximated very crudely as extending over a radial distance out to $r=w$ with the 
temperature perturbation proportional to $(w-r)^{2} / w^{2}$. The heat $d E$ lost by cooling a cylindrical shell at vertical position $y$ and radius $r$, of infinitesimal thickness $d y$ and $d r$, can thus be estimated as

$$
\begin{aligned}
& \text { w }(w-r)^{2} \\
& \mathrm{dE}=\Delta \mathrm{T}\left(\mathrm{r}=\mathrm{a}, \mathrm{z}=\mathrm{r}_{\mathrm{c}}\right) \rho \mathrm{c} \underset{\mathrm{r}_{\mathrm{c}}}{-} \quad \begin{array}{c}
- \\
\mathrm{w}^{2}
\end{array}
\end{aligned}
$$

where $\rho$ and $\mathrm{c}$ are the density and specific heat capacity of the surrounding rock. Substituting for $\Delta T$ from equation (4) and using equations (5) and (10), together with $\kappa \rho c \equiv k$, one obtains

$$
E(t)=\frac{2 Q \ln \left(r_{C} / a\right)}{-z_{M} \kappa(1-f) r_{C}} \int_{w=0}^{r_{C}} w \int_{r=0}^{w} \quad w^{2} \quad r d r d w
$$

as an estimate for the total heat lost by cooling of this borehole end zone from time zero up to time t. After multiple algebraic steps, one obtains

$$
\begin{aligned}
& 4 \kappa \mathrm{t} \quad 4 \kappa \mathrm{t}
\end{aligned}
$$

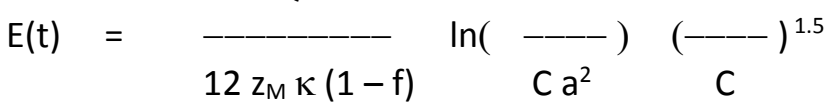

$$
\begin{aligned}
& \text { or } \\
& E\left(r_{C}\right)=\frac{Q}{6 z_{M} \kappa(1-f)} \ln \left(\begin{array}{l}
r_{C} \\
a
\end{array}\right) r_{c}^{3} .
\end{aligned}
$$

The effect of this contribution can be illustrated using a representative example with $Q=100 \mathrm{~kW}$, $\mathrm{z}_{\mathrm{M}}=2500 \mathrm{~m}, \mathrm{k}=1 \mathrm{~mm}^{2} \mathrm{~s}^{-1}, \mathrm{a}=0.1 \mathrm{~m}$, and $\mathrm{t}=20$ years, a realistic representative lifespan for a cDGSW (see below). Over this period of time the uncorrected heat production will thus be $100 \mathrm{~kW} \times 20$ years or $\sim 63.2$ TJ. With these values, $r_{c}$ will be $\sim 37.7 \mathrm{~m}$ after 20 years, and the additional heat production, from the borehole 'end correction', will be $\sim 2.1 \mathrm{TJ}$. Including this correction would thus only change the estimated overall heat production on this timescale by $\sim 3 \%$. Over time scales such as this, the correction is so small that the various approximations made in its derivation are not of major importance. The essential reason for this is that on these time scales the roughly cone-shaped zone at the base of the borehole, whose heat loss is calculated as this correction, is very small compared with the cylindrical volume flanking the borehole, whose heat loss was calculated previously.

A further correction is necessary to incorporate the upward geothermal heat flow $k \times u$. After time $t$ the rock volume cooled, of radius $r_{c}$, will present a horizontal cross-sectional area $\pi r_{c}{ }^{2}$ to this heat flow. The borehole will thus 'capture' a heat flux of

$$
\mathrm{Q}_{\mathrm{G}}=\pi \mathrm{r}_{\mathrm{C}}^{2} \mathrm{ku} \text {, }
$$

For $\mathrm{u}=32{ }^{\circ} \mathrm{C} \mathrm{km}^{-1}$ (the value adopted by Law et al., 2015, representative of geothermal gradients in radiothermal granites in different parts of Britain; e.g., Lee, 1986; Lee et al., 1987; Manning et al., 2007) and $\mathrm{k}=3.5 \mathrm{~W} \mathrm{~m} \mathrm{~m}^{-1}{ }^{\circ} \mathrm{C}^{-1}$ (likewise, a typical value for granitic rocks; e.g., Lee, 1986; Wheildon and Rollin, 1986; Lee et al., 1987; Manning et al., 2007) after 20 years, when $r_{c}$ is again $37.7 \mathrm{~m}$, the resulting additional heat flux will be $\sim 500 \mathrm{~W}$; this effect is thus even smaller in magnitude than the borehole 'end correction'. However, if a cDGSW were designed with very low heat production and a very long lifespan, $r_{c}$ would ultimately become so large that the geothermal heat flux 'captured' might balance the heat production, creating the possibility of a steady state situation. Equating $\mathrm{Q}_{\mathrm{G}}$ in equation (18) to $Q$ and using equation (10) for $r_{c}$, one obtains

$$
t_{E}=\frac{C Q}{4 \pi k \kappa u} .
$$

Taking reasonable estimates ( $\mathrm{k} \sim 3.5 \mathrm{~W} \mathrm{~m}^{-1}{ }^{\circ} \mathrm{C}^{-1}, \mathrm{\kappa} \sim 1 \mathrm{~mm}^{2} \mathrm{~s}^{-1}, \mathrm{u} \sim 32{ }^{\circ} \mathrm{C} \mathrm{km}^{-1}$, as before), one can estimate that $t_{E}$ is $\sim 40$ years per kilowatt of heat production $Q$. This steady-state limiting behaviour is 
thus only relevant for extremely low heat production, being (for example) 1000 years for $Q=25 \mathrm{~kW}$, by which time the cooled volume will have widened to $r_{c} \sim 270 \mathrm{~m}$. Such limiting behaviour is an interesting scientific curiosity, but does not help with the assessment of how cDGSW technology might be used to produce worthwhile heat outputs on timescales of practical interest.

\section{Discussion}

Figure 4 illustrates the predicted variation in output temperature for a cDGSW, for its first ten years of operation at a range of constant heat production rates. Over this timescale, the radius of the cylindrical rock volume cooled by the operation of the DGSW (Fig. 5) is so small that the aforementioned corrections for heat flow and for cooling at greater depths have no significant effect. Figure 4 thus illustrates a progressive decline in output temperature as the rock volume around the cDGSW progressively cools, the decrease on a given timescale being proportional to the heat production, as is to be expected from the linear governing equation (equation (2)). Figure 5 confirms that the thermal state of the rock volume surrounding a cDGSW progressively evolves over time, with no indication that it reaches a steady state on timescales of decades, although (as noted above) a steady state might ultimately be attained after thousands of years. Nonetheless, both Fig. 4 and Fig. 5 demonstrate that after years of operation of a cDGSW the rates of cooling in and widening of the surrounding affected rock volume will have become very low; Alimonti et al. (2016) described this behaviour as an 'almost steady state condition'.

Figure 6 demonstrates that the performance of a cDGSW depends strongly on its mode of use; if fluid is reinjected at a temperature above the value $T_{s}$ at the Earth's surface (i.e., $f>0$ ), the duration over which a given rate of heat production can be maintained is significantly reduced. This means that the performance of any such installation cannot be analysed in isolation, but must be considered in conjunction with the manner in which the heat output is used. The optimum situation is to reinject fluid at $T_{S}$ (i.e., $f=0$ ). However, since any real heat load will operate at a temperature $T_{E}$ significantly above $T_{s}$, reinjection at $f=0$ will require use of a heat pump (interfacing between the borehole circulation loop and the heat load) to lower the temperature of the fluid circulating back into the borehole below $T_{E}$, ideally to $T_{S}$. This is the essential reason why the hcDGSW configuration (Fig. 2(b)) is preferable to the simpler CDGSW variant (Fig. 2(a)). It has previously been noted (e.g., Collins and Law, 2017) that DGSW heat outputs should be interfaced through heat pumps, but the essential underlying physical reason has not previously been explained. The cost of the electricity required for powering the heat pump therefore needs to be factored into any economic analysis (see below). The electrical energy thus used will be converted to heat, contributing to the heat output supplied to the load, also influencing the analysis.

Table 2 illustrates in more detail the performance issues that arise when the heat output from a CDGSW supplies a heat load at a temperature $T_{E}$ that significantly exceeds the surface temperature $T_{S}$ (i.e., $f>0$ ), for various values of $z_{M}$ and $T_{M}$. Heat production from the $c D G S W$ is thus assumed to occur at rate $Q$, supplying a heat exchanger operating at a constant temperature $T_{E}=30{ }^{\circ} \mathrm{C}$, with no heat pump. In all cases, the output temperature $T_{0}$ from the cDGSW decreases over time at a rate that is sensitive to $Q$. The proportion of the heat production that forms useable heat output, $Q_{u}$, is estimated as $Q \times\left(T_{0}-T_{E}\right) /\left(T_{0}-T_{S}\right)$ and thus becomes ever smaller as $T_{0}$ decreases, even though $Q$ is assumed constant. These results indicate that optimal cDGSW operation is quite sensitive; if $Q$ is too high relative to $z_{M}$ and $T_{M}$ the $C D G S W$ will cool so quickly that $Q_{u}$ is limited, whereas if $Q$ is too low $Q_{u}$ will likewise be minimal. For a model $C D G S W$ with $z_{M}=2500 \mathrm{~m}$ and $T_{M}=90^{\circ} \mathrm{C}$, with $T_{E}=30{ }^{\circ} \mathrm{C}$, the optimum value of $Q$ to maximise the useable heat output over 5 years turns out to be $\sim 160 \mathrm{~kW}$, decreasing to $\sim 140 \mathrm{~kW}$ if the timescale is set to 20 years. This model cDGSW might thus produce a steady output of useable heat over 20 years of $\sim 70 \mathrm{~kW}$ or thereabouts, by initially operating at $Q \sim 80 \mathrm{~kW}$ then gradually increasing $Q$ to $\sim 140 \mathrm{~kW}$ as the surrounding rock volume cools. Table 2 also shows the corresponding 
values for $\mathrm{z}_{\mathrm{M}}=2000 \mathrm{~m}$, for which the maximum feasible steady output of useable heat over 20 years would be only $\sim 30 \mathrm{~kW}$, and for $\mathrm{z}_{\mathrm{M}}=3000 \mathrm{~m}$, for which it would be $\sim 130 \mathrm{~kW}$.

For the three cDGSW configurations discussed above, the outputs of useable heat over 20 years can be estimated, respectively, as $\sim 22.8,12.3$ and $\sim 5.3 \mathrm{GWh}$. At $£ 0.03$ per $\mathrm{kWh}$, the value of the heat produced would be $\sim £ 0.61 \mathrm{M}, \sim f 0.37 \mathrm{M}$ and $\sim £ 0.16 \mathrm{M}$; if a RHI subsidy of $£ 0.0514$ per $\mathrm{kWh}$ were included, these figures would rise to $\sim £ 1.86 \mathrm{M}, £ 1.00 \mathrm{M}$ and $\sim £ 0.43 \mathrm{M}$. The capital costs of these projects might be estimated, respectively, as $\sim f 2.9 \mathrm{M}, \sim f 2.3 \mathrm{M}$ and $\sim f 1.8 \mathrm{M}$ (see below). It is thus apparent (even before any estimation of operating costs) that such projects have no chance of being cost-effective under current UK conditions. The calculations nonetheless exemplify that (over the depth range considered) deeper cDGSW boreholes would be less uneconomic than shallower ones, the increase in output of useable heat outweighing the corresponding increase in drilling costs, an effect that is explored further later in this study.

A further point evident from Fig. 6 is that a small increase in the rate of heat production from a cDGSW or hcDGSW can dramatically shorten its lifespan. This indicates that careful design, taking account of the local geothermal gradient and other site-specific parameters, is essential. Assuming a given borehole depth $z_{M}$, rate of heat production $Q$, and value of $f$, from equation (9) it is evident that the project lifespan depends exponentially on the geothermal gradient $u$ and on the thermal conductivity $k$ of the rock volume. A hcDGSW design that performs well at one site, with particular values of $k$ and $u$, might thus have a much shorter lifespan at another site with slightly lower $k$ or $u$.

The figures for specific performance (i.e., heat output per unit length of borehole) warrant comparison with those for 'ground source heat pump' systems utilising shallow-borehole (depth $<\sim 100 \mathrm{~m}$ ) heat exchangers. The latter typically have specific performance of $\sim 50-200 \mathrm{kWh} \mathrm{m}^{-1} \mathrm{yr}^{-1}$ over annual operating cycles (e.g., Hepbasli, 2005), or $\sim 6-23 \mathrm{~W} \mathrm{~m}^{-1}$. The hcDGSW designs being discussed have higher specific performance, for instance $50 \mathrm{~W} \mathrm{~m}^{-1}$ for a $2000 \mathrm{~m}$ deep system with $\mathrm{Q}=100 \mathrm{~kW}$. For comparison, doublet systems might have heat outputs of many megawatts (say $8 \mathrm{MW}$ from two $4000 \mathrm{~m}$ boreholes; e.g., van Wees et al., 2010), indicating a specific performance of $1000 \mathrm{~W} \mathrm{~m}^{-1}$. However, the overall energy balance is very different for shallow-borehole systems compared with DGSW systems: the former can operate sustainably because of influxes of geothermal heat from below and by surface heating from above, whereas (as noted above) for the latter the issue is not sustainable operation but determination of the lifetime over which 'heat mining' is worthwhile. To establish this, it is noted that a $50 \mathrm{~m}$ borehole with specific performance $10 \mathrm{~W} \mathrm{~m}^{-1}$ would have annual heat output of $\sim 16 \mathrm{GJ}$. From Fig. 5 , a year of operation will cool the surrounding rock volume to a radial distance of $\sim 28 \mathrm{~m}$, so will cool a cross-sectional area of $\sim 2500 \mathrm{~m}^{2}$. A representative geothermal heat flow is, say, $\sim 90 \mathrm{~mW} \mathrm{~m}^{-2}$ or $\sim 3 \mathrm{MJ} \mathrm{m}^{-2} \mathrm{yr}^{-1}$. Global warming and localized surface heating due to urban development can cause downward heat flows from the surface that can exceed the upward geothermal heat flux (e.g., Bayer et al., 2016; Westaway and Younger, 2016), amounting, say, to $\sim 4 \mathrm{MJ} \mathrm{m}^{-2} \mathrm{yr}^{-1}$. The combination of these flows might thus supply $\sim 18 \mathrm{GJ} \mathrm{yr}^{-1}$ of heat into the $\sim 2500 \mathrm{~m}^{2}$ cross-sectional area, sufficient to balance the heat production. This essential difference, between shallow-borehole systems that can operate sustainably and DGSW systems that 'mine heat', has not been recognized before (cf. Collins and Law, 2017).

\section{Factors affecting dDGSW operation}

As already discussed, the alternative dDGSW variant (Fig. 3(a)) involves production of thermal ground water to enhance the heat output that is feasible from conduction alone. Law et al. (2015) have indeed suggested that heat production might be supplemented in this manner; for example, 'bleed flow' at rate $q_{B}=2 \mathrm{I} \mathrm{s}^{-1}$ at $50{ }^{\circ} \mathrm{C}$ above $T_{D}$ would generate heat output of $2 \times 10^{-3} \mathrm{~m}^{3} \mathrm{~s}^{-1} \times \mathrm{c} \times \rho \times 50{ }^{\circ} \mathrm{C}$ (where $c=4186 \mathrm{~kg} \mathrm{~m}^{-3}$ and $\rho=1000 \mathrm{~kg} \mathrm{~m}^{-3}$ are the specific heat capacity and density of water; cf. equation (6)) or $\sim 400 \mathrm{~kW}$. Law et al. (2015) stated that $\mathrm{q}_{\mathrm{B}}=2 \mathrm{I} \mathrm{s}^{-1}$ 'could be achieved from almost any geological 
formation'. In the light of this, the hydraulic conductivity of relevant rock formations will now be discussed, along with the handling of the water produced from dDGSW projects, which might include treatment costs.

\section{Effects of hydraulic conductivity}

Barker (1986) investigated the transient drawdown effect of a dDGSW, demonstrating that the required timescale is likely to be quite short. This topic can thus be analyzed, to place limits on the 'bleed flow' that might be feasible, using the standard Thiem (1906) solution for the steady-state drawdown $\Delta H$ of the phreatic surface in a confined aquifer of transmissivity $T_{K}$ in the vicinity of a production well:

$$
\Delta \mathrm{H}=\begin{array}{cc}
\mathrm{q}_{\mathrm{B}} & \mathrm{r}_{\mathrm{A}} \\
--- & \ln (-) . \\
2 \pi \mathrm{T}_{\mathrm{K}} & \mathrm{r}
\end{array}
$$

Here, $r_{A}$ denotes the 'radius of influence' of the aquifer, and $r$ is again radial distance. Law et al. (2015) envisage placing an open (screened) section in the well casing of substantial vertical extent above the well bottom. The maximum drawdown in this layer, at $r=a$, can be designated as $\Delta H_{0}$. At distance from the borehole, the transmissivity of the layer in which this drawdown occurs will equal $K \times \Delta H_{0}$, where $\mathrm{K}$ is its hydraulic conductivity, from which it follows that the minimum value of $\mathrm{K}$ that can support the required flow rate under steady-state conditions is

$$
\mathrm{K}=\frac{\mathrm{q}_{\mathrm{B}} \mathrm{r}_{\mathrm{A}}}{2 \pi \Delta \mathrm{H}_{\mathrm{O}}{ }^{2} \mathrm{a}(-) .}
$$

Taking $\Delta \mathrm{H}_{\mathrm{o}}=100 \mathrm{~m}, \mathrm{r}_{\mathrm{A}} \sim 1 \mathrm{~km}$ and $\mathrm{a}=0.1 \mathrm{~m}$, for $\mathrm{q}_{\mathrm{B}}=2 \mathrm{I} \mathrm{s}^{-1}$ one obtains $\mathrm{K} \sim 3 \times 10^{-7} \mathrm{~m} \mathrm{~s}^{-1}$. Although some lithologies have $\mathrm{K}$ above this threshold, many in the UK and elsewhere do not (e.g., Allen et al., 1997; Lewis et al., 2006). Abesser et al. (2014) reached a similar conclusion, noting that water yields of $\geq 1 \mathrm{I} \mathrm{s}^{-1}$ are only feasible from boreholes in lithologies classified as 'moderate' or 'good' aquifers. Whether 'bleed flow' can significantly supplement the limited heat output of a CDGSW is thus site-dependent and cannot be presumed in general. With $\Delta H_{0}=150 \mathrm{~m}$ and $\mathrm{q}_{\mathrm{B}}=0.9 \mathrm{I} \mathrm{s}^{-1}$, equation (21) gives $\sim 6 \times 10^{-8} \mathrm{~m} \mathrm{~s}^{-1}$ as the hydraulic conductivity threshold for dDGSW operation to be feasible, indicating (as is evident from the form of equation (21)) that this threshold decreases $\mathrm{as}_{\mathrm{B}}$ is reduced or $\mathrm{H}_{\mathrm{o}}$ is increased. Coarse sediments might well thus have sufficient hydraulic conductivity for dDGSW operation to be feasible. For example, $\mathrm{K}$ has been reported as $\sim 10^{-5} \mathrm{~m} \mathrm{~s}^{-1}$ in Triassic sandstone from southern England (e.g., Smith, 1986); the operation of the aforementioned Southampton geothermal borehole as a wDGSW / hwDGSW indeed provides clear evidence of high $\mathrm{K}$ in such rocks.

Nonetheless, given that dDGSW projects have been proposed in granite, it is important to assess whether this lithology might have sufficient hydraulic conductivity for this technology to be feasible. It is indeed well known that intact granite at depth has very low K. For example, Brace et al. (1968) determined the permeability of Westerly Granite at $\sim 50 \mathrm{MPa}$ (roughly equivalent to $\sim 2000 \mathrm{~m}$ depth) as $\sim 63 \mathrm{nD}\left(\sim 6.3 \times 10^{-20} \mathrm{~m}^{2}\right.$ ), equivalent (at $\sim 70{ }^{\circ} \mathrm{C}$, so water has a viscosity of $\sim 0.4 \mathrm{mPa}$ s) to $\mathrm{K} \sim 4 \times 10^{-12} \mathrm{~m} \mathrm{~s}^{-1}$. At $10 \mathrm{MPa}$ (depth $\sim 400 \mathrm{~m}$ ), they measured its permeability as $\sim 230 \mathrm{nD}$, indicating $\mathrm{K}$ $\sim 10^{-11} \mathrm{~m} \mathrm{~s}^{-1}$. Martinez-Landa and Carrera (2005) reported that intact granite at the Grimsel Test Site in Switzerland, at $\sim 450 \mathrm{~m}$ depth, has $\mathrm{K} \sim 10^{-12}$ to $\sim 10^{-10} \mathrm{~m} \mathrm{~s}^{-1}$, in good agreement. Such values are so far below any conceivable threshold required for a dDGSW or hdDGSW to function that this technology stands no chance of success in intact granite.

On the other hand, many workers (e.g., Martinez-Landa and Carrera, 2005; Hamm et al., 2007) have reported hydraulic conductivities orders-of-magnitude higher in fractured granite; however, the values depend on the precise geometry of the fractures at each site, and are thus not readily predictable in general. For example, Martinez-Landa and Carrera (2005) reported that in fractured granite at the Grimsel site $\mathrm{K}$ varies between $\sim 10^{-10}$ and $\sim 2 \times 10^{-8} \mathrm{~m} \mathrm{~s}^{-1}$, with occasional more conductive 
fractures. For fractured granite in Korea at depths of $<100 \mathrm{~m}$, Hamm et al. (2007) characterized the statistics of variations of $\mathrm{K}$, and how these correlate with length- and aperture-distributions of the fractures; $K$ here thus varies between $\sim 2 \times 10^{-10}$ and $~ 3 \times 10^{-6} \mathrm{~m} \mathrm{~s}^{-1}$. Illman et al. (2009) reported results of tomographic analysis of pumping-test results to constrain variations in $\mathrm{K}$ in fractured granite in Japan. Their results vary between $\sim 6 \times 10^{-8}$ and $\sim 10^{-6} \mathrm{~m} \mathrm{~s}^{-1}$, the latter value occurring at $\sim 500 \mathrm{~m}$ depth. Since fractures in granite (and other rocks) are typically created as a result of the effects of cooling and erosional unloading (cf. Brace et al., 1968; McGarr and Gay, 1978; Bourne and Willemse, 2001), one expects them to open progressively as depth decreases. Furthermore, since permeability and hydraulic conductivity depend on the cube of fracture aperture (e.g., Snow, 1969), one expects these quantities to decrease with increasing depth. However, it is difficult to extrapolate results such as those stated above for the higher pressure at greater depths. Overall, one does not expect $\mathrm{K}$ to be low enough at depths of $\sim 2000 \mathrm{~m}$ in granite to sustain hdDGSW operation, although exceptions (at the high-K 'tail' of probability distributions) occasionally occur.

To illustrate this point with UK examples, Table 3 lists analyses of the hydraulic transport properties for the Rosemanowes production well (well RH-15) in the Carnmenellis granite, Cornwall (after Richards et al., 1994), and for the Eastgate-1 borehole in the Weardale granite, County Durham (after Manning et al., 2007, and Younger and Manning, 2010). Well RH-15 only has sufficient hydraulic conductivity to be viable as a hdDGSW over restricted vertical extents, none of which has sufficient transmissivity to yield the required flow. Furthermore, the transmissivity and conductivity values are relative to a nearby injection well; if that had not been operating, no fluid would have been produced at this production well. At Eastgate, rapid ingress of water occurred at $\sim 410 \mathrm{~m}$ depth when the wellbore crossed a mineral vein, revealing the highest transmissivity ever measured within granite (Younger and Manning, 2010). Setting aside this exceptional discovery, the water ingress into the rest of this borehole at first sight indicates sufficient transmissivity for its use as a hdDGSW. However, as Manning et al. (2007) pointed out, this ingress occurs at points where the wellbore crosses other fractures, the most important of these being at $\sim 730$ and $\sim 756 \mathrm{~m}$ depths. Once again, the overwhelming majority of the section in this borehole evidently has very low hydraulic conductivity, making it unsuited for use as a hdDGSW. The flow rates in the highly transmissive parts of this borehole are far in excess of what would be needed for hdDGSW operation; as Manning et al. (2007) and Atkins (2013) indeed noted, they might indeed be utilised for a conventional well doublet.

An additional factor affecting the viability of any dDGSW system, evident from previous analyses of shallow systems (e.g., Rees et al., 2004), is the increase in operating costs that will result from the greater drawdown within the borehole, which will accompany increased rates of 'bleed flow', due to the need for pumping to lift the circulating water through a greater height. If significant 'head lift' for produced water is necessary, the electrical power requirement might be large (e.g., Younger, 2014), potentially outweighing the value of the heat produced. To analyse this effect, $q_{c}$ and $q_{B}$ may be designated, respectively, as the volume flow rate required to produce heat by conduction (i.e., for the closed-loop circulation within a DGSW borehole heat exchanger) and the rate of bleed flow, with $\Gamma \equiv q_{\mathrm{B}} / \mathrm{q}_{\mathrm{c}}$. It is assumed that the heat production utilizes a heat pump with coefficient of performance (COP; the ratio of useable heat output to electrical energy consumed) $\Psi$, the heat is sold at a price $P_{H}$ per unit of energy produced, and the electricity used to power the heat pump contributes its own heating effect, then the rate of heat sale can be expressed as $\rho \times c \times \Delta T \times\left(q_{C}+q_{B}\right) \times((\Psi+1) / \Psi) \times P_{H}$ where $\rho$ and $\mathrm{c}$ are the density and specific heat capacity of the circulating water and $\Delta \mathrm{T}$ is its temperature above ambient. The rate of expenditure on operating costs can be expressed as $\rho \times g \times H \times\left(q_{C}+q_{B}\right) \times P_{E}+$ $\rho \times c \times \Delta T \times\left(q_{C}+q_{B}\right) \times(1 / \Psi) \times P_{E}$ where $g$ is the acceleration due to gravity, $H$ is the lift height or 'hydraulic head' in the borehole, and $P_{E}$ is the cost per unit of electrical energy used. The first of these terms represents the 'head lift' pumping and the second the operation of the heat pump, both these processes being assumed $100 \%$ efficient. Defining $\beta \equiv P_{E} / P_{C}$, the difference in operating surplus (or deficit) between using bleed flow and omitting it from the design (thus assuming a closed loop 
configuration with $\mathrm{H}=0$, and with $\Gamma=0$ ) can thus be determined. The condition for the alternative open loop design (with $\mathrm{H}$ and $\gamma$ both nonzero) being the more profitable of the two can thus be written, after several algebraic steps, as $\mathrm{H}<\mathrm{H}_{\circ}$ where

$$
\mathrm{H}_{\circ}=\begin{array}{ccc}
c \Delta \mathrm{T} & \Gamma & 1+\Psi-\beta \\
--- & - & - \\
\mathrm{g} & 1+\Gamma \quad \Psi \beta
\end{array} .
$$

Using plausible values for these parameters $\left(\Delta \mathrm{T}=40^{\circ} \mathrm{C}, \mathrm{c}=4186 \mathrm{~J} \mathrm{~kg}^{-1}{ }^{\circ} \mathrm{C}^{-1}, \mathrm{~g}=9.81 \mathrm{~m} \mathrm{~s}^{-2}, \beta=3\right.$ and $\left.\Psi=4\right)$, $\mathrm{H}_{\mathrm{o}}$ is $\sim 250 \mathrm{~m}$ for $\Gamma=0.1$, increasing to $\sim 1400 \mathrm{~m}$ for $\Gamma=1$. As another example, Law et al. (2015) discussed a dDGSW scenario in which $200 \mathrm{~kW}$ of heat production at $\Delta \mathrm{T}=40{ }^{\circ} \mathrm{C}$ was inferred to include a contribution of $50 \mathrm{~kW}$ from bleed flow. Thus, $\Gamma=1 / 3, \mathrm{q}_{\mathrm{c}} \sim 0.9 \mathrm{I} \mathrm{s}^{-1}$ and $\mathrm{q}_{\mathrm{B}} \sim 0.3 \mathrm{I} \mathrm{s} \mathrm{s}^{-1}$ are required. From equation (22), $H_{\circ}$ is $\sim 700 \mathrm{~m}$; equating this value to $\Delta \mathrm{H}_{\circ}$ in equation (21) gives $\mathrm{K} \sim 9 \times 10^{-10} \mathrm{~m} \mathrm{~s}^{-1}$. Even with such extreme drawdown, it is unlikely that $\mathrm{K}$ will be low enough in intact granite to make dDGSW operation worthwhile; moreover, this calculation takes no account of capital cost, which might make neither the cDGSW nor the dDGSW option economic relative to other energy sources (see below).

\section{Produced water treatment and associated costs}

As already noted, it is a legal requirement in the UK (and other European Union member states) for produced water discharged into the environment from boreholes to comply with regulatory limits for concentrations of contaminants such as dissolved metallic ions, and if necessary to require treatment (e.g., DEFRA, 2014). From previous experience (e.g., Edmunds, 1975, 1986; Younger et al., 2016), water produced from depths of $\sim 2 \mathrm{~km}$ or more is expected to be a concentrated brine, potentially containing dissolved metallic ions including radionuclides in significant concentrations. Radium, an example radionuclide, is chemically similar to calcium, so can precipitate as radioactive scale within pipework, thus requiring costly treatment. Setting the latter aspect aside for now and concentrating on the discharge of produced water, treatment technologies are classified as active or passive (e.g., Johnson and Hallberg, 2005): the former typically require inputs of electricity and chemical reactants, making them more expensive; the latter typically involve 'natural' processes such as filtration and biochemical reactions (e.g., sulphate reducing bacteria removing metallic ions from solution as insoluble sulphide 'sludge'), which typically proceed without routine human intervention within artificial wetlands at site. Active treatment options include installing treatment plant at site or transporting produced water by tanker lorry for treatment elsewhere. There is a substantial literature on this topic; contributions relevant to UK issues include the works by Younger (2000) and Younger et al. (2002, 2005). Many workers (e.g., Kiessig et al., 2004; Younger et al., 2005) have noted that cost estimates depend on site-specific details, including discharge rates, so once again 'off the shelf' solutions are not possible. It should also be noted that rather than preventing all pollution from entering the environment, the aim of these treatment options is to reduce pollutant concentrations to 'acceptable' levels that the environment can bear (e.g., Kiessig et al., 2004); adopted strategies thus require regulatory approval.

Since hdDGSW installation in granite is being proposed (GEL et al., 2016; Collins and Law, 2017; see below), the track record of treatment of mine water discharges from this lithology is relevant. The largest mine water treatment scheme in a granitic region of the UK is for the former Wheal Jane tin and copper mine in Cornwall, SW England (e.g., Knight Piesold and partners, 1995, 1998; Coulton et al., 2003; Younger et al., 2005), which adjoins the Variscan age Carnmenellis pluton. Commissioned in the $1990 \mathrm{~s}$, this active treatment scheme was originally budgeted with $£ 4.25 \mathrm{M}$ capital cost and $f 1.03 \mathrm{M}$ annual operating cost, to treat $\sim 5 \times 10^{6} \mathrm{~m}^{3}$ of water per year (e.g., Knight Piesold and partners, 1998) at a typical rate of $\sim 160$ litres per second, principally for removal of iron, copper and zinc, also arsenic, cadmium, manganese, nickel and aluminium. The annual operating cost has subsequently been reported as $\sim £ 1.5 \mathrm{M}$ (e.g., Morris, 2014; Peacock, 2014), or $\sim £ 0.3$ per cubic metre. 
Bailey et al. (2016) describe a more recent active treatment scheme, to remove zinc from discharge from the former lead and zinc mine at Force Crag in Cumbria, NW England, a region underlain by Caledonian age granite plutons. Bailey et al. (2016) reported that the option chosen had a capital cost of $€ 1.92 \mathrm{M}$ and annual operating cost of $€ 0.17 \mathrm{M}$ to treat discharge at $\sim 6 \mid \mathrm{s}^{-1}$. The latter amount is $\sim € 0.9$ or $₹ 0.8$ per cubic metre. Alternative passive treatment options would have been cheaper, but were not preferred because of the proven technology adopted (Bailey et al., 2016).

For comparison, passive treatment is utilized for example at the former Pöhla-Tellerhäuser uranium mine in the Erzgebirge mountains of SE Germany. Uraniferous mineralization occurs here in hydrothermal veins associated with Variscan granite intrusions (e.g., Förster, 1999; Förster et al., 1999). As discussed, for example, by Kunze and Küchler (2003), Kiessig et al. (2004) and Küchler et al. (2005), after uranium mining ceased in 1990 the main concerns at this site have been dissolved iron, radium and arsenic, as well as uranium and manganese, in waters that discharge at $17 \mathrm{~m}^{3} \mathrm{hr}^{-1}$ or $\sim 5 \mathrm{I} \mathrm{s}^{-1}$. The passive treatment system, installed at a capital cost of $\sim € 0.5 \mathrm{M}$, comprises six artificial wetlands covering almost $500 \mathrm{~m}^{2}$ of land. The operating cost was estimated as $€ 2$ per cubic metre in the first two years of operation, when its performance was intensively monitored, subsequently decreasing to $€ 0.2$ or $£ 0.17$ per cubic metre. This system superseded an active treatment plant with operating cost $₹ 4$ per cubic metre; it paid for itself in circa one year.

Turning to the possible option of transporting produced water for off-site treatment, it is noted that the $2 \mathrm{I} \mathrm{s}^{-1}$ discharge rate envisaged for a dDGSW would result in $173 \mathrm{~m}^{3}$ of produced water per day. Transporting this volume to a treatment plant in $20 \mathrm{~m}^{3}$ tanker lorries would require 9 movements every 24 hours. The cost of treatment depends on local conditions and potential economies of scale; Dahm and Chapman (2014) reported that in the USA such costs might thus vary between 0.20 and 8.50 per barrel ( $\_1-f 40$ per cubic metre). As Collins (2016) has discussed, in the USA water treatment, including transportation by tanker lorry, for a small-scale installation such as this might cost 2.80 per barrel, equivalent to $\sim £ 9$ per cubic metre or $\sim £ 1600$ per day. One might break this amount down in terms of the costs of buying and operating the tanker lorries required, the wages for their drivers, and the direct costs of the water treatment, using whichever technology is adopted at the treatment site. Dahm and Chapman (2014) also described modular active treatment units, which can operate automatically at drilling sites without routine operator intervention, and might (subject to environmental permitting) discharge the treated water directly into the environment (e.g., into the sea). The treatment cost was reported as $\sim 0.75$ per barrel or $\sim £ 3.80$ per cubic metre. Each of these calculations assumes continuous operation, whereas a dDGSW might be operated intermittently, at times of peak heat demand. Such intermittency would result in higher unit costs for treatment of produced water, because assets (e.g., tanker lorries) would only see intermittent use.

It is evident that these costs require consideration relative to the value of the heat that is produced. For example, if a dDGSW or hdDGSW produces heat at $400 \mathrm{~kW}$ with $2 \mathrm{I} \mathrm{s}^{-1}$ of 'bleed flow', it implies 18 litres of discharge per $\mathrm{kWh}$. If the water treatment costs as much as $£ 3.80$ per cubic metre (see above), it would equate to $£ 0.068$ per kWh. If each kWh of heat produced has a notional value of, say, $f 0.03$, then the water treatment cost would exceed the value of the heat produced, calling the economics of the project into question. This is of course not a definitive limit as the value of the heat produced might be influenced by subsidy payments (see below). Nonetheless, even if cheaper water treatment is feasible, its cost might well be a substantial proportion of the value of the heat produced and thus form an essential budget component for any project.

\section{Analysis of hcDGSW economics}

The preceding sections highlight several difficulties with the DGSW concept. First, dDGSW or hdDGSW operation requires rocks of relatively high hydraulic conductivity at depth. Second, treatment costs for the produced water will adversely impact economic viability, making dDGSW or hdDGSW 
operation particularly problematic in granite; intact granite will have too low a hydraulic conductivity and even if the granite is fractured the probability of a given section in it of vertical extent $\sim 100-300 \mathrm{~m}$ having sufficient transmissivity is low. Whilst one might conceivably find a suitable site for this technology somewhere, it would require a substantial research (e.g., using electrical prospecting techniques; cf. Beamish, 1990), thus defeating the aim of providing an 'off the shelf' technology. The third issue concerns the cDGSW variant. In its simplest form, without a heat pump (Fig. 2(a)), the COP will be high; for example, Law (2014) reported that a prototype installation had a COP of $\sim 50$. However, as already noted, $T_{D}$ for this variant will significantly exceed the ambient temperature $T_{S}$ so $f$ will be well above zero, limiting the useable heat output. In contrast, for the hcDGSW variant, with the circulating fluid also fed through a heat pump, to reduce its reinjection temperature much closer to $T_{s}$ (Fig. 2(b)), significantly higher heat production can be anticipated, in accordance with earlier discussion, outweighing the fact that the COP for the additional heat output supplied via the heat pump will inevitably be less than that extracted via the heat exchanger (see below). On this basis, the hcDGSW is the variant with the greatest potential viability.

A model is thus developed to assess the output performance and economics of a hcDGSW. It is assumed that an electrically powered pump maintains the circulation around the closed loop at the rate necessary for the required rate of heat production by creating a pressure difference $\Delta P . \Delta P$ will equal the sum of pressure drops along the circulation loop, in the heat exchanger and the associated pipework. Most of this pressure drop will be in the pipe carrying the upward component of the circulation, as a result of its substantial length $L$ and relatively small diameter $D$. Neglecting other contributions, one may write (e.g., from Lyons et al., 2009, p. 167)

$$
\Delta \mathrm{P} \quad=\quad \frac{f_{D} \rho V^{2}}{2 D} L
$$

where $f_{D}$ is the Darcy-Weisbach friction factor for the flow regime. The value of $f_{D}$ itself depends on the Reynolds Number, Re, of the flow, where

$$
\operatorname{Re} \quad \therefore \quad \text { VD } \rho
$$

$$
\eta
$$

$\eta$ being the (dynamic) viscosity of the fluid. In general, if $\operatorname{Re}<\sim 2000$, the flow is laminar, whereas at higher $R e$ it is turbulent. For laminar flow, $f_{D}$ takes standard values as a function of Re (e.g., McKeon et al., 2004). However, for turbulent flow, $f_{D}$ also depends strongly on the roughness, $\Omega$, of the inner surface of the pipe, being markedly higher the rougher this is. $\Omega$ is defined as

$$
\Omega \quad \equiv \quad \begin{aligned}
& \varepsilon \\
& \text { D }
\end{aligned},
$$

where $\varepsilon$ is the characteristic height of surface irregularities; $\varepsilon$ might be $\sim 0.05 \mathrm{~mm}$ for steel pipe or $\sim 0.005 \mathrm{~mm}$ for composite or plastic pipe (e.g., Enggcyclopedia, 2011). One may look up $f_{D}$ for the value of $\Omega$ corresponding to any choice of $\varepsilon$ and $D$ and for any given value of Re on a standard 'Moody Diagram' (Moody, 1944) for input into calculations using equation (23).

Assuming $100 \%$ efficiency, the electrical power $\mathrm{Q}_{E}$ used by the pump will equal $\Delta \mathrm{P} \times \mathrm{Q}$; assuming, also, that all the produced heat is used, the COP, $\Psi$, will equate to $Q / Q_{E}$. These equations can be combined to give

$$
\Psi=\frac{\pi^{2} \rho^{2} \mathrm{c}^{3}\left(\mathrm{~T}_{\mathrm{o}}-\mathrm{T}_{\mathrm{s}}\right)^{3} \mathrm{D}^{5}}{8 \mathrm{fL} \mathrm{Q} \mathrm{Q}^{2}} .
$$

As a test of this equation, it is noted, once again, that Law (2014) reported $\Psi \sim 50$ for a prototype cDGSW installation, which had instantaneous heat production $Q=380 \mathrm{~kW}, \mathrm{~L}=1800 \mathrm{~m}$, and $\mathrm{T}_{\mathrm{o}}=63^{\circ} \mathrm{C}$. $\mathrm{T}_{\mathrm{s}}$ can be estimated as $\sim 10{ }^{\circ} \mathrm{C}$ and $\rho, \mathrm{c}$ and $\eta$ as $\sim 1000 \mathrm{~kg} \mathrm{~m}^{-3}, \sim 4186 \mathrm{~J} \mathrm{~kg}^{-1}{ }^{\circ} \mathrm{C}^{-1}$, and $\sim 0.45 \mathrm{mPa} \mathrm{s}$, 
respectively, so $\mathrm{q}_{\mathrm{B}}$ was $\sim 1.7 \mathrm{I} \mathrm{s}^{-1}$ but $\mathrm{D}$ was not specified. Westaway (2016) estimated $\mathrm{D}$ as $\sim 40 \mathrm{~mm}$ from a photograph of the pipe used in this prototype test, which implies $V \sim 1.4 \mathrm{~m} \mathrm{~s}^{-1}$, suggesting $\operatorname{Re}$ $\sim 120,000$. The flow was thus highly turbulent; from Moody (1944) for very smooth pipe $f_{D}$ would be $\sim 0.018$. For this configuration, equation (26) predicts $\Psi \sim 300$, although with $D \sim 30 \mathrm{~mm}$ it would reduce to 70 , in rough agreement with the Law (2014) estimate. The 'thermosiphon effect', whereby the lower mean density of the fluid in the inner pipe, due to its higher mean temperature, reduces the pressure drop below the value of $\Delta \mathrm{P}$ calculated using equation (23), and thus reduces the electrical power requirement for pumping (e.g., Alimonti et al., 2016; Spitler et al., 2016) and the associated operating cost, is also neglected; the calculations set out below indicate that this item forms a minimal part of the overall budget of a DGSW project.

The COP for the heat pump, when extracting heat from a source at temperature $T$ to a heat load at temperature $T_{E}$, is assumed to vary, after Baster (2011), as

$$
\Psi \quad=\quad 6.70 \exp \left(-0.022 \times\left(T_{E}-T\right)\right)
$$

If the heat pump thus cools the circulating fluid from an initial temperature $T_{1}$ to the ambient surface temperature $T_{S}$, its mean $C O P, \Psi_{M}$, will be



The heat exchanger is presumed to cool the circulating fluid to temperature $T_{E}$; the heat pump then cools it further, from $T_{E}$ to $T_{S}$, after which it is reinjected. If $T_{O}<T_{E}$ then the heat exchanger is assumed to be bypassed, such that $T_{1}=T_{0}$. Equation (27), for heat pump performance, was derived by Baster (2011) by regression analysis using an ensemble of performance data for air source heat pumps. It is used here as an approximation, in the absence of performance data for any water source heat pump with the required operating characteristics. The analysis proceeds by calculating the variation of $T_{0}$ with time for a given $Q$ using equations (3), (4) and (5), then calculating the heat outputs from the heat exchanger and heat pump, along with their electricity consumption. The calculations are run for a lifespan of 20 years consistent with the current $\mathrm{RHI}$ subsidy regime.

Recent geothermal projects in the UK have involved drilling to $\sim 1 \mathrm{~km}$ at Eastgate, County Durham (Manning et al., 2007; Younger and Manning, 2010), with a budget of $\sim f 0.5 \mathrm{M}$, and to $\sim 1.8 \mathrm{~km}$ at the Science Central site in Newcastle upon Tyne (e.g., Westaway and Younger, 2016; Younger et al., 2016), with a budget of $\sim f 1.2 \mathrm{M}$. The $f 1.35 \mathrm{M}$ capital cost estimated by GEL et al. (2016) for the proposed $2 \mathrm{~km}$ AECC borehole is consistent with these values. In the geothermal project costing model used in the Netherlands, boreholes of depth $\mathrm{z}_{\mathrm{M}}$ (in metres) have estimated capital cost $\Sigma$ (in $€$ )

$$
\Sigma=f_{K}\left(0.2 \times z_{m}^{2}+700 \times z_{M}+250000\right)
$$

(van Wees et al., 2010), where $f_{k}$ is a scale factor to incorporate overheads, typically set to 1.5 . This predicts much higher costs than would be expected in the UK, reflecting different local conditions (salaries, etc). However, it can be used to estimate the costs of deeper onshore boreholes in the UK, none having been drilled for many years, in proportion to the cost of drilling to $2000 \mathrm{~m}$. One can thus

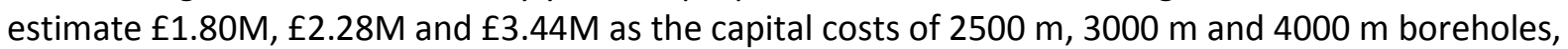
$\sim 33 \%, \sim 69 \%$ and $\sim 155 \%$ higher, respectively. Again for the AECC project, GEL et al. (2016) have 
estimated a budget of $f 2.293 \mathrm{M}$, consisting of $f 1.350 \mathrm{M}$ for drilling and completion of the well, $f 0.265 \mathrm{M}$ for the required equipment, and $f 0.678 \mathrm{M}$ for overheads, including project planning and project management costs. The 'off the shelf' nature of hcDGSW schemes is expected to reduce planning and project management costs; such a project based on a $2 \mathrm{~km}$ borehole might thus be delivered for well below $£ 2 \mathrm{M}$, say $\sim f 1.8 \mathrm{M}$, with corresponding costs estimated as $\sim £ 2.4 \mathrm{M}, \sim f 3.0 \mathrm{M}$ and $\sim f 4.6 \mathrm{M}$ for $2.5 \mathrm{~km}, 3 \mathrm{~km}$ or $4 \mathrm{~km}$ boreholes. It is assumed that the electricity used costs $£ 0.095$ per kWh, a typical tariff for a 'large' industrial consumer in the UK (DECC, 2016a), the heat produced is sold at $£ 0.03$ per $\mathrm{kWh}$, and a RHI subsidy of $£ 0.0514$ per kWh is payable. Once the system is commissioned, it is assumed to operate automatically, so the operating costs equate to the cost of the electricity used.

Figure 7(a) illustrates the predicted revenue surplus (revenue, including RHI subsidy payments, minus operating costs) over a 20 year project lifespan for the $2000 \mathrm{~m}$ hcDGSW installation. The optimum configuration has $Q=193 \mathrm{~kW}$ and yields a revenue surplus of $f 2.44 \mathrm{M}$. Figures $7(\mathrm{~b})$ and $(\mathrm{c})$ illustrate the corresponding solutions for $\mathrm{z}_{\mathrm{M}}=2500 \mathrm{~m}$, with the optimum at $\mathrm{Q}=295 \mathrm{~kW}$, yielding a revenue surplus of $f 3.71 \mathrm{M} ; z_{M}=3000 \mathrm{~m}$, with the optimum at $Q=416 \mathrm{~kW}$, yielding a revenue surplus of $f 5.23 \mathrm{M}$; and $z_{M}=4000 \mathrm{~m}$, with the optimum at $Q=711 \mathrm{~kW}$, yielding a revenue surplus of $f 8.97 \mathrm{M}$. It is thus evident that with optimal operation each of these designs can cover its own capital cost, the budget surplus increasing with $\mathrm{z}_{\mathrm{M}}$. More formal economic calculations, for example calculating the Net Present Value at the end of the project life including index-linking, to take account of future price inflation, of subsidy payments, heat sales, and estimates of future costs of electricity purchase, would reach similar conclusions. Figure 9 illustrates the predicted variations over time in To for the four solutions in Fig. 7. Overall, these calculations indicate that, over the depth range $2-4 \mathrm{~km}$, the deeper a hcDGSW borehole is, the more heat it can produce on a given timescale, the value of the increased heat production outweighing the increased cost of drilling. The ensemble of solutions obtained for different depths $z_{M}$ indicate that the optimum heat output and operating surplus over 20 years, $Q$ and $S$, vary with $\mathrm{z}_{\mathrm{M}}$ as:

$$
\begin{aligned}
& \mathrm{Q}=0.000131 \mathrm{z}_{\mathrm{M}}^{1.87} \\
& \text { and } \\
& \mathrm{S}=0.00000166 \mathrm{z}_{\mathrm{M}}^{1.87}
\end{aligned}
$$

with $\mathrm{Q}$ in $\mathrm{kW}$ and $\mathrm{S}$ in Mf. Combining equations (31) and (32) gives

$$
S=0.0127 \mathrm{Q},
$$

indicating proportionality between $\mathrm{S}$ and $\mathrm{Q}$, a surprising result given the complexity of the equations whose solution yields the values of $S$ and $Q$.

Once the twenty-year duration of the RHI subsidy has elapsed, continued heat production at what was previously the economically optimum rate would no longer be economic for $z_{M}=2000 \mathrm{~m}, 2500 \mathrm{~m}$, or $3000 \mathrm{~m}$, but would be economic for $\sim 5$ years longer for $\mathrm{z}_{\mathrm{M}}=4000 \mathrm{~m}$ (Fig. 9). A possible next phase might be to re-purpose such a borehole for seasonal heat storage rather than heat production, as Westaway (2016) has discussed. Based on Westaway's (2016) calculations, the rocks surrounding a $3000 \mathrm{~m}$ deep vertical borehole might have a seasonal heat storage capacity of $\sim 2 \mathrm{GWh}$. Currently the RHI subsidy scheme excludes production of stored heat from any deep borehole, making it uneconomic in the UK to purpose-drill boreholes for this function. However, once the capital cost of a borehole has already been discounted as a result of heat production, it might thus be reused at little additional extra cost. Ultimately, after many such boreholes have been developed, such reuse might contribute significantly 
towards achieving a sustainable provision of heat supply, which represents $\sim 50 \%$ of the energy demand in the UK (e.g., DECC, 2012).

The limited output of useable heat from hcDGSW projects invites economic comparison with other small-scale renewable energy technologies, such as micro hydro schemes (cf. Bracken et al., 2014). Bracken et al. (2014) indeed discussed one such scheme in northern England, with a capital cost of $£ 415,000$, producing $0.165 \mathrm{GWh}$ of electricity per year with an estimated 40 year lifespan, so $6.6 \mathrm{GWh}$ in total. Assuming the resulting zero-carbon output substitutes for electricity derived from the UK's current generating mix (in 2015, 337.7 TWh of electricity was generated with $144.1 \mathrm{MT}$ of $\mathrm{CO}_{2} \mathrm{e}$ emissions, according to DECC, 2016b, and BEIS, 2017, giving $0.427 \mathrm{~kg} \mathrm{CO}{ }_{2}$ e per $\mathrm{kWh}$ ), the lifetime carbon budget can be calculated. If the project began operating now (November 2017) its electricity sales into the National Grid might attract a feed in tariff (FIT) of 7.78 p per kWh (OFGEM, 2017) in addition to a sale price of maybe $5 \mathrm{p}$ per kWh (e.g., Renewables First, 2015), so $12.78 \mathrm{p} \mathrm{per} \mathrm{kWh} \mathrm{in}$ total. The total revenue from electricity sales over 40 years, at present prices, $\sim_{f 843,000 \text {, would }}$ significantly outweigh the capital cost, and would involve an overall saving in $\mathrm{CO}_{2} \mathrm{e}$ emissions of 2818 tonnes. As a worst-case scenario, if a small part of the capital cost had been covered by a grant from public funds, making the entire project ineligible for FIT subsidy, the revenue from electricity sales would be only $\sim £ 330,000$, making the net cost of the project at present prices $\sim £ 85,000$, so the emissions saving would have been achieved at a cost of $\sim f 30$ per tonne. However, DTI (1999) estimated that the potential of micro hydro (and small-scale hydro) projects in the UK is 35 TWh per year, or roughly $10 \%$ of the present generating capacity (and, thus, $\sim 2.5 \%$ of the total energy supply). Thus, although this technology is economic under the present subsidy regime, it has insufficient capacity to make a significant difference to the present-day energy mix.

The economically optimum $\mathrm{z}_{\mathrm{M}}=3000 \mathrm{~m}$ hcDGSW solution in Fig. $7(\mathrm{c})$ and Fig. 9 produces $92.7 \mathrm{GWh}$ of heat and consumes $24.4 \mathrm{GWh}$ of electricity over 20 years, at average annual rates of 4.64 and 1.22 $\mathrm{GWh} \mathrm{yr}^{-1}$. If the heat were used to offset burning of natural gas (with emissions equivalent to $0.181 \mathrm{~kg}$ $\mathrm{CO}_{2}$ e per kWh according to EIA, 2016) and the electricity were again derived from the UK's current generating $\mathrm{mix}$, the lifetime carbon budget can be calculated. Allowing for the carbon embodied in the construction of the hcDGSW $\left(\mathrm{CO}_{2} \mathrm{e}\right.$ of $\sim 110$ tonnes for the drilling activities and $\sim 240$ tonnes for the materials used, assuming use of well-casing made of a corrosion-resistant composite material; data from GEL et al., 2016, scaled in proportion to $z_{M}=3000 \mathrm{~m}$ ), the overall carbon budget (expressed in terms of $\mathrm{CO}_{2} \mathrm{e}$ emissions) balances a saving of 16785 tonnes against 10422 tonnes for the electricity used plus the embodied $\sim 350$ tonnes, giving a net saving of $\sim 6013$ tonnes. The overall cost of the RHI subsidy would be $\sim £ 4.77 \mathrm{M}$, or $\sim f 793$ per tonne of $\mathrm{CO}_{2} \mathrm{e}$ emissions saved. Calculated on the same basis, the $z_{M}=4000 \mathrm{~m}$ solution in Fig. $7(\mathrm{~d})$ and Fig. 9 would produce $151 \mathrm{GWh}$ of heat and consume $34.7 \mathrm{GWh}$ of electricity over 20 years, achieving a net saving of $\sim 11995$ tonnes of $\mathrm{CO}_{2} \mathrm{e}$ emissions in return for a RHI subsidy of $\sim f 7.75 \mathrm{M}$ or $\sim f 646$ per tonne.

The above values can be compared with costs and environmental benefits of other energy supply technologies (such as, micro hydro projects) or energy efficiency measures. The results indicate that hcDGSW projects can be economic in a locality with a geothermal gradient as high as $32^{\circ} \mathrm{C} \mathrm{km}^{-1}$. Table 4 lists the towns and cities in Britain where the geothermal gradient is as high as this. The urban areas thus covered represent $\sim 20 \%$ of the UK population, so the potential capacity of DGSW projects in these localities might amount to $\sim 20 \%$ of the demand for space heating or $\sim 10 \%$ of the total energy demand in the UK. Thus, although the cost per unit emission saving is much greater than for, say, micro hydro, the overall potential of this technology is also much greater.

The cost per unit emission saving can be reduced significantly by operating a hcDGSW below its economically optimum heat production rate. For example, for the aforementioned $\mathrm{z}_{\mathrm{M}}=3000 \mathrm{~m}$ design, operation for twenty years at $\mathrm{Q}=215 \mathrm{~kW}$ would consume $4.9 \mathrm{GWh}$ of electricity at cost of $\sim f 0.5 \mathrm{M}$ and 
output $42.6 \mathrm{GWh}$ of heat providing $~ £ 3.5 \mathrm{M}$ of revenue, including $\mathrm{RHI}$ subsidy, thus just covering the $\sim f 3.0 \mathrm{M}$ capital cost, but reducing the cost per unit emission saving to $\sim f 416$ per tonne of $\mathrm{CO}_{2} \mathrm{e}$ emissions saved. Likewise, for the $\mathrm{z}_{\mathrm{M}}=4000 \mathrm{~m}$ design, operation for twenty years at $\mathrm{Q}=328 \mathrm{~kW}$ would consume $5.2 \mathrm{GWh}$ of electricity costing $\sim f 0.5 \mathrm{M}$ and output $62.7 \mathrm{GWh}$ of heat providing $\sim f 5.1 \mathrm{M}$ of revenue, thus just covering the $\sim f 4.6 \mathrm{M}$ capital cost, but further reducing the cost per unit emission saving to $\sim 372$ per tonne of $\mathrm{CO}_{2} \mathrm{e}$ emissions saved. Anticipating future decarbonisation of electricity generation, greater savings in emissions at correspondingly reduced unit cost would result. A future regulatory regime might approve subsidy payments subject to a mode of operation that achieves an approved compromise between the economically optimum and environmentally optimum heat outputs. These economic and environmental considerations confirm that the hcDGSW concept might have substantial potential as a source of low-carbon heat, warranting more detailed investigation.

\section{DGSW Case studies}

Arguably the most detailed published numerical model for a CDGSW is that by Alimonti and Soldo (2016), which was applied by these authors and by Alimonti et al. (2016) to assess the geothermal potential of repurposing a disused oil well at Villafortuna in northern Italy. Their analysis makes various assumptions, for instance that the radius of the cooling effect around a cDGSW, given by equation (12), is exact rather than an approximation. Their method, analyzing heat flow using the thermal resistance of each concentric component of the borehole heat exchanger and surrounding rock volume, is valid under steady-state conditions (e.g., Carslaw and Jaeger, 1959, pp. 189-193), and is thus also an approximation under the non-steady-state conditions during DGSW operation. Furthermore, as already noted, their analysis assumed operation at constant volume flow rate, with heat production declining over time, rather than at a constant rate of heat production, although after many years of operation their predicted rate of change of the rate of heat production is low. Nonetheless, for the parameters applicable to their case study $\left(\mathrm{z}_{\mathrm{M}}=6100 \mathrm{~m}, \mathrm{a} \sim 0.1 \mathrm{~m}\right.$, and $\mathrm{D}=0.045 \mathrm{~m}$ for the borehole; $\mathrm{T}_{\mathrm{s}}=25^{\circ} \mathrm{C}, \mathrm{T}_{\mathrm{M}}=170{ }^{\circ} \mathrm{C}, \mathrm{k}=2.5 \mathrm{~W} \mathrm{~m}^{-1}{ }^{\circ} \mathrm{C}^{-1}$, and $\mathrm{k}=1.2 \mathrm{~mm}^{2} \mathrm{~s}^{-1}$ for the surrounding rock volume; and $\mathrm{T}_{D}=40^{\circ} \mathrm{C}$ for the surface heat exchanger installation) Alimonti et al. (2016) determined that the optimum operational mode required $\mathrm{q}_{\mathrm{B}}=20 \mathrm{~m}^{3} \mathrm{hr}^{-1}$, resulting in $\mathrm{Q}=1200 \mathrm{~kW}$ at $\mathrm{T}_{0}=100^{\circ} \mathrm{C}$ after 10 years of operation. For comparison, using the present analytic model with the same input parameters, $T_{0}=100{ }^{\circ} \mathrm{C}$ after 10 years of operation would require output at a steady $Q=530 \mathrm{~kW}$. However, it is unclear whether this means that the present analytic approach has a tendency to underestimate the output achievable from CDGSW installations, or whether the difference in operational mode or the approximations made in the Alimonti et al. (2016) analysis account for the difference. Comparison will now be made between the results of the present analysis and the Law et al. (2015) DGSW conceptual model. The economics of two proposed DGSW projects, in Aberdeen and Kilmarnock, Scotland, and a hypothetical hcDGSW project in Darlington, northern England (cf. Table 4), will also be discussed.

\section{Law et al. (2015) conceptual model}

Law et al. (2015) presented numerical modelling results for a model DGSW operating in either cDGSW or dDGSW modes. This was assumed to have $\mathrm{z}_{\mathrm{M}} 2500 \mathrm{~m}, \mathrm{u} 32{ }^{\circ} \mathrm{C} \mathrm{km}^{-1}$, and $\mathrm{T}_{\mathrm{M}} 80^{\circ} \mathrm{C}$, implying $\mathrm{T}_{\mathrm{s}}=0{ }^{\circ} \mathrm{C}$; other parameters (including $T_{L}, a, k$, and $\kappa$ ) were not specified. Law et al. (2015) stated that their analysis used the U.S. Geological Survey finite element code SUTRA (Voss and Provost, 2010), their mesh being defined for a volume of square cross-section with sides extending $250 \mathrm{~m}$ away from the borehole, representing a single $90^{\circ}$ quadrant (the other three quadrants being equivalent, given the symmetry of the problem). They did not specify the spacing of elements within their mesh or indicate the nature of the boundary conditions applied at its vertical and horizontal surfaces. Although SUTRA is primarily intended for solving subsurface fluid flow problems, it can also calculate heat conduction in the absence of fluid flow. As Law et al. (2015) explained, their method incorporates calculations using the thermal resistance of each concentric component of the borehole heat exchanger and surrounding rock volume. However, as already noted, this method is valid under steady-state 
conditions (e.g., Carslaw and Jaeger, 1959, pp. 189-193), and thus serves only as an approximation under the non-steady-state conditions that develop during DGSW operation.

The outputs of this model in cDGSW mode, for steady heat production of 50, 100, 200 and $400 \mathrm{~kW}$, over ten years of operation, are summarized in Fig. 4. Thus, after ten years, $T_{0}$ is predicted to be $\sim 70$, $\sim 64, \sim 51$ and $\sim 27^{\circ} \mathrm{C}$, respectively, indicating cooling in each of these cases by $\sim 10, \sim 16, \sim 29$ and $\sim 53{ }^{\circ} \mathrm{C}$ at the bottom hole depth. The cooling on this timescale per kilowatt of heat production is thus $\sim 0.20$, $\sim 0.16, \sim 0.15$, and $\sim 0.13{ }^{\circ} \mathrm{C} \mathrm{kW}^{-1}$ for these four configurations. Their model is therefore non-linear, despite the governing equations (e.g., equation (2)) being linear, which is difficult to understand. Law et al. (2015) also inferred that for $Q=50$ or $100 \mathrm{~kW}$ their model cDGSW reaches a steady state within ten years, which is untenable given that heat is being produced much faster than it is being replenished by conduction from surrounding parts of the subsurface rock volume; however, this behaviour can be described as an 'almost steady state condition' (see earlier discussion).

Although Fig. 4 indicates that the cooling curves predicted in the present study have similar general shape to those reported by Law et al. (2015), they do not match closely, and cannot be made to agree for any single set of model parameters. This latter aspect is illustrated in Fig. 8 in which the present analytic solutions are converted into dimensionless form, using the dimensionless variables $\mathrm{y}=-4 \pi \mathrm{k} \Delta \mathrm{T} / \mathrm{q}_{\mathrm{M}}$ and $\mathrm{x}=\ln \left(4 \kappa \mathrm{t} / \mathrm{a}^{2}\right)$. Transformed thus, these solutions all plot as the same straight line with gradient -1 and $y$-intercept $\gamma$. However, when transformed in the same way, the Law et al. (2015) solutions plot as curves, which do not overlie each other and diverge as $x$ increases. Different choices of the parameter values required to transform these solutions to dimensionless variables would change the positions of these solutions on this plot but would not affect the predicted shape of the transformed solutions, so incorrect choices of these values are not the cause of these mismatches.

It was initially assumed that the cause of these mismatches was the omission from the analytic model, in its original form, of the borehole 'end-correction' and the effect of geothermal heat flow; hence, the derivation of these corrections. It was indeed initially thought possible that these corrections might have a larger effect the greater the subsurface cooling, and might thus act to 'draw in' additional heat from the surroundings to the borehole, either below it or beyond it to the sides. However, the small magnitude of these corrections (noted above), for DGSW operation over timescales relevant to Figs. 4 and 8 , mean that this is not the explanation.

It will be recalled that the calculations for CDGSW operation in the present study incorporate a balance between heat production from the borehole heat exchanger and heat lost by conduction due to cooling of the surrounding rock volume. It can also be presumed that the Law et al. (2015) calculations likewise incorporate conservation of energy. Nonetheless, the Law et al. (2015) calculations indicate less cooling of the rock volume surrounding the borehole at its bottom hole depth than the calculations in the present study, despite indicating higher heat outputs. For this to be feasible while maintaining conservation of energy requires the Law et al. (2015) numerical model to produce more cooling than the present model across at least part of the range of depth between the Earth's surface and the well bottom. The resulting creation of a non-linear geothermal gradient along the borehole might account for the non-linear behaviour that has been noted. Nonetheless, the test data provided by Law (2014) indicate a linear temperature gradient at depths where the temperature exceeds the injection temperature $T_{D}$, and indeed motivated incorporating the equivalent assumption into the present analytic model. However, these data only relate to eight hours of operation; in the absence of test data documenting the DGSW behaviour on much longer timescales, this discrepancy cannot currently be resolved. 
The mismatch between predictions $Q_{A}$ from the present analytic model and for $Q_{N}$ from the Law et al. (2015) and Alimonti et al. (2016) numerical models, for heat output rates over ten years of cDGSW operation, is illustrated in Fig. 10. These data points fit the regression equation

$$
Q_{N}=0.2995 Q_{A}^{1.3134} \quad\left(Q_{A} \geq 50 \mathrm{~kW}\right) \text {. }
$$

Calculations in the present study incorporate values of $Q_{A}$, but might in principle be modified to use values of $Q_{N}$ from this regression equation. This would result in significantly more favourable assessments for options with $Q_{A} \gg 50 \mathrm{~kW}$. On the other hand, it is possible that the apparent consistency between these two numerical modelling approaches might reflect their use of similar methods, including applying theory for steady-state behaviour to non-steady-state situations, in which case neither numerical method approach might provide accurate results.

\section{The HALO project, Kilmarnock}

Planning documentation (East Ayrshire, 2017) states that this project will produce heat at a rate of $2.1 \mathrm{GWh} \mathrm{yr}^{-1}$, equivalent to a steady rate of $239 \mathrm{~kW}$, from a $2 \mathrm{~km}$ deep borehole to be located at British National Grid (BNG) reference NS 42641 38505. The geothermal gradient in this part of SW Scotland can be estimated using data from the Slatehole borehole (British Geological Survey [BGS] identifier NS42SE4; at NS $49072343, \sim 16 \mathrm{~km}$ to the SSE), where a bottom hole temperature of $40.0^{\circ} \mathrm{C}$ at $1024 \mathrm{~m}$ depth and a geothermal gradient of $29.8^{\circ} \mathrm{C} \mathrm{km}^{-1}$ have been measured (e.g., Gillespie et al., 2013). Extrapolation at a constant geothermal gradient would give a temperature of $\sim 69^{\circ} \mathrm{C}$ at $2 \mathrm{~km}$ depth. The capital cost of this DGSW installation has been funded through a $£ 1.8 \mathrm{M}$ grant from the Scottish Government (Geon, 2017); as a result of this public funding of capital expenditure, the heat output is ineligible for RHI subsidy. Law and Collins (2017) state that a heat pump would be used in any DGSW installation with a basal temperature as low as this, given the need to interface with a heating system operating at $\sim 70{ }^{\circ} \mathrm{C}$. Preliminary documentation (Geon, 2017) depicted a closed circulation loop, implying (in the terminology used in the present study) that the design is for a hcDGSW. Subsequent definitive documentation (East Ayrshire, 2017) indicates that the design will allow for the possibility of bleed flow, but the standard operational mode will involve closed circulation; this project will therefore be analysed as a hcDGSW. The same documentation (East Ayrshire, 2017) also indicates that the design includes a very wide borehole, with a diameter of $0.75 \mathrm{~m}$.

The reported output, equivalent to a steady $239 \mathrm{~kW}$, is well above the optimum value of $194 \mathrm{~kW}$ for a $2 \mathrm{~km}$ borehole under the high geothermal gradient conditions envisaged for Fig. 7(a), and is thus likely to exceed even more the optimum operational mode for the lower geothermal gradient in the Kilmarnock area. The local outcrop consists of the Scottish Coal Measures Group of Upper Carboniferous (Westphalian) age, underlain by the Clackmannan Group (Namurian), Strathclyde Group (Viséan), Inverclyde Group (Tournaisian), and Stratheden Group (Late Devonian). Like elsewhere in Britain (cf. Westaway and Younger, 2016) such Carboniferous sequences consist of cyclic alternations of lithologies (mudstone, sandstone, limestone, and coal) with diverse thermal properties. For example, Carboniferous sandstone may have $\mathrm{k}$ as high as $4.9 \mathrm{~W} \mathrm{~m}^{-1}{ }^{\circ} \mathrm{C}^{-1}$ (England et al., 1980 ) whereas the value of $k$ for coal will be an order-of-magnitude less (e.g., Westaway and Younger, 2016). The underlying Devonian 'Old Red Sandstone' rocks include tight sandstones for which $\mathrm{k}$ as high as $5.2 \mathrm{~W} \mathrm{~m}^{-1}{ }^{\circ} \mathrm{C}^{-1}$ has been measured elsewhere in Europe (Chekhonin et al., 2012). The thermal conductivity and diffusivity applicable for the HALO DGSW will be a harmonic mean of the values for these diverse lithologies in representative proportions, and has not been reported. Values of $\mathrm{k}=4 \mathrm{~W} \mathrm{~m}^{-1}{ }^{\circ} \mathrm{C}^{-1}$ and $\mathrm{\kappa}=1.5 \mathrm{~mm}^{2} \mathrm{~s}^{-1}$ will be assumed for the present analysis, although these might well be overestimates; moreover, the high $\mathrm{k}$ in the deeper part of the section implies a lower geothermal gradient than has been assumed by extrapolation from the Slatehole borehole dataset, suggesting that the $69{ }^{\circ} \mathrm{C}$ bottom-hole temperature is probably also overestimated. This combination of 
optimistic assumptions has been made to avoid any risk of underestimating the potential of the HALO project, for the quantitative assessment that follows.

Figure 11(a) indicates that if heat were to be produced from the HALO DGSW at a steady rate of $239 \mathrm{~kW}$, the output temperature would rapidly decline from the initial $69^{\circ} \mathrm{C}$, falling to $23{ }^{\circ} \mathrm{C}$ over twenty years. Figure 11 (b) depicts the economic analysis of this DGSW for a 20 year assumed lifespan. The economically optimum heat production rate is surprisingly low, $\sim 32.4 \mathrm{~kW}$, despite the optimistic assumptions. This value is highly sensitive to the assumed pricing structures for heat and for electricity, it being evident that the modest budget surplus depicted is due to the very small difference calculated between expenditure on electricity and revenue from heat sales. A less favourable pricing structure, or a lower bottom hole temperature $\left(<58.1^{\circ} \mathrm{C}\right)$, would make operation of this DGSW uneconomic relative to the option of shutting it down and using the electricity saved (by not powering its heat pump) to heat buildings directly. The economics of this project are indeed hampered by the output temperature being always below the assumed $70^{\circ} \mathrm{C}$ input temperature of the heat load (after Collins and Law, 2017), so all the heat output has to be transferred through the heat pump, $13.6 \mathrm{~kW}$ of electrical power being required to supplement the $\sim 32.4 \mathrm{~kW}$ of heat production to produce an overall output of $\sim 46 \mathrm{~kW}$ of useable heat. As Fig. 11(a) shows, with such a low rate of heat production, very little temperature fall occurs within the DGSW over 20 years, so in principle this project could function at this very low rate for a very long time.

Figure 12 shows the equivalent outputs for a project with the same design parameters as for HALO, but with the borehole diameter reduced to $0.2 \mathrm{~m}$. With this narrower borehole, if heat were to be produced at a steady $239 \mathrm{~kW}$, the output temperature would fall more rapidly, reaching $\sim 23^{\circ} \mathrm{C}$ within eighteen months and $\sim 11{ }^{\circ} \mathrm{C}$ after twenty years. However, the economically optimum heat production rate, $\sim 29.3 \mathrm{~kW}$, producing $\sim 41.5 \mathrm{~kW}$ of useable heat, does not differ much compared with the widerborehole design adopted. Given the lower capital cost and lower $\mathrm{CO}_{2}$ emissions from drilling, which would result from this alternative narrower-borehole design, the appropriateness of the proposed design is called into question.

Overall, this HALO case study provides a graphic demonstration of the need to make DGSW evaluations site specific, taking account of local thermal regime and mode of operation (cf. Law et al., 2015; Collins and Law, 2017), the critical factor being accurate estimation of the initial bottom hole temperature. Nonetheless, such calculations are much less challenging than the analysis of hydraulic transport properties and groundwater contamination that would be required, from earlier discussion, to quantify the output and economics of a dDGSW.

\section{Aberdeen Exhibition and Conference Centre}

A candidate hdDGSW project has been proposed for the Aberdeen Exhibition and Conference Centre (AECC) in the Scottish city of Aberdeen (GEL et al., 2016), a $2 \mathrm{~km}$ deep borehole being envisaged (to be located circa BNG reference NJ 884 105), with a bottom hole temperature estimated by GEL et al. (2016) as $\sim 70{ }^{\circ} \mathrm{C}$. It has been proposed that heat will be extracted via a heat exchanger to maintain the temperature of an anaerobic digester (AD) for processing municipal waste, then the residual heat (below $T_{E} \sim 40{ }^{\circ} \mathrm{C}$ ) will be output via heat pumps for space-heating in adjacent buildings, before the circulating water is reinjected. The project description mentions system design to facilitate 'bleed flow', the proposal specifying the bottom $300 \mathrm{~m}$ of the borehole uncased; given the preceding calculations it is evident that the high heat output envisaged (up to $400 \mathrm{~kW}$ ) will only be feasible with bleed flow. Moreover, since the design calls for the AD unit to operate continuously, the proposal envisages continuous (or near-continuous) bleed flow to sustain its operation.

The draft budget (GEL et al., 2016) indicates a $\sim f 1.6 \mathrm{M}$ capital cost, $\sim £ 1.35 \mathrm{M}$ for the borehole, the rest for the ancillary equipment. Estimated annual operating costs would be $\sim £ 49 \mathrm{k}$ and annual revenue 
based on sale of heat at $£ 0.03$ per kWh would be $\sim £ 239 k$. On this basis the project has been reported as achieving a high net present value of $\sim f 10.7 \mathrm{M}$ after 40 years with a high internal rate of return of 19\%; these economic parameters, which favour commercial investment, assume that RHI subsidy payments (currently $£ 0.0514$ per $\mathrm{kWh}$ ) are included. However, this analysis does not include water treatment costs on the basis that 'as the Aberdeen granite is rather deficient in heavy metals it is very unlikely that any fluids from the DGSW will be the cause of significant environmental contamination by heavy metals', although no quantitative data were provided to substantiate this assertion.

Nonetheless, the surface heat flow in this part of Scotland is low, being depicted on BGS maps (e.g., Busby et al., 2011) as $50 \mathrm{~mW} \mathrm{~m}^{-2}$. Some $50 \mathrm{~km}$ to the SSW, the Montrose (or Charleton-1) borehole (BGS identifier NO76SW12, circa BNG reference NO 715605 ) has yielded a heat flow of $46 \mathrm{~mW} \mathrm{~m}^{-2}$ based on measurements of temperature and thermal conductivity $\mathrm{k}$ between 301 and $751 \mathrm{~m}$ depths (e.g., Burley et al., 1984; Rollin, 1995); the $\sim 20^{\circ} \mathrm{C}$ temperature at $500 \mathrm{~m}$ depth indicates a geothermal gradient $\mathrm{u}$ of $\sim 22.8{ }^{\circ} \mathrm{C} \mathrm{km}^{-1}$, given the $\sim 8.6^{\circ} \mathrm{C}$ annual mean surface temperature (e.g., Met Office, 2017), which would imply $\sim 54{ }^{\circ} \mathrm{C}$ at $2 \mathrm{~km}$ depth. However, $\sim 7 \mathrm{~km}$ east of the AECC site, the Bridge of Don-3 borehole (BGS identifier NJ91SE3, circa NJ 951 109) was drilled in basement schist to $1465 \mathrm{~m}$ (TVD; $1494 \mathrm{~m} \mathrm{MD)} \mathrm{but} \mathrm{is} \mathrm{now} \mathrm{cased} \mathrm{to} 1433 \mathrm{~m}$ for use as a test facility by the oilfield service provider Weatherford. The bottom hole temperature is reported as $32{ }^{\circ} \mathrm{C}$ (Groves et al., 2012), indicating $\mathrm{u}$ $\sim 16.3^{\circ} \mathrm{C} \mathrm{km}^{-1}$, which would imply $\sim 41^{\circ} \mathrm{C}$ at $2 \mathrm{~km}$. However, this measurement was made during drilling and thus requires correction for the associated cooling effect. Established correction procedures exist (e.g., Manetti, 1973; Barelli and Palama, 1981); there is also UK experience, such as for the Eskdale-12 borehole (BGS identifier NZ80NE4, NZ 85783 08180) in northern England, drilled in 1963 to $1873 \mathrm{~m}$ depth, within which temperature was measured one hour after drilling and later, so the calculated correction could be verified (Burley et al., 1984). Taking all this into account, it is estimated that the Bridge of Don-3 measurement requires upward revision by $\sim 15^{\circ} \mathrm{C}$ at most, making $\mathrm{u} \leq 26.2^{\circ} \mathrm{C} \mathrm{km}^{-1}$ and the temperature at $2 \mathrm{~km} \leq 61{ }^{\circ} \mathrm{C}$. The Aberdeen granite has low radioactive heat production: McCay (2016) has reported 11 measurements spanning 1.55 to $3.11 \mu \mathrm{W} \mathrm{m}{ }^{-3}$, with a mean of 2.17 and a median of $2.04 \mu \mathrm{W} \mathrm{m}{ }^{-3}$, confirming the $\sim 2.2 \mu \mathrm{W} \mathrm{m}$ m $^{-3}$ mean value reported by Wheildon and Rollin (1986) from 3 measurements. Basement rocks like those beneath Aberdeen are typically assigned heat production of $\sim 2 \mu \mathrm{W} \mathrm{m}{ }^{-3}$ (e.g., Wheildon and Rollin, 1986); the Aberdeen granite is therefore not expected to create a significant local heat flow 'high' relative to the above values. Part of the rationale behind the GEL et al. (2016) temperature estimate at $2 \mathrm{~km}$ depth was their best-estimate measurement for $\mathrm{k}$ in the Aberdeen granite of $2.71 \mathrm{~W} \mathrm{~m}^{-1}{ }^{\circ} \mathrm{C}^{-1}$, on which basis they converted the reported heat flow of $\sim 50 \mathrm{~mW} \mathrm{~m}{ }^{-2}$ back to $\mathrm{u} \sim 18.5^{\circ} \mathrm{C} \mathrm{km}^{-1}$, giving $\sim 46{ }^{\circ} \mathrm{C}$ at $2 \mathrm{~km}$ depth. However, Caledonian age granite intrusions in Scotland and northern England typically have $\mathrm{k} \sim 3.1-3.5 \mathrm{~W} \mathrm{~m}^{-1}{ }^{\circ} \mathrm{C}^{-1}$ (e.g., Wheildon and Rollin, 1986), which (calculating on the same basis) would imply rather lower temperatures at depth. GEL et al. (2016) also argued that the heat flow data require correction for palaeoclimate, citing Westaway and Younger (2013), as a basis for their $\sim 70{ }^{\circ} \mathrm{C}$ temperature estimate at $2 \mathrm{~km}$ depth. However, the Westaway and Younger (2013) analysis (see, e.g., their Fig. 3) indicates a negligible correction to $u$ for the Bridge of Don-3 borehole and a $\sim 5^{\circ} \mathrm{C} \mathrm{km}^{-1}$ upward correction for the Montrose borehole. On the latter basis, if the thermal state of the Earth's crust is the same at the AECC site as at Montrose, one might argue for a temperature as high as $\sim 64^{\circ} \mathrm{C}$ at $2 \mathrm{~km}$ depth, although the Bridge of Don-3 evidence indicates less than this. The discussions earlier in the present study, which demonstrate high sensitivity of DGSW output to crustal thermal regime, mean that overestimation of the bottom hole temperature can have a fundamental impact on project economics. Nonetheless, $\geq 70{ }^{\circ} \mathrm{C}$ is expected at $2 \mathrm{~km}$ depth elsewhere in the UK, in more radiothermal granites (e.g., Lee, 1986) and in Mesozoic depocentres such as the Wessex and Lincolnshire basins of England and the Larne Basin of Northern Ireland (e.g., Smith, 1986). It is thus worthwhile to pursue the implications of the GEL et al. (2016) analysis, since DGSW-based project proposals for such localities might emerge in future. 
Assuming income of $£ 0.0814 \mathrm{kWh}^{-1}$ the revenue reported by GEL et al. (2016) implies heat sales of $\sim 2.93 \mathrm{GWh}$ per annum, equivalent to a constant rate of $\sim 334 \mathrm{~kW}$. This is so far above what might be feasibly delivered from a CDGSW of the specified dimensions with the proposed $T_{E}$ that 'bleed flow' will be essential, as already noted. This scenario can be analysed to first order assuming that $\sim 100 \mathrm{~kW}$ of this heat supply might be obtained through heat conduction (based on the preceding calculations), the rest being obtained by 'bleed flow'. Setting aside the question of accurate estimation of $T_{M}$, two issues thus call this project into question: the required high hydraulic conductivity of the granite that is presumed to provide the groundwater reservoir for this project; and the arguable need to factor in treatment costs for this produced water. Assuming $T_{M}=70^{\circ} \mathrm{C}$ and that all the heat is utilized down to $\mathrm{T}_{\mathrm{S}}=10^{\circ} \mathrm{C}$, the required circulation rate including the bleed flow would be $\sim 334 \mathrm{~kW} /\left(4186 \mathrm{~kg} \mathrm{~m}^{-3} \times\right.$ $1000 \mathrm{~kg} \mathrm{~m}^{-3} \times 60{ }^{\circ} \mathrm{C}$ ) or $\sim 1.3 \mathrm{I} \mathrm{s}^{-1} ; \sim 0.9 \mathrm{I} \mathrm{s}^{-1}$ of this would be 'bleed flow' and the parameter $\Gamma$ would take the value $\sim 234 / 100$ or $\sim 2.34$. If the $A D$ heat exchanger rejects heat below $T_{E}=40^{\circ} \mathrm{C}$ then this component of its heat supply will be $\sim 334 \mathrm{~kW} \times\left(70{ }^{\circ} \mathrm{C}-40{ }^{\circ} \mathrm{C}\right) /\left(70^{\circ} \mathrm{C}-10^{\circ} \mathrm{C}\right)$ or $\sim 167 \mathrm{~kW}$. Taking $\Delta \mathrm{T}$ as $70{ }^{\circ} \mathrm{C}-10^{\circ} \mathrm{C}=60^{\circ} \mathrm{C}$, equation (22) indicates $\mathrm{H}_{\mathrm{o}} \sim 3000 \mathrm{~m}$, greater than the assumed borehole depth. However, for 'head lift' to have only a minimal effect on the project budget, the drawdown must be only a small proportion of this, say $5 \%$ or $\sim 150 \mathrm{~m}$.

As already noted, Law (2014) reported a high value of $\sim 50$ for the COP at a DGSW test site where the produced water was reinjected. As has also already been noted, this is not necessarily so in dDGSW mode; if significant 'head lift' for the produced water is necessary, the electrical energy requirement might outweigh the value of the heat produced. The AECC project design evidently assumes zero or minimal 'head lift', meaning that the groundwater reservoir at depth has been assumed to be under hydrostatic equilibrium with the ground surface which, as already discussed, requires a very high hydraulic conductivity in the granite. Negligible electrical energy would therefore be needed for pumping the produced water against gravity, the cost of which is neglected in these first-order calculations. It is thus inferred that most of the electrical power consumed will be used by the heat pumps, whose COP, $\Psi$, will be much lower (say, 4). If these cool the circulating water to $10{ }^{\circ} \mathrm{C}$ the additional $\sim 167 \mathrm{~kW}$ heat loss will require $\sim 167 \mathrm{~kW} \times 1 /(\Psi-1)$ or $\sim 56 \mathrm{~kW}$ of electrical power. Assuming once again that the electricity used costs $f 0.095$ per kWh, this heat pump operation will cost of $\sim £ 46 \mathrm{k}$ per annum, indeed consuming most of the $\sim £ 49 \mathrm{k}$ estimated operating budget. This is evidently an approximate analysis, but it implies that, per day of operation, typically, $\sim 80 \mathrm{~m}^{3}$ of produced water $\left(\sim 0.9 \mathrm{I} \mathrm{s}^{-1} \times 24 \mathrm{hrs}\right)$ will require treatment. If this costs $\sim € 3.80$ per cubic metre (see above) it will imply an additional cost of $\sim £ 300$ per day or $\sim £ 110 \mathrm{k}$ per annum. Even with this additional budget item, then provided $\mathrm{T}_{\mathrm{M}}$ is indeed $\sim 70^{\circ} \mathrm{C}$, the project would still be predicted to make an annual surplus of $\sim £ 80 \mathrm{k}$ ( $£ 239 \mathrm{k}$ revenue $-£ 49 \mathrm{k}$ operating costs $-£ 110 \mathrm{k}$ water treatment costs), again with the RHI subsidy included in the revenue, although the $\sim f 1.6 \mathrm{M}$ budget surplus thus accumulated over 20 years of operation would barely cover the capital cost of the drilling. Nonetheless, like for the HALO project, this calculated small surplus is the difference between much larger figures for revenue and expenditure, so is sensitive to small changes in these. If the granite has insufficient hydraulic conductivity to maintain the required 'bleed flow', or if significant 'head lift' pumping is required, increasing the electricity consumption with no additional heat output, or if the bottom hole temperature is significantly below $70{ }^{\circ} \mathrm{C}$, this project might well not recover its own capital expenditure and might even operate at a deficit, with revenue unable to cover operating costs.

\section{Hypothetical Darlington hcDGSW project}

Table 4 lists Darlington as the town with the highest temperature at $1 \mathrm{~km}$ depth in Britain. This is based on evidence from the Brafferton-1 borehole (BGS identifier NZ22SE105, located at BNG reference NZ 2843221493 ) drilled to $1987 \mathrm{~m}$ depth, 6 km north of Darlington town centre, for which Busby et al. (2011) reported a temperature of $54{ }^{\circ} \mathrm{C}$ at $1 \mathrm{~km}$ depth. Darlington is located within the Stainmore Trough or Stainmore Basin, one of several sedimentary basins in northern England, which formed as a result of crustal extension during the Early Carboniferous. The base of the Carboniferous succession 
is reported, from seismic surveys, at $\sim 5700 \mathrm{~m}$ depth in the Darlington area (Chadwick et al., 1995). The Brafferton-1 borehole record remains commercially confidential and unpublished, but from the regional context (e.g., Collier, 1991; Chadwick et al., 1995), including deep drilling elsewhere (Johnson et al., 2011), the local Carboniferous succession can be inferred to consist mainly of mudstone with interbedded sandstone, limestone, and coal seams. A similar succession farther north, beneath Gateshead, has $\mathrm{k} \sim 1.7 \mathrm{~W} \mathrm{~m}^{-1}{ }^{\circ} \mathrm{C}^{-1}$ and $\kappa \sim 0.9 \mathrm{~mm}^{2} \mathrm{~s}^{-1}$ (Westaway and Younger, 2016); these values will be adopted for the present analysis. With this value of $k$, and a surface temperature of $\sim 9{ }^{\circ} \mathrm{C}$ from meteorological data, the $\sim 45{ }^{\circ} \mathrm{C} \mathrm{km}^{-1}$ geothermal gradient implies $\sim 77 \mathrm{~mW} \mathrm{~m}^{-2}$ of heat flow. Other localities beyond the northern margin of the Stainmore Basin have much higher heat flow, due to heat production in granite intrusions, but lower temperatures at depth due to the higher thermal conductivity of the rock column (e.g., Busby et al., 2011). The borehole cost model in use (equation (30)) gives the capital cost of a $6000 \mathrm{~m}$ deep borehole, reaching the base of this sedimentary succession, as $\sim f 8.6 \mathrm{M}$.

It is assumed that this hcDGSW scheme will form part of a future district heating scheme for the urban area of Darlington. In Denmark, such schemes often take as their input water at a temperature as low as $\sim 50{ }^{\circ} \mathrm{C}$ (DEA, 2017); they achieve satisfactory space heating using radiators rather larger than are customary in the UK. Even lower input temperatures, as low as $\sim 35{ }^{\circ} \mathrm{C}$, are feasible if underfloor heating is used (e.g., Joule, 2017), rather than radiators of any size. It is assumed that the hypothetical Darlington district heating scheme will be designed on this basis, with $T_{E}=35^{\circ} \mathrm{C}$. It is also assumed that heat is sold, RHI subsidy applies, and electricity purchased, all at the same rates as before. The electricity purchased is again assumed to reflect the present UK generation mix and the heat output is again assumed to substitute for burning natural gas.

Figure 13 illustrates results of analysis of this hcDGSW scheme, developed, costed, and operated for 20 years on this basis. The economically optimum operational mode (Fig. 13(b)) has Q=1095 kW. This generates net revenue of $f 14.4 \mathrm{M}$, including a surplus of $f 5.8 \mathrm{M}$ after taking account of drilling costs, outputting $211.9 \mathrm{GWh}$ of heat and consuming $30.2 \mathrm{GWh}$ of electricity, saving 24769 tonnes of $\mathrm{CO}_{2} \mathrm{e}$ emissions at a cost of $£ 440$ per tonne. The environmentally optimum operational mode has $\mathrm{Q}=490 \mathrm{~kW}$. This produces $89.1 \mathrm{GWh}$ of heat output and consumes $3.1 \mathrm{GWh}$ of electricity, saving 14098 tonnes of $\mathrm{CO}_{2}$ e emissions at a cost of $£ 325$ per tonne. The net revenue is $£ 7.0 \mathrm{M}$, indicating a shortfall of $£ 1.6 \mathrm{M}$ relative to the drilling costs. Any rate of heat production between 23 and $1208 \mathrm{~kW}$ results in a net saving of $\mathrm{CO}_{2} \mathrm{e}$ emissions: below $23 \mathrm{~kW}$, the emissions embodied in the borehole drilling and completion are not recouped; whereas, above $1208 \mathrm{~kW}, \mathrm{~T}_{0}$ falls so low (Fig. 13(a)) that much of the heat extraction is via the heat pump and the associated consumption of electricity is so high that the emissions associated with its generation outweigh those saved by the production of geothermal heat. Despite the higher geothermal gradient and bottom hole temperature, and the greater length of the borehole heat exchanger, the economically optimum heat production rate of $1095 \mathrm{~kW}$ is not much greater than for the configuration in Fig. 7(d)). The essential reason for this is the smaller values of $\mathrm{k}$ and $\kappa$ that have been assumed $\left(\sim 1.7 \mathrm{~W} \mathrm{~m}^{-1}{ }^{\circ} \mathrm{C}^{-1}\right.$ and $\sim 0.9 \mathrm{~mm}^{2} \mathrm{~s}^{-1}$ compared with $\sim 3.5 \mathrm{~W} \mathrm{~m}^{-1}{ }^{\circ} \mathrm{C}^{-1}$ and $\sim 1.2 \mathrm{~mm}^{2} \mathrm{~s}^{-1}$ ), reflecting the exponential dependence on $\mathrm{k}$ (cf. equation (9)). Nonetheless, once again, the economically optimum output scenario lies very close to the maximum output feasible, again demonstrating the need for careful calculations to determine this optimum mode. This exercise nonetheless demonstrates that deployment of a hcDGSW in a locality of high geothermal gradient, used in an optimal manner, can produce worthwhile savings in $\mathrm{CO}_{2} \mathrm{e}$ emissions.

\section{Conclusions}

A critical appraisal of the DGSW concept has been presented, driven by the apparent contradiction between the long-standing view (Rybach et al., 1992) that this technology has no potential, other than for repurposing existing boreholes, and claims by commercial developers. The present simplified analytical modelling, which approximates the operational state of a DGSW installation under real 
conditions, enables some misconceptions about DGSW technology, which have emerged through previous work, to be corrected. It is thus evident, first, that although a cDGSW or hcDGSW might look like an enlarged version of a shallow borehole heat exchanger used for a conventional GSHP installation (and the governing equations, such as equation (4) [cf. Banks, 2012], are similar), its operational principles are different: conventional GSHP installations can function sustainably, whereas a cDGSW or hcDGSW is instead a form of 'heat mining'. Operation of a cDGSW will indeed not attain a steady state over timescales of practical projects (i.e., timescales of decades); the associated 'heat mining' will instead progressively cool an ever-widening volume of surrounding rock, although each part of this rock volume will cool at ever-decreasing rates. The governing thermal physics is linear, the cooling at any point on any particular timescale being proportional to the rate of heat production. Second, when analysing a cDGSW one must distinguish between the heat produced (the heat that reaches the surface) and useable heat output, given that a proportion of the heat production (this proportion depending on the input temperature of the surface heat exchanger) will be reinjected as the heat transfer fluid is circulated. Analysis of the potential of any DGSW installation thus requires consideration of the site-specific combination of geological properties (such as thermal conductivity/diffusivity and geothermal gradient) and mode of operation, not the geological properties alone. The heat reinjected during operation of a cDGSW makes this a less favourable technological variant compared with the hCDGSW, notwithstanding the lower overall COP of the latter due to the electricity consumed by its heat pump. The electrical energy thus consumed will be converted to heat, providing another reason why the heat output from the system (including its heat pump) will differ from the heat produced from the borehole. Furthermore, the heat production from DGSW boreholes is sensitive to the site-specific geological properties; DGSW design must therefore consider such properties on a site-by-site basis, rather than assuming nominal values or that an analysis for one site is applicable to another. Moreover, economically optimal operation of a hcDGSW involves a rate of heat production that is close to the maximum that can be sustained over the lifetime of a project. This means that if a project has been 'under-engineered' (i.e., its heat output capacity has been overestimated, even by a small margin), the surrounding rock volume will cool so rapidly that the actual lifetime of the project is significantly reduced. The environmentally optimum operational mode (optimizing savings in $\mathrm{CO}_{2} \mathrm{e}$ emissions) involves heat production at a lower rate than the economically optimum mode (maximizing profit). If such projects are subsidized from public funds, then a particular operational mode might be specified, maybe as a compromise between these optima. Additional issues also affect dDGSW or hdDGSW installations. First, the produced water might well require decontamination treatment, especially if the installation is in granite, which will add significantly to operating costs and might cause regulatory difficulties. Second, these DGSW variants can only function in rocks of relatively high permeability and hydraulic conductivity, and the cost of pumping to maintain 'head lift' can further impact upon the economics of operation.

The present analytic modelling, which approximates the operational state of a DGSW installation under real conditions, indicates that the CDGSW variant has only limited potential; for $2 \mathrm{~km}$ deep boreholes, outputs over 20 year timescales of at most $\sim 100 \mathrm{~kW}$ are feasible, the value of which (under current UK conditions) is unlikely to cover the capital costs. hdDGSW operation can produce higher heat outputs, and can in principle be economic under current UK conditions with RHI subsidy payments included in revenue, but it is debateable whether this is a justifiable technology for public subsidy given its potential for environmental pollution, even after the produced water undergoes treatment. Furthermore, it requires site-dependent investigations that negate the original aim of providing an 'off the shelf' geothermal energy source. The hcDGSW variant, with a heat pump used to supplement the heat output of a cDGSW and to lower the reinjection temperature of the circulating fluid as close as possible to the ambient surface temperature (Fig. 2(b)), is shown to have the most potential. The analytical solutions have been used to develop an economic model for this variant, which indicates that the optimal heat output and operating surplus increase with borehole depth to the power of 1.87. This increase is faster than the corresponding increase in drilling costs, indicating 
that optimal hcDGSW designs will involve boreholes rather deeper than the $\sim 2 \mathrm{~km}$ depths considered hitherto. When RHI subsidy is included, the hcDGSW variant is indeed shown to have the potential for economic viability, assuming that a heat pump with the specified performance characteristics can be developed. Moreover, after the timescale for RHI subsidy eligibility has expired, this infrastructure can be easily repurposed for seasonal heat storage, thus offering the potential of making a significant longterm contribution to sustainable future heat supply.

\section{Acknowledgements}

The author, who has no conflicts of interest, has been funded in part by European Union Horizon2020 project EC-691728, DESTRESS (DEmonstration of soft Stimulation TREatmentS of geothermal reservoirS). Any mention of company names or products is for identification purposes only and does not imply endorsement by the University of Glasgow. Both anonymous reviewers are thanked for their thoughtful and constructive comments.

\section{Glossary}

Algebraic symbols used in equations in this study are defined here.

\section{Symbol Units}

C none

D $m$

E J

$\mathrm{K} \quad \mathrm{m} \mathrm{s}^{-1}$

$\mathrm{L} \quad \mathrm{m}$

$P_{E} \quad f k W h^{-1}$

$\mathrm{P}_{\mathrm{H}} \quad \mathrm{fkWh} \mathrm{k}^{-1}$

Q $\quad W$

$Q_{A} \quad W$

$Q_{G} \quad W$

$Q_{N} \quad W$

Qu W

Re none

$\mathrm{S} f$

$\mathrm{T} \quad{ }^{\circ} \mathrm{C}$

$\mathrm{T}_{\mathrm{D}} \quad{ }^{\circ} \mathrm{C}$

$T_{E} \quad{ }^{\circ} \mathrm{C}$

$\mathrm{T}_{1} \quad{ }^{\circ} \mathrm{C}$

$\mathrm{T}_{\mathrm{K}} \quad \mathrm{m}^{2} \mathrm{~s}^{-1}$

$\mathrm{T}_{\mathrm{K}} \quad \mathrm{Dm}$

$\% \mathrm{~T}_{\mathrm{K}} \quad$ none

$\% \mathrm{~T}_{\kappa} \quad$ none

$\mathrm{T}_{\mathrm{L}} \quad{ }^{\circ} \mathrm{C}$

$42 \mathrm{~T}_{0} \quad{ }^{\circ} \mathrm{C}$

43 Ts $\quad{ }^{\circ} \mathrm{C}$

$44 \mathrm{~V} \quad \mathrm{~m} \mathrm{~s}^{-1}$

45 a $\quad m$

46 c $\quad \mathrm{J} \mathrm{kg}^{-1}{ }^{\circ} \mathrm{C}^{-1}$

$47 \mathrm{f}$ none

$48 \mathrm{f}_{\mathrm{D}}$ none

$49 f_{k}$ none

$50 \mathrm{~g} \quad \mathrm{~m} \mathrm{~s}^{-2}$

$51 \mathrm{k} \quad \mathrm{W} \mathrm{m}^{-1}{ }^{\circ} \mathrm{C}^{-1}$

\section{Quantity represented}

Algebraic constant, defined as equal to $\exp (\gamma)$

Internal diameter of a pipe

Heat loss

Hydraulic conductivity

Length of a pipe

Unit cost of electrical energy used

Unit cost of heat energy sold

Rate of production of heat energy from a DGSW borehole

Estimate of $Q$ using analytic calculation

Rate of upward heat flow from below into cylindrical rock volume of radius $r_{c}$

Estimate of $Q$ using numerical modelling

Rate of production of heat energy that is useable by the associated heat load

Reynolds number quantifying the vigour of fluid flow

Operating surplus

Temperature

Temperature at which fluid is injected into a DGSW borehole

Output temperature from a surface heat exchanger or heat pump

Temperature at which circulating fluid enters a heat pump

Hydraulic transmissivity

Hydraulic transmissivity

Percentage of the total transmissivity of a borehole interval

Percentage of the total transmissivity of a borehole interval

Subsurface temperature at depth $\mathrm{z}_{\mathrm{L}}$

Temperature at which fluid is produced from a DGSW borehole

Temperature at the Earth's surface

Velocity of flow along a pipe

Radius of a borehole (internal radius of borehole casing)

Specific heat capacity

Ratio, $\mathrm{z}_{\mathrm{L}} / \mathrm{z}_{\mathrm{M}}$

Darcy-Weisbach friction factor

Scale factor to incorporate overheads onto the capital cost of a borehole

Acceleration due to gravity

Thermal conductivity 


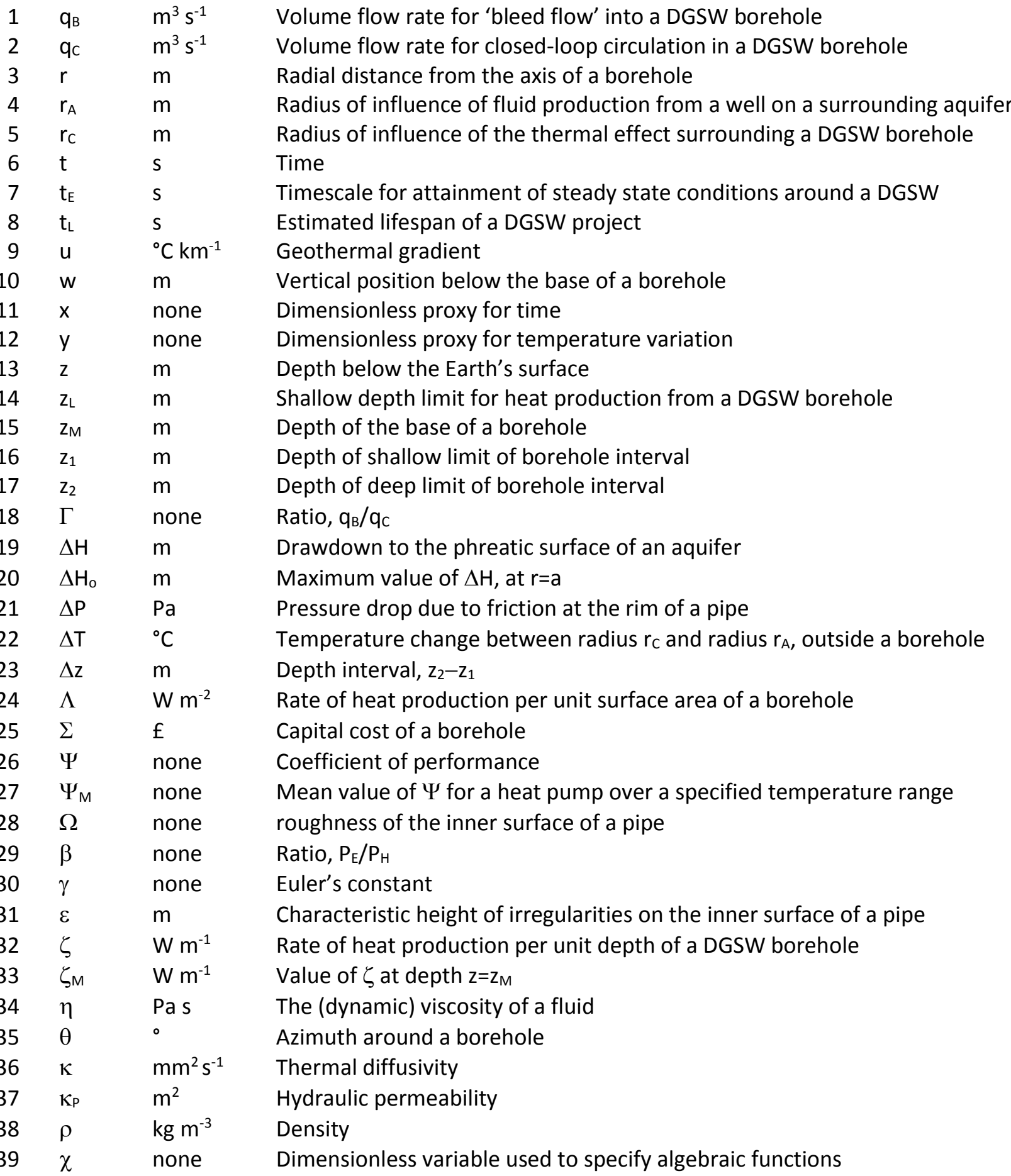

\section{References}

Abesser, C., Lewis, M.A., Marchant, A.P., Hulbert, A.G., 2014. Mapping suitability for open-loop ground source heat pump systems: a screening tool for England and Wales, UK. Quarterly Journal of Engineering Geology and Hydrogeology, 47, 373-380.

Abramowitz, M., Stegun, I., 1964. Handbook of Mathematical Functions with Formulas, Graphs, and Mathematical Tables. Dover, New York.

AECOM, 2013. Study into the potential for deep geothermal energy in Scotland: volume 1. AECOM UK, London, for the Scottish Government, Edinburgh, $216 \mathrm{pp}$. Available online: http://www.gov.scot/Resource/0043/00437977.pdf (accessed 8 March 2018)

Alimonti, C., Soldo, E., 2016. Study of geothermal power generation from a very deep oil well with a wellbore heat exchanger. Renewable Energy, 86, 292-301. 
Alimonti, C., Berardi, D., Bocchetti, D., Soldo, E., 2016. Coupling of energy conversion systems and wellbore heat exchanger in a depleted oil well. Geothermal Energy, 4 (11), 17 pp., doi: 10.1186/s40517-016-0053-9

Allen, D.J., Brewerton, L.J., Coleby, L.M., Gibbs, B.R., Lewis, M.A., MacDonald, A.M., Wagstaff, S.J., Williams, A.T., 1997. The physical properties of major aquifers in England and Wales. BGS Technical Report WD/97/34 and Environment Agency R\&D Publication 8. British Geological Survey, Keyworth, Nottingham, 333 pp. Available online: http://nora.nerc.ac.uk/13137/1/WD97034.pdf (accessed 13 February 2017)

Atkins, 2013. Deep Geothermal Review Study: Final Report. Atkins Ltd., Epsom, Surrey, for UK Government Department of Energy \& Climate Change, 156 pp. Available online: https://www.gov.uk/government/publications/Deep Geothermal Review Study Final Report F inal.pdf (accessed 20 February 2017)

Bailey, M.T., Gandy, C.J., Jarvis, A.P., 2016. Reducing life-cycle costs of passive mine water treatment by recovery of metals from treatment wastes. In: Drebenstedt, C., Paul, M. (eds.), Mining Meets Water - Conflicts and Solutions. Proceedings of the International Mine Water Association Symposium 2016, Freiberg, Germany, pp. 1255-1262. Available online: https://www.imwa.info/docs/imwa 2016/IMWA2016 Bailey 48.pdf (accessed 17 February 2017)

Banks, D., 2012. An Introduction to Thermogeology: Ground Source Heating and Cooling, 2nd edition. Wiley, Chichester, $544 \mathrm{pp}$.

Barelli, A., Palama, A., 1981. A new method for evaluating formation equilibrium temperature in holes during drilling. Geothermics, 10, 95-102.

Barker, J.A., 1986. Modelling of low enthalpy geothermal sources. In: Downing, R.A., Gray, D.A., eds, Geothermal Energy: the potential in the United Kingdom. Her Majesty's Stationery Office, London, 124-131.

Barker, J.A., Downing, R.A., Gray, D.A., Findlay, J., Kellaway, G.A., Parker, R.H., Rollin, K.E., 2000. Hydrogeothermal studies in the United Kingdom. Quarterly Journal of Engineering Geology and Hydrogeology, 33, 41-58.

Baster, M.E., 2011. Modelling the performance of air source heat pump systems. M.Sc. thesis, Strathclyde University, Glasgow, Scotland, $82 \mathrm{pp}$. Available online: http://www.esru.strath.ac.uk/Documents/MSc 2011/Baster.pdf (accessed 14 February 2017)

Bayer, P., Rivera, J.A., Schweizer, D., Schärli, U., Blum, P., Rybach, L., 2016. Extracting past atmospheric warming and urban heating effects from borehole temperature profiles. Geothermics, 64, 289299.

Beamish, D., 1990. A deep geoelectric survey of the Carnmenellis granite. Geophysical Journal International, 102, 679-693.

Baujard, C., Genter, A., Dalmais, E., Maurer, V., Hehn, R., Rosillette, R., Vidal, J., Schmittbuhl, J., 2017. Hydrothermal characterization of wells GRT-1 and GRT-2 in Rittershoffen, France: Implications on the understanding of natural flow systems in the Rhine Graben, Geothermics, 65, 255-268.

BEIS, 2017. 2015 UK Greenhouse Gas Emissions, Final Figures. UK Government Department of Business, Energy \& Industrial Strategy, 54 pp. Available online: https://www.gov.uk/government/uploads/system/uploads/attachment data/file/589825/2015 Final Emissions statistics.pdf (accessed 20 February 2017)

Bloomquist, R.G., 1999. Geothermal heat pumps four plus decades of experience. GHC Bulletin, December 1999, 13-27.

Bourne, S.J., Willemse, E.J.M., 2001. Elastic stress control on the pattern of tensile fracturing around a small fault network at Nash Point, UK. Journal of Structural Geology, 23, 1753-1770.

Brace, W.F., Walsh, J.B., Frangos, W.T., 1968. Permeability of granite under high pressure. Journal of Geophysical Research, 73, 2225-2236.

Bracken, L.J., Bulkeley, H.A., Maynard, C., 2014. Micro-hydro power in the UK: the role of communities in an emerging energy resource. Energy Policy, 68, 92-101. 
Bu Xianbiao, Ma Weibin, Li Huashan, 2012. Geothermal energy production utilizing abandoned oil and gas wells. Renewable Energy, 41, 80-85.

Burley, A.J., Edmunds, W.M., Gale, I.N., 1984. Catalogue of Geothermal Data for the Land Area of the United Kingdom. Technical Report WJ/GE/84/020. British Geological Survey, Keyworth, Nottingham, 161 pp. Available online: http://nora.nerc.ac.uk/id/eprint/512272/1/WJGE84020.pdf (accessed 7 March 2018)

Busby, J., Kingdon, A., Williams, J., 2011. The measured shallow temperature field in Britain. Quarterly Journal of Engineering Geology and Hydrogeology, 44, 373-387.

Carslaw, H.S., Jaeger, J.C., 1959. Conduction of heat in solids. Clarendon Press, Oxford, 510 pp.

Chadwick, R.A., Holliday, D.W., Holloway, S., Hulbert, A.G., 1995. The structure and evolution of the Northumberland-Solway Basin and adjacent areas. British Geological Survey Subsurface Memoir. HMSO, London, $90 \mathrm{pp}$.

Chekhonin, E., Parshin, A., Pissarenko, D., Romushkevich, R., Safonov, S., Spasennykh, M., Chertenkov, M.V., Stenin, V.P., 2012. When rocks get hot: thermal properties of reservoir rocks. Oilfield Review, 24 (3), 20-37.

Cheng Wen-Long, Li Tong-Tong, Nian Yong-Le, Wang Chang-Long, 2013. Studies on geothermal power generation using abandoned oil wells. Energy, 59, 248-254.

Cho Jeong-Heum, Nam Yujin, Kim Hyoung-Chan, 2016. Performance and feasibility study of a Standing Column Well (SCW) system using a deep geothermal well. Energies, 9, 108, 13 pp.; doi: $10.3390 /$ en9020108

Collier, R.E.L., 1991. The Lower Carboniferous Stainmore Basin, N. England: extensional basin tectonics and sedimentation. Journal of the Geological Society, London, 148, 379-390.

Collins, G., 2016. Don't ask what wastewater costs but what it's worth. http://oilprice.com/Energy/Energy-General/Dont-Ask-What-Wastewater-Costs-But-What-itsWorth.html (accessed 14 February 2017)

Collins, M.A., Law, R., 2017. The development and deployment of deep geothermal single well (DGSW) technology in the United Kingdom. European Geologist Journal, 43, 63-68.

Cornwall, 2017. Historic building pre-application advice for drilling of a geothermal borehole for the use of heating Jubilee Pool, Penzance, Cornwall. Cornwall Council Planning reference PA17/01106/PREAPP. Available online: http://planning.cornwall.gov.uk/online-applications/ (accessed 14 November 2017)

Coulton, R., Bullen, C., Dolan, J., Hallett, C., Wright, J., Marsden, C., 2003. Wheal Jane mine water active treatment-design, construction and operation. Land Contamination \& Reclamation, 11, 245-252.

Dahm, K., Chapman, M., 2014. Produced water treatment primer: case studies of treatment applications. U.S. Department of the Interior, Bureau of Reclamation, Denver, Colorado, $70 \mathrm{pp}$. Available online: https://www.usbr.gov/research/projects/download product.cfm?id=1214 (accessed 14 February 2017).

DEA, 2017. Regulation and planning of district heating in Denmark. Danish Energy Agency, Copenhagen, 28 pp. Available online: https://ens.dk/sites/ens.dk/files/Globalcooperation/regulation and planning of district heatin $\mathrm{g}$ in denmark.pdf (accessed 28 November 2017).

DECC, 2012. The Future of Heating: A strategic framework for low carbon heat in the UK. Department of Energy and Climate Change, London, 120 pp. Available online: https://www.gov.uk/government/uploads/system/uploads/attachment data/file/48574/4805future-heating-strategic-framework.pdf (accessed 26 February 2017)

DECC, 2016a. Quarterly Energy Prices, 30 June 2016. UK Government Department of Energy \& Climate Change, $\quad 39 \quad$ pp. Available online: https://www.gov.uk/government/uploads/system/uploads/attachment data/file/532712/QEP J une 2016 Final.pdf (accessed 20 February 2017) 
DECC, 2016b. UK Energy Statistics, 2015 \& Q4 2015. UK Government Department of Energy \& Climate Change, $16 \quad$ pp. Available https://www.gov.uk/government/uploads/system/uploads/attachment data/file/513244/Press Notice March 2016.pdf (accessed 20 February 2017)

DEFRA, 2011. Environmental permitting guidance, radioactive substances regulation; for the Environmental Permitting (England and Wales) Regulations 2010. UK Government Department for Environment, Food and Rural Affairs, London, $89 \mathrm{pp}$. Available online: https://www.gov.uk/government/uploads/system/uploads/attachment data/file/69503/pb1363 2-ep-guidance-rsr-110909.pdf (accessed 25 February 2017)

DEFRA, 2014. Water Framework Directive implementation in England and Wales: new and updated standards to protect the water environment. UK Government Department for Environment, Food and Rural Affairs, London, $41 \mathrm{pp}$ Available online: https://www.gov.uk/government/uploads/system/uploads/attachment data/file/307788/riverbasin-planning-standards.pdf (accessed 25 February 2017)

Deng Zheng, Rees, S.J., Spitler, J.D., 2005. A model for annual simulation of standing column well ground heat exchangers. International Journal of Heating, Ventilating, Air-Conditioning and Refrigerating Research, 11 (4), 637-655.

Donselaar, M.E., Groenenberg, R.M., Gilding, D.T., 2015. Reservoir geology and geothermal potential of the Delft Sandstone Member in the West Netherlands Basin. Proceedings, World Geothermal Congress 2015, Melbourne, Australia, 19-25 April 2015, paper 12054, 9 pp.

Downing, R.A., 1986. Engineering and economic aspects of low enthalpy development. In: Downing, R.A., Gray, D.A., eds, Geothermal Energy: the potential in the United Kingdom. Her Majesty's Stationery Office, London, pp. 148-151.

Downing, R.A., Allen, D.J., Barker, J.A., Burgess, W.G., Gray, D.A., Price, M., Smith, I.F., 1984. Geothermal exploration at Southampton in the UK: a case study of a low enthalpy resource. Energy Exploration \& Exploitation, 2, 327-342.

DTI, 1999. New and Renewable Energy: Prospects for the 21st Century. Department of Trade and Industry, London, $\quad 70 \quad \mathrm{pp} \quad$ Available online: http://webarchive.nationalarchives.gov.uk/20000817030113/http://www.dti.gov.uk:80/renew/c ondoc/ (accessed 23 November 2017)

East Ayrshire, 2017. Screening Request for proposed deep geothermal single well; Kilmarnock, East Ayrshire. East Ayrshire Council pre-screening planning application 17/0009/EIASCR. Available online: $\quad$ https://www.east-ayrshire.gov.uk/PlanningAndTheEnvironment/Planningapplications/Planning-applications.aspx (accessed 14 November 2017)

Edmunds, W.M., 1975. Geochemistry of brines in the coal measures of Northeast England. Transactions of the Institution of Mining and Metallurgy, London (Section B: Applied Earth Science), 84, B39-B52.

Edmunds, W.M., 1986. Geochemistry of geothermal waters in the UK. In: Downing, R.A., Gray, D.A., eds, Geothermal Energy: the potential in the United Kingdom. Her Majesty's Stationery Office, London, pp. 111-123.

EIA, 2016. Carbon Dioxide Emissions Coefficients. U.S. Energy Information Administration, Washington, DC. Available online: https://www.eia.gov/environment/emissions/co2 vol mass.cfm (accessed 10 March 2017)

Enggcyclopedia, 2011. Absolute Pipe Roughness. Available online: http://www.enggcyclopedia.com/2011/09/absolute-roughness/ (accessed 14 November 2017)

England, P.C., Oxburgh, E.R., Richardson, S.W., 1980. Heat refraction and heat production in and around granite plutons in north-east England. Geophysical Journal International, 62, 439-455.

Förster, H.-J., 1999. The chemical composition of uraninite in Variscan granites of the Erzgebirge, Germany. Mineralogical Magazine, 63, 239-252.

Förster, H.-J., Tischendorf, G., Trumbull, R.B., Gottesmann, B., 1999. Late-collisional granites in the Variscan Erzgebirge, Germany. Journal of Petrology, 40, 1613-1645. 
GEL, 2014. 2 October 2014: First deep geothermal energy produced in Cornwall for 25 years. Geothermal Engineering Ltd., London. Available online: http://www.geothermalengineering.co.uk/news.php (accessed 20 February 2017)

GEL, University of St Andrews, \& Arup, 2016. Feasibility report of a deep geothermal single well, Aberdeen Exhibition and Conference Centre. Scottish Government, Edinburgh, 103 pp. Available online: http://www.gov.scot/Resource/0049/00497878.pdf (accessed 20 February 2017)

Geon, 2017. September 2017: Scotland's first deep geothermal district heating network. Geon Energy Ltd., London. Available online: http://geonenergy.com/wordpress/geonenergy news/ (accessed 17 November 2017)

Gillespie, M.R., Crane, E.J., Barron, H.F., 2013. Study into the potential for deep geothermal energy in Scotland: volume 2. Scottish Government, Edinburgh, 125 pp. Available online: http://www.gov.scot/Resource/0043/00437996.pdf (accessed 13 February 2018)

Groves, P., Hochwimmer, A., Seastres Jr., J., 2012. A pre-feasibility study for energy recovery from geothermal prospects in Scotland. In: Proceedings, New Zealand Geothermal Workshop 2012. Auckland, New Zealand, 19-21 November 2012, 7 pp.

Hamm, S.-Y., Kim, M.S., Cheong, J.-Y., Kim, J.-Y., Son, M., Kim, T.-W., 2007. Relationship between hydraulic conductivity and fracture p5roperties estimated from packer tests and borehole data in a fractured granite. Engineering Geology, 92, 73-87.

Hepbasli, A., 2005. Thermodynamic analysis of a ground-source heat pump system for district heating. International Journal of Energy Research, 29, 671-687.

IIIman, W.A., Liu, X., Takeuchi, S., Yeh, T.-C.J., Ando, K., Saegusa, H., 2009. Hydraulic tomography in fractured granite: Mizunami underground research site, Japan. Water Resources Research, 45, W01406, 18 pp., doi: 10.1029/2007WR006715.

Johnson, D.B., Hallberg, K.B., 2005. Acid mine drainage remediation options: a review. Science of the Total Environment, 338, 3-14.

Johnson, G.A.L., Somerville, I.D., Tucker, M.E., Cózar, P., 2011. Carboniferous stratigraphy and context of the Seal Sands No. 1 Borehole, Teesmouth, NE England: the deepest onshore borehole in Great Britain. Proceedings of the Yorkshire Geological Society, 58, 173-196.

Johnston, D., Potter, H., Jones, C., Rolley, S., Watson, I., Pritchard, J., 2008. Abandoned mines and the water environment. Science project SC030136-41. The Environment Agency, Bristol, 40 pp. Available

online: https://www.gov.uk/government/uploads/system/uploads/.../LIT 8879 df7d5c.pdf (accessed 25 February 2017)

Joule, 2017. Underfloor heating. Joule UK Ltd., Bromborough, England, 24 pp. Available online: http://www.jouleuk.co.uk/wp-content/uploads/2015/09/Joule-Underfloor-Heating-Brochure.pdf (accessed 28 November 2017)

Kavanaugh, S., Green, M., Mescher, K., 2012. Long-term commercial GSHP performance. Part 4: Installation costs. ASHRAE Journal, 54 (10), 26-36. Available online: www.geokiss.com/technotes/LongTermGSHPsPt4.pdf (accessed 16 July 2017)

Kiessig, G., Gatzweiler, R., Jakubick, A.T., 2004. Remediation options and the importance of water treatment at former uranium production sites in eastern Germany. In: Treatment of Liquid Effluent from Uranium Mines and Mills, IAEA-TECHDOC-1419. International Atomic Energy Agency, Vienna, pp. 127-143. Available online: www-pub.iaea.org/MTCD/publications/PDF/te 1419 web.pdf (accessed 16 February 2017).

King, D., Browne, J., Layard, R., O’Donnell, G., Rees, M., Stern, N. \& Turner, A. 2015. A Global Apollo Programme to Combat Climate Change. Centre for Economic Performance, London School of Economics and Political Science, 40 pp. Available online: http://cep.Ise.ac.uk/pubs/download/special/Global Apollo Programme Report.pdf (accessed 2 March 2017) 
Knight Piesold and partners, 1995. Wheal Jane Minewater Study: Environmental Appraisal and Treatment Strategy. Knight Piesold Ltd, Ashford, Kent, 446 pp. Available online: http://www.environmentdata.org/fedora/repository/ealit:2627/OBJ/20000033.pdf (accessed 17 February 2017)

Knight Piesold and partners, 1998. Wheal Jane Minewater Project: Consultancy Studies 1996-1999. Appraisal and Selection of Long Term Treatment Option. Knight Piesold Ltd, Ashford, Kent, 183 pp. Available online: http://ea-lit.freshwaterlife.org/archive/ealit:1620/OBJ/20000888.pdf (accessed 17 February 2017)

Küchler, A., Kiessig, G., Kunze, C., 2005. Passive biological treatment systems of mine waters at WISMUT sites. Proceedings, 9th International Congress on Mine Water \& the Environment, Oviedo, Spain, pp. 361-368. Available online: https://www.imwa.info/docs/imwa 2005/IMWA2005 051 Kuechler.pdf (accessed 16 February 2017).

Kunze, C., Küchler, A., 2003. Passive biological treatment systems of mine waters at WISMUT sites. Proceedings, 8th International Congress on Mine Water \& the Environment, Johannesburg, South Africa, pp. 187-199. Available online: https://www.imwa.info/docs/imwa 2003/imwa 2003 187199.pdf (accessed 16 February 2017).

Law, R., 2014. Deep Geothermal Heat Production - Single Well Trial. In: Renewable Heating \& Renewable Cooling; Ground Source Heat Pump Association $5^{\text {th }}$ Technical Seminar, De Montfort University, Leicester, 16 November 2014, 8 pp. Available online: http://www.gshp.org.uk/DeMontfort/GeothermalEngineeringLtd.pdf (accessed 20 February 2017)

Law, R, Bridgland, D., Nicholson, D., Chendorain, M., 2015. Heat extraction from deep single wells. Proceedings World Geothermal Congress 2015. Melbourne, Australia, 19-25 April 2015. https://pangea.stanford.edu/ERE/db/WGC/papers/WGC/2015/28002.pdf

Lee, M.K., 1986. Hot dry rock. In: Downing, R.A., Gray, D.A., eds, Geothermal Energy: the potential in the United Kingdom. Her Majesty's Stationery Office, London, pp. 21-41.

Lee, M.K., Brown, G.C., Webb, P.C., Wheildon, J., Rollin, K.E., 1987. Heat flow, heat production and thermo-tectonic setting in mainland UK. Journal of the Geological Society, London, 144, 35-42.

Lewis, M.A., Cheney, C.S., O'Dochartaigh, B.E., 2006. Guide to permeability indices. BGS Open Report CR/06/160N, British Geological Survey, Keyworth, Nottingham, 29 pp. Available online: http://nora.nerc.ac.uk/7457/1/CR06160N.pdf (accessed 13 February 2017)

Liu Xiaobing, Hughes, P., Anderson, A., 2016. An overview of geothermal heat pump applications and a preliminary assessment of its technical potential in the United States. GRC Transactions, 40, 707716.

Lockett, G.E., 1986. Single borehole geothermal energy extraction system for electrical power generation. Proceedings, Eleventh Workshop on Geothermal Reservoir Engineering, Stanford University, Stanford, California, 21-23 January 1986. SGP-TR-93, 2 pp. Available online: https://www.geothermal-energy.org/pdf/IGAstandard/SGW/1986/Lockett.pdf $\quad$ (accessed 25 February 2017)

Lyons, W.C., Go BoYun, Graham, R.L., Hawley, G.D., 2009. Air and Gas Drilling Manual: Applications for Oil and Gas Recovery Wells and Geothermal Fluids Recovery Wells. Elsevier, Amsterdam.

McCay, A.T., 2016. Heat production measurements from Scottish granites. Available online: http://researchdata.gla.ac.uk/id/eprint/302 (accessed 2 March 2017)

McDermott, C.I., Randriamanjatosoa, A.L., Tenzer, H., Kolditz, O., 2006. Simulation of heat extraction from crystalline rocks: the influence of coupled processes on differential reservoir cooling. Geothermics, 35, 321-344.

McGarr, A., Gay, N.C., 1978. State of stress in the Earth's crust. Annual Review of Earth and Planetary Sciences, 6, 405-436.

McKeon, B.J., Swanson, C.J., Zagarola, M.V., Donnelly, R.J., Smits, A.J., 2004. Friction factors for smooth pipe flow. Journal of Fluid Mechanics, 511, 41-44. 
Manetti, G., 1973. Attainment of temperature equilibrium in holes during drilling. Geothermics, 2, 94100.

Manning, D.A.C., Younger, P.L., Smith, F.W., Jones, J.M., Dufton, D.J., Diskin, S., 2007. A deep geothermal exploration well at Eastgate, Weardale, UK: a novel exploration concept for lowenthalpy resources. Journal of the Geological Society, London, 164, 371-382.

Martinez-Landa, L., Carrera, J., 2005. An analysis of hydraulic conductivity scale effects in granite (Fullscale Engineered Barrier Experiment (FEBEX), Grimsel, Switzerland). Water Resources Research, 41, W03006, 13 pp., doi: 10.1029/2004WR003458 (with 2005 correction: Water Resources Research, 41, W11703, 1 p., doi: 10.1029/2005WR004446).

Met Office, 2017. Aberdeen Airport climate. UK Meteorological Office, Exeter. Available online: http://www.metoffice.gov.uk/public/weather/climate/gfnmmyh91 (accessed 2 March 2017).

Moody, L.F., 1944. Friction factors for pipe flow. Transactions of the American Society of Mechanical Engineers, 66, 671-684.

Morris, J., 2014. Pumping the polluted water from mines. BBC News. Available online: http://www.bbc.co.uk/news/uk-england-26573994 (accessed 17 February 2017).

Nalla, G., Shook, G.M., Mines, G.L., Bloomfield, K., 2004. Parametric sensitivity study of operating and design variables in wellbore heat exchangers. Proceedings, Twenty-Ninth Workshop on Geothermal Reservoir Engineering Stanford University, Stanford, California, 26-28 January 2004, SGP-TR-175, 9 pp. Available online: http://citeseerx.ist.psu.edu/viewdoc/download?doi=10.1.1.545.9839\&rep=rep1\&type=pdf (accessed 16 July 2017).

Noorollahi, Y., Bina, S.M., Yousefi, H., 2016. Simulation of power production from dry geothermal well using down-hole heat exchanger in Sabalan Field, northwest Iran. Natural Resources Research, 25, 227-239.

OFGEM, 2017. Feed-In Tariff (FIT) rates. Office of Gas and Electricity Markets, London. Available online: https://www.ofgem.gov.uk/environmental-programmes/fit/fit-tariff-rates $\quad$ (accessed 21 November 2017).

O'Neill, Z.D., Spitler, J.D., Rees, S.J., 2006. Modeling of standing column wells in ground source heat pump systems. ASHRAE Transactions, 101 (1), 173-185. Available online: http://www.hvac.okstate.edu/sites/default/files/pubs/papers/2006/05Oneill Spitler Rees 06.pdf (accessed 16 July 2017).

ONS, 2017. Population estimates for UK, England and Wales, Scotland and Northern Ireland, mid-2016. UK Office for National Statistics, London. Available online: https://www.ons.gov.uk/peoplepopulationandcommunity/populationandmigration/populationes timates/datasets/populationestimatesforukenglandandwalesscotlandandnorthernireland (accessed 28 November 2017).

Orio, C.D., Johnson, C.N., Rees, S.J., Chiasson, A., Deng Zheng, Spitler, J.D., 2005. A survey of standing column well installations in North America. ASHRAE Transactions, 111 (2), 109-121. Available online: $\quad$ http://www.hvac.okstate.edu/sites/default/files/pubs/papers/2005/05Orio Johnson Rees Chiasson Deng Spitler 05.pdf (accessed 16 July 2017).

Peacock, C., 2014. Pumping water from disused UK mines. Available online: http://www.aquaread.com/pumping-water-disused-uk-mines/ (accessed 17 February 2017).

Rafferty, K. 2001. Design aspects of commercial open-loop heat pump systems. Geo-Heat Center Quarterly Bulletin, 22, 16-24.

Ramaekers, J., Geel, K., Lokhorst, A., Simmelink, H.J., 2006. Nader onderzoek naar mogelijkheden van aardwarmtewinning voor de vleestomaatkwekerij van Fa A\&G van den Bosch BV te Bleiswijk. Report 2006-U-R0016/B, 71 pp. Nederlandse Organisatie voor Toegepast Natuurwetenschappelijk Onderzoek, Utrecht, the Netherlands. Available online: http://nlog.nl/cmis/browser?id=workspace\%3A//SpacesStore/5355c256-c291-4204-bb52fda100f91327 (accessed 28 January 2017) 
Renewables First, 2015. How much hydropower income would my system provide? Renewables First Ltd., Stroud, Gloucestershire. Available online: http://www.renewablesfirst.co.uk/hydropower/hydropower-learning-centre/how-much-incomewould-my-hydro-system-provide/ (accessed 21 November 2017)

Rees, S.J., Spitler, J.D., Deng Zheng, Orio, C.D., Johnson, C.N., 2004. A study of geothermal heat pump and standing column well performance. ASHRAE Transactions 110 (1), 3-13. Available online: http://www.hvac.okstate.edu/sites/default/files/pubs/papers/2004/06-

Rees Spitler Deng Orio Johnson 04.pdf (accessed 16 July 2017).

Riahi, A., Moncarz, P., Kolbe, W., Damjanac, B., 2017. Innovative closed-loop geothermal well designs using water and super critical carbon dioxide as working fluids. Proceedings, Forty-second Workshop on Geothermal Reservoir Engineering, Stanford University, Stanford, California, 13-15 February 2017. SGP-TR-212, 9 pp. Available online: https://pangea.stanford.edu/ERE/db/GeoConf/papers/SGW/2017/Riahi.pdf (accessed 16 July 2017).

Richards, H.G., Parker, R.H., Green, A.S.P., Jones, R.H., Nicholls, J.D.M., Nicol, D.A.C., Randall, T.M.M., Richards, S., Stewart, R.C., Willis-Richards, J., 1994. The performance and characteristics of the experimental Hot Dry Rock geothermal reservoir at Rosemanowes, Cornwall (1985-1988). Geothermics, 23, 73-109.

Rollin, K.E., 1995. A simple heat-flow quality function and appraisal of heat-flow measurements and heat-flow estimates from the UK Geothermal Catalogue. Tectonophysics, 244, 185-196.

Rybach, L., Eugster, W.J., Hopkirk, R.J., Kaelin, B., 1992. Borehole heat exchangers: longterm operational characteristics of a decentral geothermal heating system. Geothermics, 21, 861-867.

Satman, A., 2011. Sustainability of geothermal doublets. Proceedings, Thirty-Sixth Workshop on Geothermal Reservoir Engineering, Stanford University, Stanford, California, 31 January - 2 February 2011. SGP-TR-191, 9 pp. Available online: https://pangea.stanford.edu/ERE/pdf/IGAstandard/SGW/2011/satman.pdf (accessed 14 July 2017)

Simmelink, H.J., Geel, K., 2008. Sustainable tomatoes are growing on geothermal heat. Nederlandse Organisatie voor Toegepast Natuurwetenschappelijk Onderzoek, Utrecht, the Netherlands. Available online: https://www.tno.nl/media/2629/information20-art1.pdf (accessed 28 January 2017)

Smit, R.C.A., 2012. Optimisation of geothermal well doublet placement. M.Sc. thesis, Technical University Delft, Delft, the Netherlands. Available online: https://repository.tudelft.nl/islandora/object/uuid\%3A09d6081e-33ab-4511-8c5e-31016f841716 (accessed 14 July 2017)

Smith, I.F., 1986. Mesozoic basins. In: Downing, R.A., Gray, D.A., eds, Geothermal Energy: the potential in the United Kingdom. Her Majesty's Stationery Office, London, pp. 42-83.

Snow, D.T., 1969. Anisotropic permeability of fractured media. Water Resources Research, 5, 12731289.

Spitler, J.D., Javed, S., Kalskin Ramstad, R., 2016. Natural convection in groundwater-filled boreholes used as ground heat exchangers. Applied Energy, 164, 352-365.

Tenzer, H., Park Chan-Hee, Kolditz, O., McDermott, C.I., 2010, Application of the geomechanical facies approach and comparison of exploration and evaluation methods used at Soultz-sous-Forêts (France) and Spa Urach (Germany) geothermal sites. Environmental Earth Sciences, 61, 853-880.

Thiem, G., 1906. Hydrologische Methoden. J.M. Gebhardt, Leipzig, Germany, 56 pp.

van Wees, J.D.A.M., Kramers, L., Kronimus, R.A., Pluymaekers, M.P.D., MijnLieff, H.F., Vis, G.J., 2010. ThermoGIS ${ }^{\mathrm{TM}}$ V1.0: Part II: Methodology. Nederlandse Organisatie voor Toegepast Natuurwetenschappelijk Onderzoek (TNO; Netherlands Organisation for Applied Scientific Research), Utrecht, the Netherlands, 61 pp. Available online: www.thermogis.nl/downloads/ThermoGISmanual partll.pdf (accessed 21 February 2017) 
Vidal, J., Genter, A., Schmittbuhl, J., 2016. Pre- and post-stimulations of the geothermal well GRT-1 (Rittershoffen, France): insights from acoustic image logs on hard fractured rock investigations, Geophysical Journal International, 206, 845-860.

Voss, C.I., Provost, A.M., 2010. SUTRA: A model for saturated-unsaturated, variable-density groundwater flow with solute or energy transport. Water-Resources Investigations Report 02-4231. U.S. Geological Survey, Reston, Virginia, 300 pp.

Wang Zhe, 2009. Modeling study of a single-well enhanced geothermal system (EGS). Proceedings, Thirty-fourth Workshop on Geothermal Reservoir Engineering Stanford University, Stanford, California, 9-11 February 2009. SGP-TR-190, 81 pp. Available online: https://pangea.stanford.edu/ERE/research/geoth/publications/.../SGP-TR-190.pdf (accessed 16 July 2017)

Wang Zhe, McClure, M.W., Horne, R.N., 2010. Modeling study of single-well EGS configurations. Proceedings World Geothermal Congress 2010, Bali, Indonesia, 25-29 April 2010, paper 3113, 12 pp. Available online: https://www.geothermal-energy.org/pdf/IGAstandard/WGC/2010/3113.pdf (accessed 16 July 2017)

Westaway, R., 2016. Repurposing of disused shale gas wells for subsurface heat storage: preliminary analysis concerning UK issues. Quarterly Journal of Engineering Geology and Hydrogeology, 49, 213-227.

Westaway, R., Younger, P.L., 2013. Accounting for palaeoclimate and topography: a rigorous approach to correction of the British geothermal dataset. Geothermics, 48, 31-51.

Westaway, R., Younger, P.L., 2016. Unravelling the relative contributions of climate change and ground disturbance to subsurface temperature perturbations: case studies from Tyneside, UK. Geothermics, 64, 490-515.

Wheildon, J., Rollin, K.E., 1986. Engineering and economic aspects of low enthalpy development. In: Downing, R.A., Gray, D.A., eds, Geothermal Energy: the potential in the United Kingdom. Her Majesty's Stationery Office, London, pp. 8-20.

Younger, P.L., 2000. The adoption and adaptation of passive treatment technologies for mine waters in the United Kingdom. Mine Water and the Environment, 19, 85-97.

Younger, P.L., 2014. Hydrogeological challenges in a low-carbon economy. Quarterly Journal of Engineering Geology and Hydrogeology, 47, 7-27.

Younger, P.L., Banwart, S.A., Hedin, R.S., 2002. Mine Water: Hydrology, Pollution, Remediation. Kluwer, Dordrecht, the Netherlands, $464 \mathrm{pp}$.

Younger, P.L., Coulton, R.H., Froggatt, E.C., 2005. The contribution of science to risk-based decisionmaking: Lessons from the development of full-scale treatment measures for acidic mine waters at Wheal Jane, UK. Science of the Total Environment, 338, 137-154.

Younger, P.L., Manning, D.A.C., 2010. Hyper-permeable granite: lessons from test-pumping in the Eastgate Geothermal Borehole, Weardale, UK. Quarterly Journal of Engineering Geology and Hydrogeology, 43, 5-10.

Younger, P.L., Manning, D.A.C., Millward, D., Busby, J.P., Jones, C.R.C., Gluyas, J.G., 2016. Geothermal exploration in the Fell Sandstone Formation (Mississippian) beneath the city centre of Newcastle upon Tyne, UK: the Newcastle Science Central Deep Geothermal Borehole. Quarterly Journal of Engineering Geology and Hydrogeology, 49, 350-363.

Table 1 - on a separate sheet. 
Table 2: Estimates of cDGSW performance

\begin{tabular}{|c|c|c|c|c|c|c|}
\hline $\begin{array}{l}\mathrm{Q} \\
(\mathrm{kW})\end{array}$ & $\begin{array}{l}\mathrm{T}_{\mathrm{o}}(5 \mathrm{yrs}) \\
\left({ }^{\circ} \mathrm{C}\right)\end{array}$ & $\begin{array}{l}\mathrm{Q}_{u}(5 \mathrm{yrs}) \\
(\mathrm{kW})\end{array}$ & $\begin{array}{l}\mathrm{T}_{0}(10 \mathrm{yrs}) \\
\left({ }^{\circ} \mathrm{C}\right)\end{array}$ & $\begin{array}{l}\mathrm{Q}_{u}(10 \mathrm{yrs}) \\
(\mathrm{kW})\end{array}$ & $\begin{array}{l}\mathrm{T}_{0}(20 \text { yrs }) \\
\left({ }^{\circ} \mathrm{C}\right)\end{array}$ & $\begin{array}{l}\text { Qu(20 yrs) } \\
(\mathrm{kW})\end{array}$ \\
\hline \multicolumn{7}{|c|}{$z_{M}=2000 \mathrm{~m} ; T_{L}=30^{\circ} \mathrm{C} ; T_{M}=74^{\circ} \mathrm{C}(f \approx 0.31)$} \\
\hline 0 & 74.0 & 0.0 & 74.0 & 0.0 & 74.0 & 0.0 \\
\hline 20 & 66.9 & 13.0 & 66.5 & 12.9 & 66.0 & 12.9 \\
\hline 40 & 59.9 & 24.0 & 59.0 & 23.7 & 58.0 & 23.3 \\
\hline 60 & 52.8 & 32.0 & 51.5 & 31.1 & 50.0 & 30.0 \\
\hline 80 & 45.8 & 35.3 & 44.0 & 32.9 & 42.0 & 30.0 \\
\hline 100 & 38.3 & 29.3 & 36.6 & 24.8 & 34.0 & 16.7 \\
\hline 120 & 31.7 & 9.4 & 29.1 & 0.0 & 26.0 & 0.0 \\
\hline \multicolumn{7}{|c|}{$z_{M}=2500 \mathrm{~m} ; T_{L}=30{ }^{\circ} \mathrm{C} ; T_{M}=90^{\circ} \mathrm{C}(f=0.25)$} \\
\hline 0 & 90.0 & 0.0 & 90.0 & 0.0 & 90.0 & 0.0 \\
\hline 20 & 84.8 & 14.7 & 84.5 & 14.6 & 84.1 & 14.6 \\
\hline 40 & 79.7 & 28.5 & 79.0 & 28.4 & 78.3 & 28.3 \\
\hline 60 & 74.5 & 41.4 & 73.5 & 41.1 & 72.4 & 40.8 \\
\hline 80 & 69.3 & 53.0 & 68.0 & 52.4 & 66.6 & 51.7 \\
\hline 100 & 64.2 & 63.1 & 62.6 & 62.0 & 60.7 & 60.6 \\
\hline 120 & 59.0 & 71.0 & 57.0 & 68.9 & 54.9 & 66.5 \\
\hline 140 & 53.8 & 76.1 & 51.5 & 72.5 & 49.0 & 68.2 \\
\hline 160 & 48.6 & 77.1 & 46.0 & 71.1 & 43.2 & 63.6 \\
\hline 180 & 43.5 & 72.5 & 40.6 & 62.4 & 37.3 & 48.1 \\
\hline 200 & 38.3 & 58.7 & 35.1 & 40.6 & 31.4 & 13.1 \\
\hline 220 & 33.2 & 30.3 & 29.6 & 0.0 & 25.5 & 0.0 \\
\hline \multicolumn{7}{|c|}{$z_{M}=3000 \mathrm{~m} ; T_{L}=30^{\circ} \mathrm{C} ; T_{M}=106^{\circ} \mathrm{C}(f \approx 0.21)$} \\
\hline 0 & 106.0 & 0.0 & 106.0 & 0.0 & 106.0 & 0.0 \\
\hline 20 & 101.9 & 15.6 & 101.7 & 15.6 & 101.4 & 15.6 \\
\hline 40 & 97.9 & 30.9 & 97.3 & 30.8 & 96.8 & 30.8 \\
\hline 60 & 93.8 & 45.7 & 93.0 & 45.5 & 92.1 & 45.4 \\
\hline 80 & 89.7 & 59.9 & 88.7 & 59.7 & 87.5 & 59.4 \\
\hline 100 & 85.6 & 73.5 & 84.3 & 73.1 & 82.9 & 72.6 \\
\hline 120 & 81.5 & 86.4 & 80.0 & 85.7 & 78.3 & 84.9 \\
\hline 140 & 77.5 & 98.5 & 75.6 & 97.3 & 73.6 & 96.0 \\
\hline 160 & 73.4 & 109.5 & 71.3 & 107.8 & 69.0 & 105.8 \\
\hline 180 & 69.3 & 119.3 & 66.9 & 116.7 & 64.4 & 113.8 \\
\hline 200 & 65.2 & 127.5 & 62.6 & 124.0 & 59.7 & 119.5 \\
\hline 220 & 61.1 & 133.9 & 58.3 & 128.9 & 55.1 & 122.4 \\
\hline 240 & 57.0 & 137.9 & 53.9 & 130.7 & 50.5 & 121.5 \\
\hline 260 & 52.9 & 138.8 & 49.6 & 128.7 & 45.9 & 115.2 \\
\hline 280 & 48.9 & 136.0 & 45.3 & 121.4 & 41.3 & 101.1 \\
\hline 300 & 44.8 & 127.6 & 41.0 & 106.5 & 36.6 & 74.4 \\
\hline 320 & 40.7 & 111.5 & 36.6 & 79.4 & 32.0 & 29.1 \\
\hline 340 & 36.6 & 84.4 & 32.3 & 35.1 & 27.4 & 0.0 \\
\hline 360 & 32.6 & 41.4 & 28.0 & 0.0 & 22.8 & 0.0 \\
\hline
\end{tabular}

50 Calculations, on the basis explained in the main text, demonstrating the performance issues that result 51 for CDGSW installations operated at nonzero values of $f$. Values of useable heat output $Q_{u}$ and output 52 temperature $T_{0}$ after 5,10 and 20 years of operation are listed. The calculations assume $a=0.1 \mathrm{~m}$, $53 \mathrm{~T}_{\mathrm{s}}=10^{\circ} \mathrm{C}, \mathrm{u}=32^{\circ} \mathrm{C} \mathrm{km}^{-1}, \mathrm{k}=3.5 \mathrm{~W} \mathrm{~m}^{-1}{ }^{\circ} \mathrm{C}^{-1}$, and $\mathrm{\kappa}=1.2 \mathrm{~mm}^{2} \mathrm{~s}^{-1}$ (cf. Fig. 4). 
Table 3: Hydraulic transport properties of granites: on a separate sheet.

Table 4: Temperatures at $1 \mathrm{~km}$ depth: on a separate sheet.

\section{Figure Captions}

Figure 1. Schematic diagrams depicting groundwater extraction DGSWs. Thin solid arrows indicate directions of fluid flow; the fluid is shaded to convey an impression of its temperature and/or whether it is warming or cooling at each point in the model. Temperatures at key points are labelled for comparison with the main text. (a) A simple wDGSW in which hot water is pumped out of a permeable aquifer, is cooled by transferring heat to working fluid (which supplies heat to a heat load), then the resulting warm water is discharged into the environment. (b) A hwDGSW, in which after passing through the heat exchanger the ground water is cooled further using a heat pump. The Southampton geothermal project, discussed in the text, operated as in (a) from 1988 to 1991 then was modified as in (b). It does not incorporate treatment of the discharged water but this is depicted schematically as it will arguably be necessary for any future projects of this type.

Figure 2. Schematic diagrams depicting conductive DGSWs, using the same notation as in Fig. 1 plus broad open arrows indicate directions of heat conduction in the subsurface. (a) A cDGSW, in which the borehole contains part of a closed circulation loop. Note that with this variant much of the heat produced (at temperature $T_{0}$ ) is not used, because the output temperature of the heat exchanger, $T_{E}$, and thus the reinjection temperature $T_{D}$ of the circulating fluid, significantly exceeds the ambient surface temperature $T_{S}$. This heat is reinjected and warms the subsurface down to depth $z_{L}$ where the initial rock temperature $T_{L}$ equals the fluid temperature $T_{E}\left(=T_{D}\right)$. The circulating fluid is thus warmed between depth $z_{L}$ and the well bottom at $z_{M}$, not throughout the full vertical extent of the borehole (the parameter $f$, which appears in equations defined in the text, being the ratio $z_{L} / z_{M}$ ). To the best of my knowledge, this system design was first proposed by Rybach et al. (1992). (b) A hcDGSW, in which a heat pump is added to the closed-loop configuration in (a), to supplement the useful heat output by cooling the circulating fluid to the ambient temperature $T_{s}$. This also increases the proportion of the borehole available for heat production. This configuration, not previously analysed in detail, is favoured in the present study as the preferred DGSW variant.

Figure 3. Schematic diagrams depicting 'dual mode' DGSWs, combining the option of water extraction (with the deeper part of the borehole open to its surroundings) with heat production by conduction, using the same notation as in Fig. 2. (a) A dDGSW, in which ground water is drawn into the borehole heat exchanger at depth and discharged at the surface, potentially increasing the thermal output. This variant suffers from the principal disadvantages in Fig, 2(a), that reinjection of warm water reduces the output of useful heat and warms the surroundings of the shallow part of the borehole, limiting the proportion of it available for heat production. It also introduces other disadvantages, including the need for relatively permeable bedrock at depth, scaling of the pipe loop due to precipitation of substances dissolved in the circulating ground water, the need for treatment of the discharged water, and associated regulatory issues. (b) A hdDGSW, in which a heat pump is added to the configuration in (a), to supplement the useful heat output by cooling the circulating fluid to the ambient temperature $T_{s}$. This also increases the proportion of the borehole available for heat production. However, the difficulties remain over identification of permeable bedrock and disposal of the ground water that is discharged into the environment. A system of this type is proposed at the AECC (GEL et al., 2016). 
Figure 4. Calculated variations in output temperature $T_{0}$ for a cDGSW operating for 10 years at constant rates of heat production $Q 50,80,140$ and $260 \mathrm{~kW}$, assuming $\mathrm{z}_{\mathrm{M}}=2500 \mathrm{~m}, \mathrm{~T}_{\mathrm{M}}=80^{\circ} \mathrm{C}, \mathrm{T}_{\mathrm{S}}=0{ }^{\circ} \mathrm{C}$, $\mathrm{a}=0.1 \mathrm{~m}, \mathrm{k}=3.5 \mathrm{~W} \mathrm{~m}^{-1}{ }^{\circ} \mathrm{C}^{-1}, \mathrm{~K}=1.2 \mathrm{~mm}^{2} \mathrm{~s}^{-1}$, and $\mathrm{f}=0$, based on equations (4) and (5) (open symbols). For comparison, solid and dashed lines indicate variations in $T_{0}$ for a cDGSW with $\mathrm{z}_{\mathrm{M}}=2500 \mathrm{~m}, \mathrm{~T}_{\mathrm{M}}=80^{\circ} \mathrm{C}$, and $T_{s}=0{ }^{\circ} \mathrm{C}$, operating for 10 years with heat production at $\mathrm{Q}=50,100,200$ and $400 \mathrm{~kW}$, according to Fig. 5 of Law et al. (2015). See text for discussion.

Figure 5. Predicted temperature variations at depth $z_{M}=2500 \mathrm{~m}$ as a function of radial distance $r$, calculated using equations (4) and (5) for $Q=50 \mathrm{~kW}$ at different times after the start of cDGSW operation. The other model parameters are as described for Fig. 4; linear ((a)) and logarithmic ((b)) scales for radial distance are used. Note that, for reasons discussed in the text, the calculated values of $r=r_{c}$ at which the cooling effect reaches zero (respectively, 2.2, 4.6, 9.2, 18.5, 29.2 and $41.3 \mathrm{~m}$ ) are approximate and underestimate the actual radial distance at which this effect becomes infinitesimally small by a factor of $\sqrt{ } \mathrm{C}$ or $\sim 1.33$. Note, also, that despite the low rate of heat production assumed, the borehole does not reach a thermal steady state on any of the timescales depicted (cf. Law et al., 2015).

Figure 6. Graphs of the notional project lifespan $t_{L}$ (calculated using equation (9)) for CDGSWs with $\mathrm{a}=0.1 \mathrm{~m}$ in a region with $\mathrm{T}_{\mathrm{s}}=10^{\circ} \mathrm{C}, \mathrm{u}=32{ }^{\circ} \mathrm{C} \mathrm{km}^{-1}, \mathrm{k}=3.5 \mathrm{~W} \mathrm{~m}^{-1}{ }^{\circ} \mathrm{C}^{-1}$, and $\kappa=1.2 \mathrm{~mm}^{2} \mathrm{~s}^{-1}$. (a) For $\mathrm{z}_{\mathrm{M}}=2000 \mathrm{~m}$, so $\mathrm{T}_{\mathrm{M}}=74{ }^{\circ} \mathrm{C}$; the values of $\mathrm{f}=0.0,0.2,0.4$ and 0.6 correspond to $\mathrm{T}_{\mathrm{L}}=10.0,22.8,35.6$, and $48.4{ }^{\circ} \mathrm{C}$. For $\mathrm{f}=0.6, \mathrm{t}_{\mathrm{L}}=20$ years corresponds to $\mathrm{Q}=43 \mathrm{~kW}$. (b) For $\mathrm{z}_{\mathrm{M}}=2500 \mathrm{~m}$, so $\mathrm{T}_{\mathrm{M}}=90^{\circ} \mathrm{C}$; the values of $f=0.0,0.15,0.3$ and 0.45 correspond to $T_{L}=10.0,22.0,34.0$, and $46.0^{\circ} \mathrm{C}$. For $f=0.45, t_{L}=20$ years corresponds to $Q=125 \mathrm{~kW}$. (c) For $z_{M}=3000 \mathrm{~m}$, so $T_{M}=106{ }^{\circ} \mathrm{C}$; the values of $f=0.0,0.1,0.2$ and 0.3 correspond to $T_{L}=10.0,19.6,29.2$, and $48.4^{\circ} \mathrm{C}$. For $f=0.3, t_{L}=20$ years corresponds to $Q=286 \mathrm{~kW}$.

Figure 7. Depictions of the potential cost-effectiveness of hcDGSW boreholes for 20 years of operation with different values of $z_{M}$ as a function of rates of heat supply to the associated heat load. (a) 2000 m; (b) $2500 \mathrm{~m}$; (c) $3000 \mathrm{~m}$; (d) $4000 \mathrm{~m}$. Calculations assume $\mathrm{T}_{\mathrm{s}}=10{ }^{\circ} \mathrm{C}, \mathrm{u}=32{ }^{\circ} \mathrm{C} \mathrm{km}^{-1}, \mathrm{a}=0.1 \mathrm{~m}$, $\mathrm{k}=3.5 \mathrm{~W} \mathrm{~m}^{-1}{ }^{\circ} \mathrm{C}^{-1}, \kappa=1.2 \mathrm{~mm}^{2} \mathrm{~s}^{-1}, \mathrm{~T}_{\mathrm{E}}=\mathrm{T}_{\mathrm{D}}=40{ }^{\circ} \mathrm{C}, \mathrm{L}=\mathrm{z}_{\mathrm{M}}$ (i.e., boreholes are vertical), $\rho=1000 \mathrm{~kg} \mathrm{~m}^{-3}$, $\mathrm{c}=4186 \mathrm{~J} \mathrm{~kg}^{-1}{ }^{\circ} \mathrm{C}^{-1}, \mathrm{D}=0.04 \mathrm{~m}$, and $\Omega=5 \times 10^{-5}$, with heat and electricity pricing, subsidy payments, and other input parameters as described in the text. Dashed horizontal lines denote estimated capital costs; dashed vertical lines denote optimum solutions, at $193 \mathrm{~kW}$ in (a), $295 \mathrm{~kW}$ in (b), $416 \mathrm{~kW}$ in (c), and $711 \mathrm{~kW}$ in (d). Note that at power outputs of $\geq 213 \mathrm{~kW}$ in (a), $\geq 326 \mathrm{~kW}$ in (b), $\geq 465 \mathrm{~kW}$ in (c), and $808 \mathrm{~kW}$ in (d), greater financial returns would result from ending operation before 20 years have elapsed, because in the later stages of operation $\mathrm{T}_{\mathrm{o}}$ is predicted to fall so low $\left(<15.7^{\circ} \mathrm{C}\right.$ in $(\mathrm{a}),<18.2^{\circ} \mathrm{C}$ in (b), $<20.9^{\circ} \mathrm{C}$ in (c), and $<27.1^{\circ} \mathrm{C}$ in (d)) that $\Psi$ declines sufficiently for the cost of the electricity used to exceed the value of the heat produced, even with $\mathrm{RHI}$ subsidy included.

Figure 8. Comparison between calculations of heat production from a cDGSW calculated using equations (4) and (5) with the outputs in Fig. 5 of Law et al. (2015) (cf. Fig. 4). Both sets of outputs have been converted to dimensionless variables $x$ and $y$ (defined in the text), where $x$ is a proxy for time and $y$ is a proxy for the fall over time in the output temperature. The calculations of $\Delta T\left(z_{M}\right)$, using equations (4) and (5), and the transformation to dimensionless variables utilise the following parameter values: $\mathrm{z}_{\mathrm{M}}=2500 \mathrm{~m}, \mathrm{~T}_{\mathrm{M}}=80^{\circ} \mathrm{C}$, and $\mathrm{T}_{\mathrm{S}}=0{ }^{\circ} \mathrm{C}$ (all specified by Law et al., 2015), along with $\mathrm{a}=0.1 \mathrm{~m}, \mathrm{k}=3.5 \mathrm{~W} \mathrm{~m}^{-1}{ }^{\circ} \mathrm{C}^{-1}, \mathrm{k}=1.2 \mathrm{~mm}^{2} \mathrm{~s}^{-1}$, and $\mathrm{f}=0$. See text for discussion.

Figure 9. Variations over time in $T_{0}$ for the optimum hcDGSW configurations from Fig. 7. After $T_{0}$ falls below $T_{E}$ it is assumed that all the heat output is via the heat pump, with the heat exchanger bypassed (cf. Fig. 2(b)). Crosses mark the times when the three setups become uneconomic in the absence of RHI subsidy (i.e., when the operating cost first exceeds the revenue from sale of heat). These are: for $\mathrm{T}_{0} \leq 21.8^{\circ} \mathrm{C}$ (after $\sim 17$ years) for $\mathrm{z}_{\mathrm{M}}=2000 \mathrm{~m} ; \mathrm{T}_{\mathrm{O}} \leq 25.7^{\circ} \mathrm{C}$ (after $\sim 18.5$ years) for $\mathrm{z}_{\mathrm{M}}=2500 ; \mathrm{T}_{0} \leq 29.9^{\circ} \mathrm{C}$ (after 20 years) for $\mathrm{z}_{\mathrm{M}}=3000 \mathrm{~m}$; and $\mathrm{T}_{\mathrm{O}} \leq 38.8^{\circ} \mathrm{C}$ (after $\sim 25$ years) for $\mathrm{z}_{\mathrm{M}}=4000 \mathrm{~m}$. 
1 Figure 10. Comparison of rates of heat output, for 10 years of operation, of cDGSW installations, 2 predicted by the present analytic model $\left(Q_{A}\right)$ and by numerical models. The present analytic models 3 are adjusted to give the same values of $T_{0}$ as the extant numerical models. Data points $\left(Q_{A}, Q_{N}\right.$, in $\left.k W\right)$ 4 are $(50,50),(80,100),(140,200)$, and $(260,400)$, based on comparison with Law et al. $(2015)$, and $5(530,1200)$, based on comparison with Alimonti et al. (2016). Values for all model parameters are 6 noted in the text. The trend line defined in equation (34) is also depicted.

Figure 11. Summary estimates for the technical and economic performance of the HALO hcDGSW project in Kilmarnock, Scotland. (a) Graphs of predicted temperature decline, calculated using the same procedure as for Fig. 4. The calculations assume different values of $Q$, with $T_{M}=69^{\circ} \mathrm{C}, T_{S}=T_{D}=9{ }^{\circ} \mathrm{C}$, $T_{E}=70{ }^{\circ} \mathrm{C}, \mathrm{f}=0, \mathrm{a}=0.375 \mathrm{~m}, \mathrm{u}=26{ }^{\circ} \mathrm{C} \mathrm{km}^{-1}, \mathrm{k}=4 \mathrm{~W} \mathrm{~m}^{-1}{ }^{\circ} \mathrm{C}^{-1}$, and $\mathrm{k}=1.5 \mathrm{~mm}^{2} \mathrm{~s}^{-1}$. (b) Graphs of predicted economic performance, calculated using the same operational parameters as for part (a) and the same economic model as for Fig. 7. See text for discussion.

Figure 12. Revision to Fig. 11 for a=0.1 m instead of $0.375 \mathrm{~m}$.

Figure 13. Summary estimates for the technical and economic performance of a hypothetical hcDGSW project in Darlington, northeast England. (a) Graphs of predicted temperature decline, calculated using the same procedure as for Fig. 4. The calculations assume different values of $Q$, with $z_{M}=6000 \mathrm{~m}$, $T_{M}=279{ }^{\circ} \mathrm{C}, T_{S}=T_{D}=9{ }^{\circ} \mathrm{C}, T_{E}=35{ }^{\circ} \mathrm{C}, f=0, a=0.1 \mathrm{~m}, \mathrm{u}=45^{\circ} \mathrm{C} \mathrm{km}^{-1}, k=1.7 \mathrm{~W} \mathrm{~m}^{-1}{ }^{\circ} \mathrm{C}^{-1}$, and $\mathrm{k}=0.9 \mathrm{~mm}^{2} \mathrm{~s}^{-1}$. (b) Graphs of predicted economic performance, calculated using the same operational parameters as for part (a) and the same economic model as for Fig. 7. See text for discussion. 
Notation Illustration Description

wDGSW Fig. 1(a) Open-loop design in which hot water is produced, flows through a heat exchanger, and is then discharged into the environment circa the rejection temperature of the heat exchanger. Corresponds to the Southampton project in its original form. Requires permeable bedrock; in the UK requires regulatory approval for the discharge, which will limit future applicability.

hwDGSW Fig. 1(b) Open-loop design in which hot water is produced and flows through a heat exchanger, before being cooled further to near-ambient temperature using a heat pump, then discharged into the environment. Corresponds to the Southampton project in its present, modified, form. Requires permeable bedrock; in the UK requires regulatory approval for the discharge, which will limit future applicability. In the USA, shallow versions of this design are known as open loop groundwater heat pump systems.

cDGSW Fig. 2(a) Closed-loop design in which water circulates through a borehole, passing through a heat exchanger at the surface, re-entering the borehole circa the rejection temperature of the heat exchanger. Subsurface heat flow to and from the borehole is by conduction only, so the design imposes no constraints on bedrock permeability. However, the reinjection above ambient temperature means that some of the heat produced contributes to heating the bedrock at shallow depths, limiting the usefulness of this design (and favouring the hcDGSW variant, discussed below, instead). I am not aware of any deep geothermal project that uses this variant, although it has featured in desk studies (e.g., by Law et al., 2015).

hcDGSW Fig. 2(b) Closed-loop design in which water circulates through a borehole, passing through a heat exchanger then a heat pump at the surface, re-entering the borehole near ambient temperature. The surface heat exchanger is bypassed if the produced water is below its reject temperature. Subsurface heat flow to and from the borehole is by conduction only, so the design imposes no constraints on bedrock permeability. I am not aware of any deep geothermal project that uses this variant, which is investigated in detail in the present study given its future potential. Excluding the surface heat exchanger, this design is equivalent to an upscaled (deep geothermal) version of what is known in the UK a ground source heat pump system and in the USA a closed loop ground coupled heat pump system.

dDGSW Fig. 3(a) Open-loop design in which water circulates through a borehole, passing through a heat exchanger at the surface, re-entering the borehole circa the rejection temperature of the heat exchanger, supplemented by flow bled from groundwater then discharged into the environment. Requires permeable bedrock; in the UK requires regulatory approval for the discharge, which will limit future applicability. I am not aware of any deep geothermal project that uses this variant, although it has featured in desk studies (e.g., by Law et al., 2015).

hdDGSW Fig. 3(b) Open-loop design in which water circulates through a borehole, passing through a heat exchanger then a heat pump at the surface, re-entering the borehole near ambient temperature, supplemented by flow bled from groundwater then discharged into the environment. The surface heat exchanger is bypassed if the produced water is below its reject temperature. Requires permeable bedrock; in the UK requires regulatory approval for the discharge, which will limit future applicability. I am not aware of any deep geothermal project that uses this variant, although it has featured in desk studies (e.g., by GEL et al., 2016). Excluding the surface heat exchanger, this design is equivalent to an upscaled (deep geothermal) version of what is known in the USA a standing column well groundwater heat pump system.

Details summarized here are discussed at length in the text. U.S. terminology is from Deng et al. (2005). 
Table 3: Hydraulic transport properties of granites

\begin{tabular}{|c|c|c|c|c|c|c|c|c|c|c|c|c|}
\hline \multicolumn{2}{|c|}{ Depth (MD) } & \multicolumn{2}{|c|}{ Depth (TVD) } & \multirow[b]{2}{*}{$\begin{array}{l}\Delta \mathrm{z} \\
(\mathrm{m})\end{array}$} & \multirow[b]{2}{*}{$\begin{array}{l}\mathrm{T} \\
\left({ }^{\circ} \mathrm{C}\right)\end{array}$} & \multirow[b]{2}{*}{$\prod_{(\mathrm{mPa} s)}$} & \multirow[b]{2}{*}{$\% \mathrm{~T}_{\mathrm{K}}$} & \multirow[b]{2}{*}{$\% \mathrm{~T}_{\mathrm{k}}$} & \multirow[b]{2}{*}{$\begin{array}{l}T_{\kappa} \\
(\mathrm{D} \mathrm{m})\end{array}$} & \multirow[b]{2}{*}{$\begin{array}{l}T_{K} \\
\left(m^{2} s^{-1}\right)\end{array}$} & \multirow[b]{2}{*}{$\begin{array}{l}\kappa_{p} \\
\left(m^{2}\right)\end{array}$} & \multirow[b]{2}{*}{$\begin{array}{l}\mathrm{K} \\
\left(\mathrm{m} \mathrm{s}^{-1}\right)\end{array}$} \\
\hline $\begin{array}{l}\mathrm{z}_{1} \\
(\mathrm{~m})\end{array}$ & $\begin{array}{l}\mathrm{z}_{2} \\
(\mathrm{~m})\end{array}$ & $\begin{array}{l}\mathrm{z}_{1} \\
(\mathrm{~m})\end{array}$ & $\begin{array}{l}\mathrm{z}_{2} \\
(\mathrm{~m})\end{array}$ & & & & & & & & & \\
\hline \multicolumn{13}{|c|}{ Rosemanowes RH-15 } \\
\hline 2130 & 2374 & 2054 & 2273 & 219 & 55 & 0.507 & 12 & 16.20 & 0.113 & $2.18 \times 10^{-6}$ & $5.16 \times 10^{-16}$ & $9.99 \times 10^{-9}$ \\
\hline 2374 & 2395 & 2273 & 2292 & 19 & 65 & 0.436 & 59 & 68.48 & 0.477 & $1.07 \times 10^{-5}$ & $2.51 \times 10^{-14}$ & $5.65 \times 10^{-7}$ \\
\hline 2395 & 2415 & 2292 & 2310 & 18 & 68 & 0.417 & 12 & 11.76 & 0.093 & $2.18 \times 10^{-6}$ & $5.16 \times 10^{-15}$ & $1.21 \times 10^{-7}$ \\
\hline 2415 & 2466 & 2310 & 2356 & 46 & 78 & 0.365 & 0 & 0.00 & - & - & - & - \\
\hline 2466 & 2490 & 2356 & 2376 & 20 & 80 & 0.355 & 12 & 11.34 & 0.079 & $2.18 \times 10^{-6}$ & $3.95 \times 10^{-15}$ & $1.09 \times 10^{-7}$ \\
\hline \multirow[t]{2}{*}{2490} & 2700 & 2376 & 2565 & 189 & 95 & 0.299 & 5 & 3.98 & 0.028 & $9.10 \times 10^{-7}$ & $1.47 \times 10^{-16}$ & $4.81 \times 10^{-9}$ \\
\hline & & & & 511 & & & 100 & 100 & 0.790 & $1.82 \times 10^{-5}$ & & \\
\hline \multicolumn{13}{|c|}{ Eastgate-1 } \\
\hline 410 & 432 & 410 & 432 & 22 & 26 & 0.880 & 99 & 99.34 & 3920 & $4.37 \times 10^{-2}$ & $1.78 \times 10^{-10}$ & $1.99 \times 10^{-3}$ \\
\hline \multirow[t]{2}{*}{432} & 995 & 432 & 995 & 563 & 27 & 0.859 & 1 & 0.66 & 25.6 & $2.92 \times 10^{-4}$ & $4.55 \times 10^{-14}$ & $5.19 \times 10^{-7}$ \\
\hline & & & & 585 & & & 100 & 100 & 3925 & $4.40 \times 10^{-2}$ & & \\
\hline
\end{tabular}

Here, $z_{1}$ and $z_{2}$ denote the depth limits above and below each interval of each borehole, in terms of both Measured Depth (MD) and True Vertical Depth (TVD). The Eastgate-1 borehole is vertical so these measures of depth are equivalent. $\Delta z$ is the difference between $z_{2}$ and $z_{1}$ measured as TVD. T is a representative temperature of the water in each interval. $\eta$ is the viscosity of water at temperature $T T_{\kappa}$ and $\% T_{\kappa}$ are the transmissivity of each interval and its percentage of the total transmissivity, expressed as $\kappa_{\mathrm{p}} \times \Delta z$, where $\kappa_{\mathrm{p}}$ is the permeability of the interval. $\mathrm{T}_{\mathrm{K}}$ and $\% \mathrm{~T}_{\mathrm{K}}$ are the transmissivity of each interval and its percentage of the total transmissivity, expressed as $K \times \Delta z$, where $K$ is the hydraulic conductivity of the interval. Data (i.e., the stated values for $z_{1}, z_{2}, T$, $\% \mathrm{~T}_{\kappa}$, and $\mathrm{T}_{\mathrm{K}}$ ) are from Richards et al. (1994) for the Carnmenellis Granite (in the Rosemanowes RH-15 borehole, Cornwall), and from Manning et al. (2007) and Younger and Manning (2010) for the Weardale Granite (in the Eastgate-1 borehole, County Durham). The other parameters are calculated as part of the present study, using standard formulae for the inter-relationships between the quantities listed. See text for discussion. 
Table 4. Subsurface temperatures

\begin{tabular}{|c|c|c|c|c|}
\hline Locality & Population & $\mathrm{T}\left({ }^{\circ} \mathrm{C}\right)$ & Ref. & Note \\
\hline \multicolumn{5}{|c|}{ Northern and North-central England } \\
\hline Darlington & 105,600 & 54 & B & \\
\hline Harrogate & 156,300 & 52 & B & \\
\hline Leeds & 781,700 & 50 & B & \\
\hline Wakefield & 336,800 & 50 & B & \\
\hline Bury & 188,700 & 50 & $\mathrm{~B}$ & \\
\hline Rochdale & 216,200 & 49 & $\mathrm{~B}$ & \\
\hline Newcastle upon Tyne & 296,500 & 48 & Y & \\
\hline Barnsley & 241,200 & 48 & $\mathrm{~B}$ & \\
\hline Oldham & 232,700 & 48 & $\mathrm{~B}$ & \\
\hline Gateshead & 201,600 & 48 & Y & \\
\hline Stockton-on-Tees & 195,700 & 48 & B & \\
\hline Sheffield & 575,400 & 46 & $\mathrm{~B}$ & \\
\hline Manchester & 541,300 & 46 & $\mathrm{~B}$ & \\
\hline Bradford & 534,300 & 46 & B & \\
\hline Huddersfield & 437,000 & 46 & B & 1 \\
\hline Hull & 260,200 & 46 & B & \\
\hline Ashton-under-Lyne & 223,200 & 46 & $\mathrm{~B}$ & 2 \\
\hline Middlesbrough & 140,400 & 46 & $\mathrm{~B}$ & \\
\hline Lichfield & 103,100 & 46 & $\mathrm{~B}$ & \\
\hline Stockport & 290,600 & 45 & B & \\
\hline Chesterfield & 104,400 & 44 & B & \\
\hline Nottingham & 325,300 & 42 & B & \\
\hline Bolton & 283,100 & 42 & B & \\
\hline Walsall & 278,700 & 42 & $\mathrm{~B}$ & \\
\hline Rotherham & 261,900 & 42 & B & \\
\hline Derby & 256,200 & 42 & $\mathrm{~B}$ & \\
\hline Salford & 248,700 & 42 & $\mathrm{~B}$ & \\
\hline Trafford & 234,700 & 42 & B & 3 \\
\hline York & 208,400 & 42 & B & \\
\hline Grimsby & 159,100 & 42 & B & 4 \\
\hline Mansfield & 107,400 & 42 & B & \\
\hline \multicolumn{5}{|c|}{ Wessex Basin and surroundings } \\
\hline Southampton & 254,300 & 48 & $\mathrm{~B}$ & \\
\hline Eastleigh & 129,600 & 48 & $\mathrm{~B}$ & \\
\hline Winchester & 122,000 & 48 & $\mathrm{~B}$ & \\
\hline Chichester & 118,200 & 48 & $\mathrm{~B}$ & \\
\hline Tunbridge Wells & 117,100 & 48 & $\mathrm{~B}$ & \\
\hline Eastbourne & 103,100 & 48 & B & \\
\hline Bournemouth & 197,700 & 46 & B & \\
\hline Maidstone & 166,400 & 46 & B & \\
\hline Poole & 151,500 & 46 & $\mathrm{~B}$ & \\
\hline Tonbridge & 127,300 & 46 & $\mathrm{~B}$ & \\
\hline Sevenoaks & 119,100 & 46 & $\mathrm{~B}$ & \\
\hline Fareham & 115,400 & 46 & $\mathrm{~B}$ & \\
\hline Crawley & 111,400 & 46 & B & \\
\hline Basingstoke & 174,600 & 44 & B & \\
\hline Havant & 123,600 & 44 & B & \\
\hline Worthing & 108,600 & 44 & B & \\
\hline
\end{tabular}




$\begin{array}{lllll}\text { Croydon } & 382,300 & 42 & \text { B } & 5 \\ \text { Bromley } & 326,900 & 42 & \text { B } & 5 \\ \text { Brighton } & 289,200 & 42 & \text { B } & 6 \\ \text { Greenwich } & 279,800 & 42 & \text { B } & 5 \\ \text { Medway } & 278,500 & 42 & \text { B } & \\ \text { Plymouth } & 264,200 & 42 & \text { B } & \\ \text { Bexley } & 244,800 & 42 & \text { B } & 5 \\ \text { Portsmouth } & 214,800 & 42 & \text { B } & \\ \text { Sutton } & 202,200 & 42 & \text { B } & 5 \\ \text { Thurrock } & 167,000 & 42 & \text { B } & \\ \text { Horsham } & 138,000 & 42 & \text { B } & \\ \text { Torbay } & 133,900 & 42 & \text { B } & \\ \text { Gravesend } & 106,800 & 42 & \text { B } & 7 \\ \text { Dartford } & 105,500 & 42 & \text { B } & 5 \\ \text { Lewes } & 101,400 & 42 & \text { B } & \end{array}$

Values of the temperature T, measured or estimated at $1 \mathrm{~km}$ depth, from Busby et al. (2011) (B) or Younger et al. (2016) (Y), are plotted for towns and cities in Britain with populations $>100,000$ (population data from ONS, 2017). The values reported were measured by Younger et al. (2016) beneath Newcastle upon Tyne and are assumed beneath neighbouring Gateshead. These relatively high temperatures, listed, arise due to combinations of relatively high heat flow and/or relatively low thermal conductivity sediments, including thick sequences of Carboniferous mudstone in sedimentary basins in northern and central England. Sites are grouped geographically; no localities in Scotland or Wales have high enough subsurface temperatures for inclusion, whereas Northern Ireland has not been assessed. Annual mean surface temperatures are within $\sim \pm 1{ }^{\circ} \mathrm{C}$ of $10^{\circ} \mathrm{C}$ at almost all localities listed, so geothermal gradients in the uppermost $1 \mathrm{~km}$ beneath the Earth's surface can be readily calculated approximately. Notes: 1, Kirklees Metropolitan Borough (MB); 2, Tameside MB; 3, Trafford MB; 4, North East Lincolnshire Unitary local Authority (UA); 5, London Borough; 6, Brighton \& Hove UA; 7, Gravesham District. 


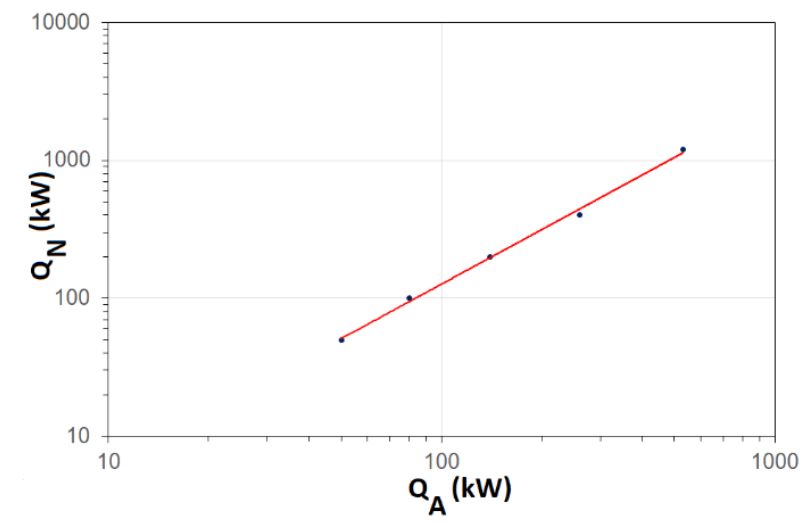

Figure 10 


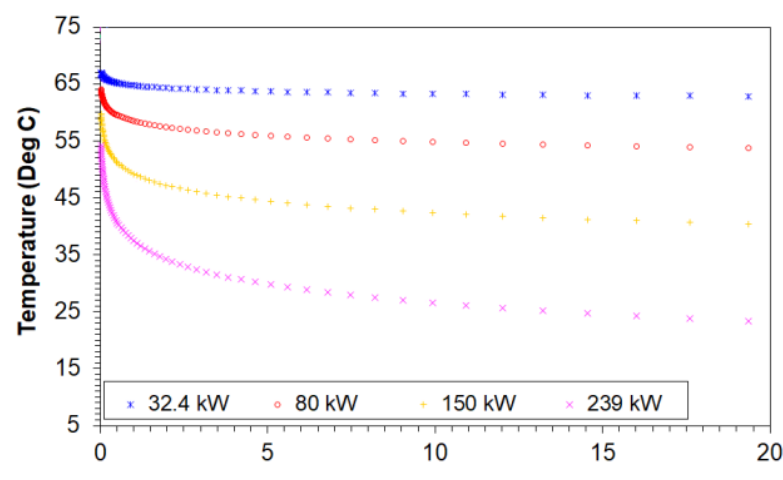

(a)

Time (yrs)

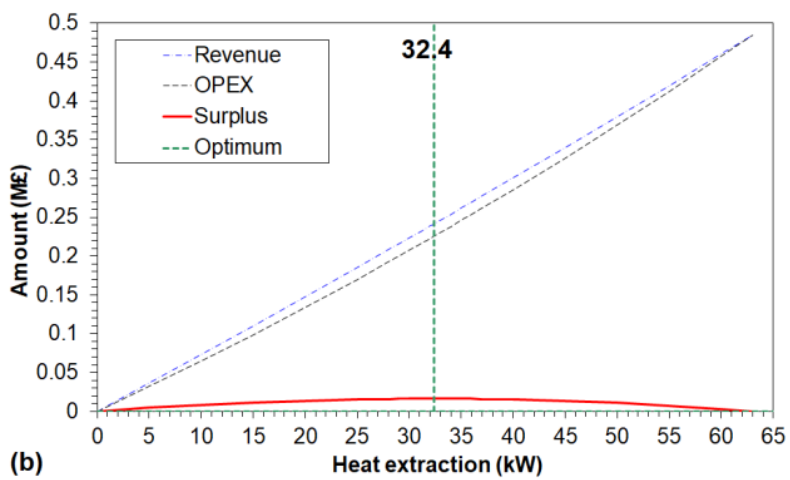

Figure 11 




(a)

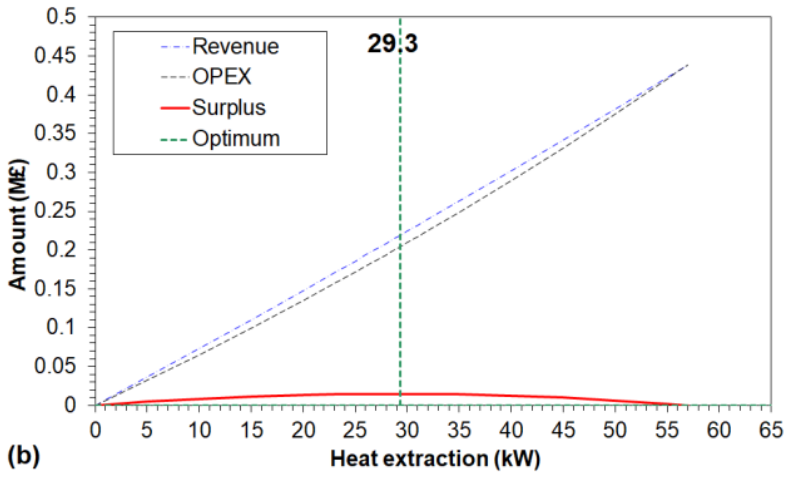

Figure 12 


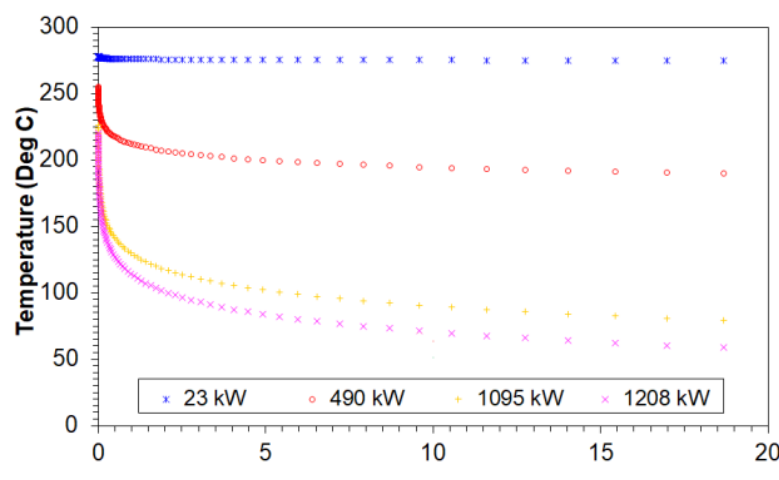

(a)

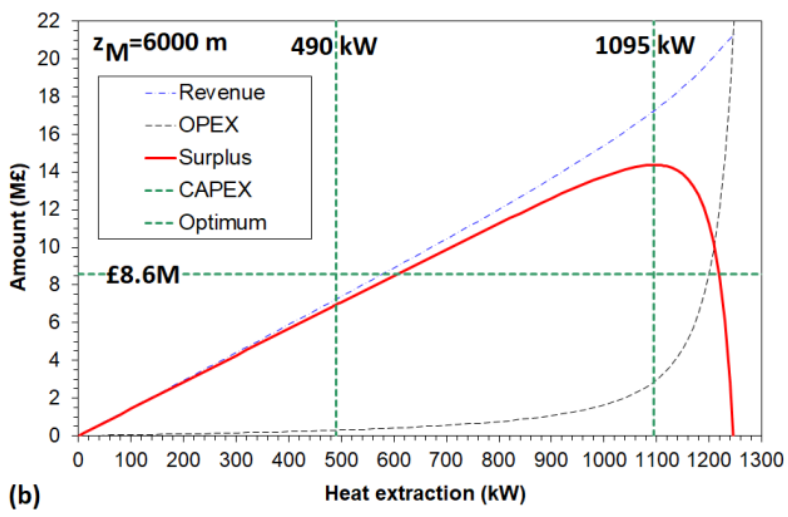

Figure 13 